\title{
La Psicología de Vygotski: sobre la larga proyección de una corta biografía *
}

\section{Angel Rivière **}

Universidad Autónoma de Madrid

\section{INDICE}

Notas biográficas: el periodo de formación.

La psicologia soviética en los años veinte: antecedentes y condiciones.

Reflejos y conciencia: aportaciones críticas de Vygotski a la búsqueda de una psicologia dialéctica.

La crisis de la Psicologia y la aportación metateórica de Vygotski.

La actividad instrumental y la reiteración como unidades de análisis de la Psicologia de las funciones superiores.

Los estudios experimentales sobre la genesis y variabilidad cultural de las funciones superiores y el método genético experimental.

Las relaciones entre aprendizaje y desarrollo y la "zona de desarrollo potencial». Las concepciones educativas de Vygotski y sus aportaciones a la Paidologia $y$ Defectologia.

La Unión Soviética en los primeros años treinta y algunas criticas a Vygotski. El desarrollo como proceso histórico: las aportaciones de Vygotski a una teoria general del desarrollo.

El boceto de una teoria de la organización neurofisiológica de las funciones superiores y los intereses neuropsicológicos de Vygotski.

Pensamiento y babla: la concepción semiótica de la conciencia y la génesis, estructura y función del lenguaje interno.

Algunas bipótesis vygotskianas más allá de Vygotski.

Las criticas a Vygotski y el periodo del largo silencio en la psicología soviética. Referencias bibliográficas.

- YGOTSKI cruzó, como una furia veloz, la Psicologia cientifica de nuestro siglo. En un breve período de diez años tuvo tiempo suficiente para analizar a fondo las alternativas teóricas de la Psicología de su tiempo, proponer soluciones originales a algunos de sus problemas más difíciles, diseñar una concepción nueva sobre el

* Agradezco a Alberto Rosa el material bibliográfico que me ha proporcionado y que ha resultado de gran importancia para la elaboración de este articulo.

** Dirección del autor: Universidad Autónoma de Madrid. Facultad de Filosofia y Letras, Sección Psicologia, Cantoblanco. Madrid-34. 
origen y la naturaleza de las funciones superiores, escribir alrededor de doscientos trabajos científicos —entre ellos, varios libros- sobre temas diversos, contribuir a la creación y organización de instituciones de atención a niños deficientes en la Unión Soviética y dejar una larga estela de influencia y un proyecto de futuro para la Psicología, que aún permanece, en su mayor parte, sin agotar. La "década prodigiosa" de Vygotski fue la que corrió entre 1924, año en que presentó una comunicación sobre «El método de investigación reflexológica y psicológica» en el II Congreso pan-ruso de Psiconeurologia, y 1934, en que murió como consecuencia de una tuberculosis. Antes de estos diez años, era un desconocido en Psicología. Después de ellos, volvió a serlo de nuevo, y su obra permaneció relativamente olvidada (excepto para un pequeño grupo de discípulos) durante veinte años, tanto en la Unión Soviética como fuera de ella. En 1956 se reeditó un clásico de Vygotski, Pensamiento y Lenguaje, coincidiendo con el proceso de liberalización y apertura conceptual consecuente a la «desestalinización». Al traducirse esta obra al inglés, en 1962, los psicólogos occidentales descubrieron atónitos un semillero de propuestas de gran calado que, al mismo tiempo que sintonizaban con el estilo "nuevo" de estudiar las funciones cognitivas (que se estaba desarrollando por aquellas fechas), cuestionaban directa $o$ indirectamente algunos de sus supuestos esenciales. Desde entonces, la influencia de Vygotski no ha hecho más que crecer $y$, en 1984, sigue siendo, en muchos aspectos, un psicólogo estrictamente contemporáneo $y$, en otros, adelantado aparentemente a nuestro propio tiempo. Da la impresión de que le bastaron diez años para ver la perspectiva de un siglo. Diez años de furia, veinte de olvido y luego la recuperación, cada vez más evidente, de una perspectiva que, para muchos de nosotros, sigue conteniendo algunas de las propuestas más prometedoras y de los análisis más perspicaces de la Psicologia de este siglo. Si, hay un "Zeitgeist» vygotskiano en el análisis del origen de las funciones superiores y los simbolos (vid., por ejemplo, Lock, 1978); la orientación pragmática de la Psicolingǘstica reciente (por ejemplo, Ochs y Schieffelin, 1979); el examen de las relaciones entre aprendizaje y desarrollo (Brown, 1982); la investigación transcultural de los procesos de conocimiento (LCHC, 1979). Vygotski vio muy lejos desde su década furiosa.

No resulta fácil explicar cómo pudo hacer tantas cosas en diez años. Su obra sólo puede entenderse por la integración de una mente poderosa con una época sentida como un comienzo, en que todo debía ser recreado. Como ha señalado Mecacci (1979, 1983), Vygotski es el representante en Psicología de la magnífica generación de los años inmediatamente posteriores a la revolución soviética. Del mismo modo que lo fue en cine Eisenstein (que era amigo de Vygotski), o en educación Lunacharsky (con el cual colaboró). La generación de los años veinte, que aún creía en la posibilidad de reconstruir la ciencia, el arte, la sociedad y al hombre mismo desde los cinientos. Vygotski también se propuso la empresa colosal de reconstruir la Psicologia, y creyó en ella. Por su capacidad de compaginar la profundidad de análisis con la claridad y bella simplicidad de las soluciones, su destreza para deslindar los problemas esenciales de los secundarios, su habilidad para construir síntesis originales con elementos aparentemente lejanos, Vygotski era el hombre adecuado en el tiempo propicio. Y si su vida fue breve, también lo fue su época. Luego, sólo quedaron los rescoldos 
de la creación y el genio, esperando a tiempos mejores para volver a encenderse.

Los que conocieron a Vygotski coinciden en señalar que en él habia algo más que una paciente productividad y una inteligencia clara: habia un genio. Es muy conocido el comentario de su gran amigo y colaborador Alexander R. Luria: «Vygotski - dice- fue, sin duda, un genio. Tras más de medio siglo en la senda de la ciencia, no puedo nombrar a otra persona que se acerque a su infrecuente claridad de pensamiento, a su increible capacidad de convertir en simples los más complejos problemas, a su capacidad de señalar la línea recta y de prever el desarrollo de la ciencia" (1979, pág. 27). Como siempre ocurre, los mecanismos intimos de ese carácter genial de la producción de Vygotski se nos escapan en gran parte. Pero si podemos, al menos, acercarnos a ellos: comprender una obra que fue, antes que nada, «una aventura del espiritu" (Levitin, 1982) y situarla en un contexto biográfico e histórico que le dio su sentido originario, pero que no agota su significación completa. A eso vamos a dedicar estas páginas.

\section{NOTAS BIOGRAFICAS: EL PERIODO DE FORMACION}

No son muchas las observaciones biográficas que conservamos sobre Vygotski. Como en tantos aspectos de su obra, en éste se evidencia una gran escasez de fuentes y de estudios en profundidad. Sin embargo, las investigaciones de Luciano Mecacci (1979, 1983), las observaciones de Luria (1979) y los comentarios de Semyon Dobkin (1982) nos proporcionan, al menos, los datos esenciales de su corta biografia.

Por lo que sabemos, Lev Semionovitch Vygotski nació el s de noviembre de 1896 , en Orsha, una pequeña ciudad a orillas del río Dnieper, no lejana de Minsk, capital de Bielorrusia. Un año después del nacimiento de Vygotski, la familia se trasladó a otra ciudad bielorrusa: Gomel. Esta localidad de El Pale (territorio al que habían sido reducidos los judíos en la Rusia zarista), relativamente pequeña pero activa, fue realmente la ciudad de Vygotski, donde él vivió su infancia y juventud y comenzó su trabajo profesional. Allí, la familia $\checkmark$ ygotski ocupaba una posición bastante acomodada. El padre era jefe de departamento del Banco Central y representante de una compañia de seguros. Según la descripción de Dobkin (1982), era un hombre inteligente, de mentalidad abierta, irónico y serio al mismo tiempo, y preocupado por la cultura: gracias a su iniciativa se abrió una biblioteca pública en Gomel. La madre de Vygotski también era una persona culta: sabia varios idiomas (hablaba bien alemán, que enseñó a Vygotski desde pequeño) y era muy aficionada a la poesía, como luego lo fue también Lev Semionovitch. Vygotski fue el segundo de ocho hermanos (una hermana mayor y, tras él, cuatro hermanas y dos varones, que eran los más pequeños). La buena relación que se mantenía en aquella familia pudo ser uno de los factores más importantes en el desarrollo de Vygotski y, probablemente, influyera indirectamente en algunas de sus concepciones posteriores (es sugerente relacionar, por ejemplo, las reuniones de animada charla que tenían todas las tardes, alrededor del té, con la idea posterior de Vygotski del razonamiento como interiorización del diálogo social). En cualquier caso, no cabe duda de que 
Vygotski se desarrolló en un ambiente equilibrado y estimulante, desde el punto de vista cultural.

Una muestra de aquel interés cultural de los padres de Vygotski fue el cuidado que pusieron en la educación de Lev. Como no consideraban adecuada la educación del "Gimnasium" público, le buscaron un tutor privado, Solomon Ashpiz. Todo indica que Ashpiz tuvo una gran influencia en Vygotski. Había participado, como estudiante, en el movimiento revolucionario, por lo que había estado deportado en Siberia. Era un hombre amable, bienhumorado, muy respetuoso con el espontáneo desarrollo del pensamiento de sus alumnos. Enseñaba, sobre todo, a pensar con independencia (Dobkin, op. cit.). Sólo admitía alumnos muy capaces, a los que procuraba proporcionar herramientas para la evolución de sus competencias específicas. Aunque era, profesionalmente, matemático, les daba una amplia formación y enseñaba también otras materias.

Dobkin cuenta que, durante varios años, varios compañeros menores se reunieron con Vygotski en una especie de seminario sobre la historia de los judíos. Por entonces, el problema de las nacionalidades y las minorías étnicas era muy serio en la Rusia zarista. Vygotski, que dirigía aquellas reuniones, se mostraba entusiasmado por problemas de filosofia de la historia y, especialmente, por la dialéctica hegeliana. En aquellos años en que aún era bachiller se configuraba un estilo de pensamiento que luego seria característico de todo su trabajo científico: la perspectiva histórica y dialéctica de los problemas fue uno de los rasgos esenciales de su psicología.

Además de Ashpiz, otra persona que influyó mucho en Lev Semionovitch durante sus años de formación fue su primo David Vygodski (la "d") del apellido original fue luego sustituida por una (t)" por el propio Lev, que pensaba que su familia procedia de la localidad de Vygotovo). David, varios años mayor que Lev, llegó a ser un importante lingüista, cercano a las posiciones formalistas de Viktor Shklovsky y a Roman Jackobson (que fue uno de los «descubridores» de Vygotski en Occidente; vid. Levitin, 1982). Compartia muchas aficiones con Lev Semionovitch: el interés por la semiología y los problemas lingüísticos, la pasión por la poesía y el teatro (David no sólo era aficionado a la poesía, sino que fue un buen poeta), y el entusiasmo por la filatelia y el esperanto. Fue el mentor intelectual de Lev Semionovitch en aquellos tiempos de Gomel.

En los dos últimos años de su bachiller, Vygotski fue al «Gimnasium» judio de Gomel, dirigido por Ratner. Aunque el nivel de aquel centro era bastante alto, Lev sobresalía claramente por su capacidad de analizar los problemas en profundidad, su uhabilidad para pensar», como dice Dobkin. En las circunstancias de los judios en la Rusia zarista de aquellos años, era necesario alcanzar rendimientos muy altos para poder acceder a la enseñanza superior. El Ministerio de Educación limitaba a un 3 por 100 las plazas que podian ocupar los judios en las universidades de Moscú y San Petersburgo, y cuando Vygotski estaba realizando sus exámenes de final de bachillerato, apareció una nueva normativa ministerial que añadía aún más restricciones para los judios. A pesar de todo, Lev pasó la prueba y, por insistencia de sus padres, solicitó matrícula en la Facultad de Medicina de Moscú, donde fue admitido en el año 1913. 
Sin embargo, Vygotski no se sentía, por entonces, vocacionalmente llamado a la medicina. La orientación de sus estudios e intereses se habia dirigido, ya desde el ciclo medio, a la lingüistica y la literatura, las lenguas clásicas, la critica y la filosofia. Antes de comenzar los estudios universitarios en Moscú, Vygotski habia desarrollado una importante formación humanista. Es esencial comprender esto para analizar la aportación posterior de Vygotski a la Psicologia: el análisis crítico de los problemas con los instrumentos que le proporcionaba la sensibilidad humanista, la tendencia a considerarlos desde una perspectiva histórica con un enfoque dialéctico, y el interés por su vertiente semiológica fueron las premisas en que se basaron sus importantes aportaciones posteriores. $\mathrm{Y}$ esas premisas estaban ya muy desarrolladas cuando Vygotski comenzó sus estudios universitarios. Formaban parte de las raices más profundas de su educación e intereses, que eran de carácter humanista. Por eso, decidió cambiar la matrícula en la Universidad de Moscú, ingresando en la Facultad de Derecho.

Es curioso constatar que en los últimos años de su vida (cuando ya tenia más de treinta años de edad), Vygotski comenzó los estudios de medicina a los que habia renunciado a los diecisiete años. Esa aparente paradoja biográfica tenia, sin embargo, una profunda lógica: la concépción histórica del desarrollo de las funciones superiores, a la que habia llegado gracias a su formación humanista, le llevaba a replantear el problema de la organización neurológica de aquellas funciones. De modo que Vygotski inició sus estudios de medicina (que no pudo terminar, por su muerte prematura) cuando su propia evolución intelectual le llevó a ellos, y no antes por presiones externas. A los diecisiete años, su inteligencia estaba volcada en las humanidades, la filosofia y la literatura. Con arreglo a la distinción clásica en nuestros estudios, podemos decir que era un hombre "de letras».

En la Universidad Imperial de Moscú (que era la que proporcionaba los títulos reconocidos) no habia estudios de Historia y Filosofía. Por eso, Vygotski se matriculó alli en Derecho y realizó sus estudios más vocacionales (los de Filosofía e Historia) en la Universidad Popular Shanyavsky, una institución libre, cuyas titulaciones no eran reconocidas por las autoridades educativas de la Rusia zarista, y que acogía a importantes intelectuales, expulsados de la Universidad Imperial por razones políticas. El ambiente intelectual de Shanyavsky influyó mucho más en Vygotski que el de la Facultad de Derecho de la Universidad Imperial. Era más adecuado para su mente crítica y analítica. Por otra parte, aunque los estudios de Derecho pudieran influir en él (por ejemplo, en la capacidad para analizar los problemas desde una pluralidad de perspectivas diferentes o hasta contrapuestas, o perfeccionando su capacidad de hablar en público, que era una de sus habilidades más sobresalientes), fueron los problemas de Filosofía y Literatura los que absorbieron la mayor parte de su tiempo y atención.

Vygotski fue siempre, y muy fundamentalmente, un filósofo y semiólogo. Cuando aún estaba en los estudios del ciclo medio, había leido cuidadosamente un libro del lingüista Alexander Potebnya llamado Pensamiento y Lenguaje (el suyo posterior se llamaba, en realidad, Pensamiento y babla, aunque ha sido traducido al inglés y castellano con el mismo título que el de Potebnya), que se orientaba a un tratamiento psicológico de las cuestiones de semiología. A Lev Semionovitch le 
interesaban los problemas relacionados con los mecanismos psicológicos de la creación literaria y las cuestiones semiológicas relacionadas con la estructura y funciones de los símbolos, signos e imágenes poéticas. La preocupación por estos problemas no fue el resultado de sus investigaciones psicológicas, sino más bien el origen de ellas. Por otra parte, los intereses semiológicos de Vygotski estuvieron siempre enmarcados por una orientación filosófica más amplia, por la intuición -que luego desarrollaria- de que profundizar en el origen de los signos era también penetrar en el origen del hombre mismo y de la cultura.

El acercamiento de Vygotski a los problemas de crítica, estética y semiología fue, siempre, el de un pensador o, si se quiere, el de un filósofo, que trataba de desvelar los mecanismos de construcción estética desde una concepción dialéctica global del hombre y de la cultura. Recordemos que la Psicologia del Arte, de 1925, comenzaba con un pensamiento de Spinoza que - según el propio Vygotski- habia servido de núcleo conceptual a partir del cual él mismo había desarrollado sus ideas. Spinoza le había interesado siempre a Vygotski. Era su pensador favorito. Parece ser que en el bachiller comenzó un ambicioso estudio sobre su filosofía que no llegó a terminar y, al final de su vida, escribió un importante artículo sobre "La teoría de las emociones de Spinoza a la luz de la Psiconeurología contemporánea». Con toda razón, Vygotski veía una profunda línea de relación entre su propio modo de pensar y el pensamiento de Spinoza. Esta vía de conexión residia en la esencia dialéctica de la filosofia de Spinoza, en la concepción del hombre como «instrumento del pensamiento» de la Naturaleza (concebida como unidad) en la comprensión del pensamiento como acción del cuerpo organizado, como función propia del ser material en su más alta expresión. Cuando Vygotski hablaba de las «funciones superiores" contaba con la referencia a la visión del pensamiento como función universal y no deducible, sin embargo, de la estructura estática y "espacial» de la materia. Por debajo de todo el pensamiento de Vygotski corrió siempre aquella savia profunda que le habia proporcionado la lectura cuidadosa y reflexiva de la filosofia de Spinoza.

Aquella «consustancialidad» entre Spinoza y Vygotski se relaciona: ba, como ya hemos comentado, con la naturaleza dialéctica del pensamiento de ambos. Para Vygotski, la dialéctica no era un catecismo ni un dogma, sino sencillamente la estructura misma de su modo de pensar, casi tan natural como la respiración. Comprender un problema era, para él, situarlo en su génesis dialéctica. Precisamente, la familiaridad que tenía Vygotski (desde sus años de escolar) con la dialéctica como método y los fundamentos más profundos del pensamiento marxista, le impidió siempre desarrollar una actitud reverencial o escolástica como la que terminaría por imponerse en los tiempos de Stalin. El marxismo era, en Vygotski, una herramienta del pensamiento propio y no un conjunto de verdades reveladas. Ello explica que Vygotski, que fue un pensador marxista, no diera nunca muestras de sumisión al marxismo como ideologia. Como dice Kozulin, "tomó la posición más altiva y la más difícil, al menos en las circunstancias soviéticas: la de tratar a Marx como un teórico, del mismo modo que podia tratar a Hegel, Freud y Durkheim, sin prejuicios" (1984, pág. 116). Naturalmente, aquella actitud terminó por provocarle pro- 
marxismo de Vygotşki no fue el resultado de una evolución (más o menos "ayudada» o presionada por las circunstancias) simultánea o posterior a su psicologia, sino que era una actitud intelectual profunda, desarrollada a partir del conocimiento de textos de Hegel, Marx y Engels, que le eran familiares desde antes de comenzar sus estudios universitarios, y en los que siguió profundizando en su periodo de formación universitaria de Shanyavsky.

Durante aquellos años (y en los inmediatamente posteriores), Vygotski empleó las categorias intelectuales de la dialéctica para acercarse, sobre todo, a problemas relacionados con la literatura. Esta fue, siempre, la pasión intelectual de Vygotski. La compartía con su primo David y su madre, y también con un curioso personaje que influyó mucho en los años universitarios de Vygotski: Vladimir Uzin, el traductor al ruso de las obras de Lope de Vega; un autodidacta, conocedor de varios idiomas y autor de numerosos trabajos de crítica, que perfeccionaba los conocimientos de latín de Vygotski durante sus veranos universitarios en Gomel. Alli desarrollaba Vygotski una enérgica actividad relacionada con el arte. Desde sus años de Universidad (cuando volvia a Gomel, para pasar las vacaciones) se reunía con sus amigos para comentar a sus poetas favoritos, como Sasha Cherny, Tyuchev, Blok, Heine. También tenia un profundo conocimiento de novela (especialmente Dostoyevsky y también Tolstoi). Pero lo que más le apasionó siempre fue el teatro: Shakespeare, Gogol, etc. Incluso realizaba actividades de "director teatral» con el pequeño grupo de jóvenes aficionados de Gomel. Posteriormente, ya durante los años de su estancia post-universitaria en Moscú, tuvo una estrecha relación con el director de cine Sergei Eisenstein, en cuyos planteamientos estéticos y de teoría del cine influyeron mucho las ideas de Vygotski y Luria.

Es importante señalar que, antes de la terminación de los estudios universitarios, Vygotski habia dado pasos muy significativos en la construcción del «estilo mental» con que luego se acercaría a los problemas psicológicos. Como ha observado Schedrovitsky (1982), las características de ese estilo pueden definirse principalmente por los siguientes puntos:

I. Una tendencia a enfocar los problemas desde el punto de vista de un metodólogo, y a cuestionar las premisas metodológicas de la Psicología como un todo.

2. El enfoque histórico de los problemas psicológicos y la Psicología como tal.

3. La consideración como esencial del problema de la naturaleza, génesis y estructura de los signos, y la orientación semiótica del pensamiento.

4. La propensión intelectual a sintetizar la óptica histórica y dialéctica con el enfoque estructural de los problemas.

Estas fueron características esenciales de la Psicología de Vygotski y resumen, también, de su "modo de pensar", que era resultado de una evolución que era muy genuina y muy anterior a sus preocupaciones psicológicas.

Los estudios universitarios de Vygotski coincidieron con los turbulentos años anteriores a la revolución soviética. Y su terminación, 
con el estallido revolucionario de 19 17. En muchos sentidos, Vygotski era un hijo de la revolución y se incorporó activamente al proyecto de hacer una nueva sociedad y desarrollar una nueva cultura. Al terminar el ciclo universitario, volvió a Gomel, allí habría de permanecer siete años (1917-1924), que podemos considerar como una activa fase de transición, hasta su paso a Moscú, cuando comenzó a tener una posición muy relevante en la historia de la Psicología soviética. En aquella etapa de Gomel (concretamente en los años i 919-20), Vygotski enfermó de tuberculosis ( $y$ también otros miembros de su familia) y tuvo que ingresar, por primera vez, en un sanatorio, en el año veinte. Semyon Dobkin (1982) recuerda que Vygotski -a los veinticuatro años- tenía muy pocas esperanzas de seguir viviendo, y que le dio algunos manuscritos para que fueran publicados después de su muerte. Afortunadamente, sus temores no se cumplieron a tan corto plazo, aunque las fases oscilantes de la tuberculosis le hicieran mantener una lucha consciente contra el tiempo durante los catorce años que aún tuvo de vida.

Los años de Gomel fueron importantes, tanto en el plano profesional de Vygotski como en el más personal. En éste, podemos señalar que en 1924 se casó con Roza Smekhova, que fue luego una figura importante por su habilidad para ayudar a Vygotski a superar los muchos períodos difíciles de la etapa de Moscú (Vygotski tuvo una hija, Gita Vygotskaya, que se dedicó a la pedagogía). En cuanto a las actividades científicas y profesionales, estuvieron marcadas por tres grupos de intereses: ( 1 ) los relacionados con cuestiones pedagógicas y educativas; (2) los referidos a la estética, critica y promoción institucional del arte $y$, finalmente, (3) los propiamente psicológicos. Por debajo de la diversidad aparente de ocupaciones e intereses de la etapa de Gomel habia, sin embargo, una unidad de propósito, que le llevaba a Vygotski a tratar de dar cuenta de las funciones de creación cultural, tanto en el arte como en la educación, a partir de una consideración científica de la naturaleza de las funciones superiores específicamente humanas. Los intereses psicológicos de Vygotski nacieron de una preocupación más primaria por la génesis de la cultura (de forma semejante a como los intereses psicológicos de Piaget se originaron en una preocupación más primordial por la génesis del conocimiento). Vamos a detenemos brevemente en las actividades de Vygotski en los tres campos señalados (pedagogía, estética y psicologia), durante los años de Gomel:

1. Vygotski se dedicó profesionalmente a la enseñanza en varias instituciones de Gomel. A finales de 1918, junto con David Vygotski comenzó a dar clases de Literatura en la Escuela de Magisterio. También dio cursos de Estética e Historia del Arte en el Conservatorio. Además enseñó Psicología en la Escuela Normal. Posteriormente, en los años de Moscú, daría clases en la Academia Krupskaya de educación comunista y se haría cargo de la cátedra de Paidología de la segunda Universidad Estatal de Moscú. En sus últimos años, enseñó en el Instituto Pedagógico Hertzen, de Leningrado. En resumen: se dedicó a la enseñanza durante toda su vida profesional; fue profesor. $Y$ esta dedicación no se límitó al ejercicio didáctico, sino que se completó siempre con un activo interés teórico hacia los temas de pedagogía y paidologia, y abarcó tanto la educación normal como la 
pedagogo y paidólogo antes de ser psicólogo. Siempre mantuvo el interés por vincular la psicología científica con la labor educativa, y nutrió sus trabajos psicológicos de observaciones y experiencias recogidas en situaciones educativas reales. Esta referencia tenia un significado profundo, relacionado con la concepción vygotskiana de la educación formal como instrumento esencial de enculturación y bumanización.

Ciertamente, la referencia sistemática al contexto educativo no era sólo un reflejo de la vocación pedagógica de Vygotski, sino que fluía de modo natural de su concepción de la génesis de las funciones superiores y de la naturaleza de la explicación científica en Psicología (vid. Cole y Scribner, 1979). Para él, las funciones superiores eran resultado de la enculturación, de la influencia cultural en el aprendizaje y el desarrollo, y sólo podían ser explicadas en su génesis, por su historia, situándolas en su contexto originante. Por tanto, la bumanización era un producto de la educación formal e informal, concebida en términos de interacción. Por ello, Vygotski veía la escuela y las situaciones de educación informal como el mejor "laboratorio natural» (quizá sería mejor decir laboratorio cultural) de la Psicologia humana. Al mismo tiempo, sentía que el objetivo pragmático esencial de la propia Psicología era la mejora y el perfeccionamiento de la educación real, que era como decir la mejora y el perfeccionamiento del hombre mismo. En definitiva: la educación era, para Vygotski, la premisa esencial de observación y el horizonte principal de traducción pragmática de la Psicología científica.

Pero, aparte de sus implicaciones psicológicas, la educación y la escuela le interesaban a Vygotski por sí mismas. En la etapa de Gomel realizó sus primeros trabajos de pedagogía y didáctica: de 1922 data un informe sobre «los métodos de enseñanza de la literatura en la escuela secundaria», y desde esta fecha hasta su muerte no dejó de publicar artículos, comentarios y observaciones de carácter pedagógico. En 1926, apareció un libro de Vygotski sobre Psicologia Pedagógica, que recogía los aspectos esenciales de su enseñanza de Psicología en la Escuela de Magisterio de Gomel. Aquella obra estaba situada dentro de una tradición objetivista (de estilo reactológico, y aún muy basada en el concepto de reflejo), demuestra que Vygotski había relacionado, desde un principio, sus intereses pedagógiros con la exigencia de una explicación psicológica de los procesos de aptentizaie y dssarrollo. Sin embargo, en la etapa de Gomel ańn no stabati watitio las piezas del rompecabezas conceptrial, gue lievarina pesteriormente a la teoría de la génesis histónico-cuitural de las funciones stiperiores. Todavía estaban coexistiendo, sin formar una síntesis unitaria, las categorias psicológicas referidas a los procesos elementales de aprendizaje y las categorias semióticas aplicables a los productos superiores del arte y la cultura. La teoria psicológica de Vygotski fue, sobre todo, el resultado de la síntesis dialéctica de estas categorias y los datos de que disponemos no permiten afirmar que Vygotski hubiera realizado esta sintesis antes de la segunda mitad de la década de los veinte, cuando ya estaba trabajando en Moscú.

2. El segundo tipo de actividades e intereses que llenaton la etapa de Gomel es el relacionado con la vieja pasión de Vygotski por la literatura y el arte. Tampoco se limitó, en este terreno, a las consideraciones teóricas: en Gomel, Vygotski se dedicó a una labor activa de 
promoción del arte: fue director de la Sección de Teatro del Comisariado de Instrucción Pública de la ciudad y fundó una revista, Vereske, dedicada a la crítica y a la literatura de creación de vanguardia. Además instituyó unos "Lunes literarios», con reuniones en que se discutía, presentaba y comentaba la obra de novelistas, ensayistas y poetas nuevos de la Unión Soviética. También realizó actividades de edición con Dobkin y David Vygodski.

La mayor parte de los trabajos de la etapa de Gomel se relacionaban con temas de estética, crítica y teoría de la literatura. Son, sobre todo, los que se recogen en la importante Psicologia del Arte, de 1925, y que es una especie de "Summa" de la orientación de las investigaciones de Vygotski en la primera mitad de los años veinte. Sin embargo, algunos de aquellos trabajos habían sido comenzados mucho antes: recordemos que la primera versión del célebre artículo sobre Hamlet ("La tragedia de Hamlet, principe de Dinamarca») era de $191 \mathrm{~g}$. Vygotski comenzó a los diecinueve años aquella investigación que, en su elaboración publicada, es una creación sobresaliente por su erudición, claridad y finura critica.

Las investigaciones sobre estética y Psicología del Arte se vieron bruscamente interrumpidas después del traslado de Vygotski a Moscú, en 1924. Después de esta fecha fueron muy escasas: sólo tenemos conocimiento del artículo sobre "Psicología y arte contemporáneo", publicado por Arte Soviético en 1927, y los estudios sobre La imaginación y el arte en la infancia, de 1930. Desde luego, Vygotski siguió manteniendo su interés por el arte, que se muestra en la sensibilidad e impregnación estética de su obra más propiamente psicológica (y que es uno de sus aspectos más atractivos), en los frecuentes comentarios literarios para ilustrar sus ideas psicológicas (sobre todo en Pensamiento $y$ Lenguaje), y en el interés global por problemas relacionados con el origen de los signos en general, y de los símbolos artísticos en particular. Pero..., ¿por qué fue tan escasa la producción sobre arte, después de dejar Gomel en el año 24?

Una respuesta muy sencilla es que no tuvo tiempo (iya hizo bastante!). Pero quizá influyera una razón más profunda, apuntada por Leontiev: "cuando Vygotski estaba ultimando el manuscrito de Psicologia del Arte, ante él se abria ya interiormente un nuevo camino en la Psicología, ciencia a la que atribuía un valor clave, fundamental para la comprensión de los mecanismos de creación artística y de la función específica del arte. Era preciso recorrer aquel camino para terminar su obra sobre psicología del arte para expresar aquello que habia quedado sin decir” (1970, pág. 12). Sí: quizá Vygotski pensara en volver a estos temas a partir de la construcción teórica a la que se entregó en sus años de Moscú. Era importante contar con una psicologia suficientemente explicativa y capaz de dar cuenta de la génesis y naturaleza de las funciones simbólicas superiores, para acercarse a los complejísimos mecanismos de la creación artística. Pero la necesidad de construir esa psicología había nacido, a su vez, de los intereses estéticos de Vygotski. Podemos decir que él llegó a la psicología desde la crítica y la estética, desde un interés esencial por los productos superiores de la cultura.

Como ha señalado Schedrovitsky (1982), los intereses estéticos y semiológicos de Vygotski le llevaron gradualmente a enfrentarse a la categoría de la conciencia. Era necesario profundizar en esta categoria 
para dar cuenta, con mayor profundidad, de los procesos de creación y percepción estética. Probablemente, Vygotski pensara en profundizat en Psicología lo suficiente como para resolver su asunto: ¿qué es la conciencia?, ¿qué relación tiene la estructura de los símbolos y signos con la estructura de la conciencia? Sin embargo, lo que quizá fuera, en el propósito inicial de Vygotski, una "rápida excursión» por la psicologia, suficiente para dar respuesta a las preguntas formuladas desde la semiología y la estética, terminó por convertirse en un largo viaje. La razón de esta detención en el camino era muy simple: la psicología que encontró Vygotski no era capaz de proporcionar una explicación adecuada de la conciencia. Podía, desde algunas perspectivas, brindar una descripción fenoménica de ella. En otras, la reducia a procesos elementales (por ejemplo, reflejos), tan lejanos de los productos simbólicos de la cultura que obviamente no podrian constituirse nunca en premisas fundamentales de una teoría del arte. Como semiólogo, Vygotski sintió, desde el principio, una insatisfacción profunda con las respuestas que la Psicología proporcionaba a las cuestiones relacionadas con la creación artística y el estudio de la cultura. El intento de dar respuesta a estas cuestiones exigió de él un esfuerzo gigantesco: primero, analizar a fondo (desde una perspectiva de metodólogo) dónde estaba la raíz de aquella incapacidad esencial de la Psicología de su tiempo; luego, construir una psicología cientifica, que, sin perder de vista la premisa esencial de un fundamento metodológico común en toda la ciencia de la naturaleza, fuese capaz de dar cuenta de las creaciones de la cultura. Todo ello exigirá, a la larga, introducir una dimensión bistórica en el núcleo mismo de la Psicologia como ciencia explicativa, y acercarse a la conciencia desde una concepción semiológica de su naturaleza y estructura. Aquella empresa era demasiado dificil como para que dejara espacio (en la corta vida de Vygotski) a una consideración más profunda del problema de la creación artística. Vygotski sólo tuvo tiempo para establecer las premisas de una Psicología del Arte. Dedicó la mayor parte de sus esfuerzos a una tarea previa: la de construir, simplemente, una nueva Psicología. Esto nos lleva al tercer tipo de actividades realizadas por Vygotski en su etapa de Gomel, que fueron las relacionadas con la Psicologia experimental.

3. Ya hemos comentado que Vygotski enseñó psicología en la Escuela de Magisterio de Gomel. Allí organizó un pequeño laboratorio de prácticas para los estudiantes, en que éstos planteaban y hacian sus propios experimentos. Naturalmente, aquellas actividades de enseñanza teórica y práctica en la Escuela Normal de una pequeña ciudad de provincia no tenian demasiada trascendencia externa. Hay que tener en cuenta que Vygotski no había publicado ningún trabajo de psicología antes de 1924. En resumen: un completo desconocido en los círculos psicológicos soviéticos, que vivían por entonces la ebullición postevolucionaria y el fuerte enfrentamiento entre los representantes de las posiciones idealistas clásicas y los nuevos psicólogos objetivistas. Antes de 1924, Vygotski no había intervenido en aquella polémica, y cuando terció en ella, dio la impresión, desde el principio, de que trataba de formular realmente una tercera posición, que no terminaba de coincidir exactamente con la de ninguno de los grupos en liza. Ciertamente, estaba situado en el mismo proyecto común (de construir una psicología dialéctica y coherente con los conceptos marxistas) que los jóvenes objetivistas, como Kornilov o Blonsky. Pero no se encontraba cómodo 
en los postulados reduccionistas de la reflexología, la reactologia o el conductismo. Daba la impresión, desde el principio, de que Vygotski tenia algo nuevo que decir en el debate.

Probablemente, un factor importante en esa posibilidad de decir algo nuevo era, precisamente, el hecho de que Vygotski no provenia de la Psicologia, sino de fuera de ella: no era un psicólogo profesional, sino un metodólogo, un semiólogo, un crítico. Se acercaba a la psicología armado de una serie de nociones y preocupaciones que, hasta cierto punto, eran ajenas aparentemente a la polémica esencial entre idealistas y materialistas. Nociones obtenidas de otra polémica, que se estaba dando en las ciencias de la cultura, entre los estructuralistas y los partidarios de enfoques históricos o comparados de los problemas, conceptos semióticos y filosóficos que parecían lejanos a las preocupaciones más inmediatas de los psicólogos. Desde el principio, existia la impresión de que Vygotski apuntaba realmente a un enfoque nuevo, pero en sus primeras aportaciones psicológicas predominaba más bien un tono crítico, más que las propuestas positivas para salir del atolladero en que los psicólogos se sentian metidos. Vygotski dedicó sus primeros trabajos a realizar una especie de disección crítica de la Psicología de su tiempo. Este tono es el que predomina en la comunicación con la que Vygotski (antes totalmente desconocido) se dio a conocer a los psicólogos soviéticos de su tiempo. Se trataba de un análisis sobre «El método de investigación reflexológica y psicológica», presentado el 6 de enero de 1924 en el II Congreso Pan-ruso de Psiconeurología. La presentación de Vygotski causó una viva impresión en el pequeño grupo de jóvenes objetivistas que, por entonces, se habían hecho cargo de la dirección del Instituto de Psicologia de Moscú, que era la institución más relevante de la psicología soviética.

Para entender el significado de la irrupción de Vygotski en la turbulenta psicología soviética de los años veinte es necesario que examinemos el contexto global en que aquélla tenía lugar; qué significado tenia aquel congreso en que Vygotski presentaba su comunicación y cuál era la situación y los antecedentes de la psicología a la que él aportó una forma nueva de ver los problemas que había desarrollado en sus años de formación. Este es el marco en que tenemos que situar nuestro análisis: por una parte, estaba una inteligencia dedicada al estudio de la cultura y el arte desde una perspectiva dialéctica y con una orientación a plantear los problemas en términos semióticos; por otra, una psicología escindida y turbulenta que vivía una situación de debate permanente y no terminaba de encontrar su lugar en el concierto de la ciencia de la Naturaleza, ni de resolver adecuadamente el problema de su relación con la filosofia marxista, que a su vez reivindicaba el carácter de fundamento de los saberes sobre el hombre y la sociedad.

\section{LA PSICOLOGIA SOVIETICA EN LOS AÑOS VEINTE: ANTECEDENTES Y CONDICIONES}

El enfrentamiento histórico entre la psicología introspeccionista de la conciencia y los nuevos enfoques objetivistas alcanzó su culminación en la segunda década de nuestro siglo. En la Unión Soviética, aquel 
mur peculiar, al entrelazarse con los acontecimientos revolucionarios y la condición global de cambio cultural que vivia, por entonces, aquella sociedad. Lo que en otros lugares del mundo (como Alemania, Inglaterra o los Estados Unidos) era una polémica más estimulada por la "historia interna» de la psicologia - por usar el término de Lakatos- y por la problemática más relacionada con su consistencia interna (aun sin descuidar la influencia de factores sociales y culturales externos), en la Unión Soviética se convirtió en una búsqueda apremiante de una alternativa materialista que fuese, al mismo tiempo, consistente con la filosofia socialmente dominante. Sin embargo, la oposición entre las concepciones idealistas y los intentos de construir una psicologia materialista no fue sólo un resultado de la revolución. Tenia una larga historia en la psicologia rusa: en el siglo XVill, Lomonossov y Raditchev ya habian formulado el propósito de desarrollar una psicología materialista, y este ideal fue recogido por filósofos y pedagogos de posiciones «liberales» y demócratas del siglo $\mathrm{XIX}$, como Biélinski, Herzen, Tchernychevski y Dobrolioudov. Sin duda, la expresión más completa de la tentativa materialista fue en el siglo XIX, el intento de reducir a reflejos las funciones psicológicas por parte de Sétchénov (1829-1905). Como ocurrió en otros lugares con los desarrollos materialistas del siglo XIX, la obra de Sétchénov provocó una fuerte polémica y el enfrentamiento con autoridades políticas y autores de tendencia espiritualista, como Kavelin y Strakhov. A comienzos de nuestro siglo, la situación de la psicología y neuropsicología soviéticas era compleja: se conocian bien los desarrollos occidentales y se empleaban procedimientos cuantitativos de medición e investigación, por ejemplo en la Escuela de Psicología experimental de San Petersburgo, dirigida por Nétchaiev. Además, las investigaciones de Pavlov y Bekhterev estaban permitiendo desarrollar, a partir de datos objetivos, una parte del programa de Sétchénov. Sin embargo, la corriente idealista y espiritualista tenía una gran fuerza en la psicología rusa. Su representante más eminente era el catedrático de la Universidad de Moscú, G. I. Chelpanov (1862-1936).

Chelpanov había sido, junto con Grot y Lopatin, uno de los fundadores de la Sociedad de Psicología de Moscú, de tendencia espiritualista, y que editaba, desde 1890 , la revista Voprossy Filosofii $i$ Psikhologii, que era el portavoz del idealismo en psicologia. Para él, la "psicologia propiamente dicha» debia estudiar las leyes del alma, que se sirven del funcionamiento cerebral, pero no se confunden con él y tienen entidad propia. Aunque admitiera algunas aportaciones psicotécnicas (por ejemplo, las de Spearman), rechazaba la generalización de técnicas de medición a la psicología escolar, que se había extendido por influencia del materialista Nétchaiev y se oponía abiertamente a la reflexología de Bekhterev. Para Chelpanov, el método fundamental de la psicología debía ser la introspección "experimental», semejante a la realizada por los investigadores de la Escuela de Würzburgo. En el Congreso de Psicología de 1909, sus tesis ganaron terreno con respecto a las de sus adversarios Bekhterev, Nétchaiev, Berstein, Rossolimo y Lange. En 1912 fundó el Instituto de Psicología de Moscú, que habria de ser una institución de importancia decisiva en el desarrollo posterior de la psicologia soviética y en la propia actividad profesional de Vygotski. En principio, el Instituto se dedicó, sobre todo, a desarrollar las propuestas de investigación experimental al estilo introspectivo del 
propio Chelpanov. Este pensaba que la metafísica idealista era perfectamente compatible con la investigación experimental. Pocos meses antes de la revolución de octubre, Chelpanov publicó un sexta edición de uno de sus libros clásicos, La mente del hombre, en que insistía en la crítica a las concepciones materialistas de la mente y reafirmaba sus postulados idealistas.

Poco después de la revolución, en 1918, dejó de publicarse la revista de la Sociedad de Psicología de Moscú. Chelpanov dejó la dirección del Instituto que habia fundado, pero fue restituido a su cargo en 1921 . Entre 1917 y 1923 no volvió a realizarse ninguno de los congresos que habían sido habituales en la psicología soviética en la fase prerrevolucionaria (1905-1917). El año veintitrés, sin embargo, significó un cambio importante en el desarrollo de la psicología, porque la convocatoria del I Congreso Pan-ruso de Psiconeurología permitió que se manifestasen abiertamente las tensiones latentes entre los psicólogos idealistas y las diversas corrientes materialistas que germinaban en la psicología soviética. Sin embargo no fueron los "descendientes» de Sétchénov los lideres de la revuelta antiespiritualista. Pavlov estaba alejado de cualquier clase de polémica ideológica y era cauto en la extrapolación de sus hallazgos a la psicologia humana. En cuanto a Bekhterev, la situación era más compleja: su rechazo inicial de la psicología idealista se había convertido en una insatisfacción con respecto a la psicología en general y en la propuesta de sustituirla por una "reflexología», que presentaba una visión extremadamente mecanicista de las funciones psicológicas. Ese materialismo mecanicista estaba muy lejos de los planteamientos dialécticos del pensamiento marxista. Partía de la noción metafísica de una energía común a los fenómenos materiales y mentales, todos los cuales podrían reducirse a leyes mecánicas, y del supuesto de que los principios reflexológicos podian aplicarse tanto a la sociedad como a la naturaleza. La propuesta de Bekhterev (1925) era resolver la «crisis» de la psicologia soviética recurriendo a su planteamiento "energetista" y deduciendo las leyes de la actividad refleja de un proceso cósmico de transformación de la energia. El pensaba que aquellos puntos de vista eran compatibles con la filosofía marxista, pero, evidentemente, no había nada más lejano de las leyes de la dialéctica.

Desde esta perspectiva, podemos entender el hecho de que las criticas de los psicólogos más identificados con la revolución de octubre se dirigieran tanto a los postulados idealistas de Chelpanov como al reduccionismo mecanicista de Bekhterev. En este contexto debemos entender también los sarcasmos posteriores de Vygotski con respecto a las pretensiones de traducir las funciones más complejas a un conjunto muy limitado de leyes físicas de alcances universales. No, aunque el propio Bekhterev lo creyera, él no tenia la solución a la alternativa entre un materialismo «infantil» y predialéctico y las tesis espiritualistas. Incluso Chelpanov se daba cuenta de ello y decia que la reflexologia, tal como la concebía Bekhterev, no sólo no era una psicologia subjetiva, sino que tampoco era una psicología marxista.

Este fue el marco de problemas conceptuales que rodeó al congreso de 1923. Las críticas más significativas al idealismo fueron realizadas por un discípulo del propio Chelpanov: D. I. Kornilov (1879-1957), 
marxista con una psicología introspectiva completamente divorciada de la fisiología, al tiempo que rechazaba el intento reflexológico de reducir los fenómenos psicológicos a leyes biológicas y físicas. Basándose en algunos experimentos un poco ingenuos con un cronoscopio de Hipp y un dinamómetro (en que trataba de establecer una ley de relación inversa entre esfuerzo mental y muscular), Kornilov proponía una nueva forma de hacer psicología a la que designó con el nombre de "reactología». Se trataba de estudiar, de forma objetiva, las «reacciones humanas en su ambiente biosocial». En definitiva, Kornilov trataba de evitar tanto el reduccionismo social de lo psicológico, tal como el que proponia por ejemplo Zalkind, como el reduccionismo físico de Bekhterev, sin recurrir a reificar una sustancia espiritual como objeto de la psicologia. Tuvo la habilidad de presentar su posición como la única compatible con la filosofia marxista en el congreso de 1923. Sus críticas tuvieron trascendencia pública (en Izvestia y Pravda, por ejemplo, se publicaron notas sobre el desarrollo del congreso) y provocaron una situación de crisis en la institución más influyente de la psicología soviética: el Instituto de Psicologia de Moscú.

La polémica entre los seguidores de Chelpanov y Kornilov se prolongó durante varios meses en el Instituto. Aunque Chelpanov había declarado, en principio, que el marxismo era un "dogma" sin aplicación posible a la psicología, en el debate llegó a señalar que era, precisamente, una filosofía marxista lo que el Instituto estaba necesitando (Leontiev, 1982). Finalmente, Kornilov sustituyó a Chelpanov en la dirección del Instituto de Psicología de Moscú. A pequeña escala, la revolución había llegado al recinto institucional de la "pequeña provincia» de la Psicologia.

Como ocurre en todas las revoluciones, hubo que improvisar bastante: los colaboradores de Chelpanov abandonaron el Instituto como protesta, o continuaron en él, pero con menos implicación en sus actividades. Kornilov tuvo que llamar rápidamente a algunos colaboradores muy jóvenes (algunos aún estudiantes) para reorganizar las actividades del Instituto de Psicología. Entre ellos estaban Zankov, Soloviev y Alexander R. Luria, que por entonces tenía 21 años. Aquellos jóvenes comenzaron una búsqueda apremiante de nuevas hipótesis y métodos que permitieran construir una psicología marxista. Porque ése era, en realidad, el propósito fundamental: la reactología de Kornilov era apenas un símbolo para ellos (Deontiev, op. cit.). La mayor parte de ellos (incluyendo al propio Kornilov) tenían una formación marxista escasa y superficial. Eran conscientes de que la reactología no era la solución que buscaban y desarrollaron una actividad entusiasta para renovar las actividades del Instituto. Crearon laboratorios de reacciones motoras, mnésicas, intelectuales, y comenzaron a simultanear la investigación con las actividades didácticas, bajo la dirección de Kornilov, que trataba de profundizar en las implicaciones psicológicas del pensamiento marxista.

$\mathrm{El}$ análisis histórico de la importancia de Kornilov es complejo. Su aportación fue decisiva a la hora de enunciar las premisas a que deberia atender una psicología de orientación marxista, pero no fue capaz de construir una psicología coherente con los principios enunciados por él mismo. Estos principios eran esencialmente los siguientes: 
I. Monismo materialista, considerando las funciones psíquicas como propiedad de la materia organizada.

2. Reconocimiento de la irreductibilidad de los fenómenos psíquicos a los fisiológicos.

3. Reconocimiento de la naturaleza social de las reacciones humanas y de la naturaleza idealista de la psicologia individual, incapaz de dar cuenta de la influencia de las clases sociales.

4. Reconocimiento de la naturaleza cambiante de la realidad física y social, de la interconexión universal de los fenómenos y del carácter emergente de las sintesis dialécticas (Kornilov, 1926, 1927). Con un esquema hegeliano trataba de entender los estados subjetivos como tesis, los reflejos como antitesis y las reacciones como sintesis. Las reacciones se diferenciarían de los reflejos por su carácter universal, por ser respuestas del organismo como un todo y por incluir un aspecto subjetivo.

Sin embargo, la orientación de Kornilov se mostraba incapaz de resolver el problema de construir una psicología dialécrica. Su concepción de la conciencia era esencialmente pasiva y no solucionó el problema de la distinción entre energía física y conciencia, como ya le ocurriera a Bekhterev (Fernández Trespalacios, 1978). Tenía aún una concepción energetista ingenua de la conciencia (entendida como energía fisica o metafisica), muy diferente de la concepción semiótica de la conciencia que luego desarrollaría Vygotski (la conciencia como función significante de carácter instrumental).

Desde un punto de vista histórico, Kornilov jugó un papel decisivo en la orientación marxista de la psicología soviética y en la organización institucional de la nueva ciencia. En el año 1924, el Instituto de Psicología de Moscú, renovado en su mayor parte, había alcanzado una posición de vanguardia y motor de la psicología, a pesar de las indecisiones e ingenuidades que, lógicamente, se dieron. Así estaban las cosas cuando se realizó el II Congreso Pan-ruso de Psiconeurología, en Leningrado, en el mes de enero de 1924. Kornilov presentó allí una proclama de la nueva orientación que se titulaba «El método dialéctico en psicologia». En aquel congreso se dio a conocer Vygotski en los movidos circulos de la psicologia soviética y comenzaron aquellos diez años con que comenzábamos nuestra historia.

\section{REFLEJOS Y CONCIENCIA: APORTACIONES CRITICAS DE VYGOTSKI A LA BUSQUEDA DE UNA PSICOLOGIA DIALECTICA}

La comunicación de $\mathrm{V}$ ygotski sobre «El método de investigación reflexológica y psicológican planteaba algunos de los problemas fundamentales que se debatian en aquellos momentos «constituyentes» de la psicología soviética posrevolucionaria. La cuestión central era la incapacidad de la reflexologia para explicar adecuadamente la conciencia. Por una parte criticaba la vaguedad de las afirmaciones reduccionistas de los reflexólogos, la imposibilidad de formular los aspectos peculiares de los sistemas psicológicos complejos a partir del simple enunciado de que 
implicita en la posición de muchos reflexólogos que, al mismo tiempo que rechazaban el valor de los informes verbales de los sujetos, entendian estas verbalizaciones introspectivas como "reflejos de orden superior». Si eran reflejos... ¿por qué no emplearlos para el estudio objetivo del funcionamiento psicológico? Ciertamente, el tratamiento objetivo de los informes de los sujetos sobre sus procesos psíquicos exigía una metodología cuidadosa (dependiendo del carácter de tales informes), pero era una vía de acceso de importancia fundamental para el estudio objetivo de los aspectos peculiares de los «sistemas complejos de reflejos» (i. e. la conciencia y funciones superiores).

Vygotski (1924) criticaba lo que él llamaba «idealismo vuelto del revés» de Bekhterev y Pavlov; es decir, la tendencia a prescindir de lo psíquico. Advertía perspicazmente que, si bien esa tendencia conducía a una posición de materialismo puro en la esfera limitada de la fisiología, terminaba por llevar a un enfoque implícito de idealismo dualista en la esfera más general del problema de las relaciones entre mente y materia. Por entonces aún pensaba Vygotski que era posible un estudio objetivo de las funciones superiores de conciencia sin salir de los limites de la reflexologia, partiendo de la idea de la conciencia como "mecanismo de transmisión de reflejos». Es cierto que Vygotski proponía ampliar esos límites conceptuales de las explicaciones reflexológicas y trataba de llegar a una ciencia que no tuviera ni las inconsecuentes restricciones de la reflexología de su tiempo ni las premisas dualistas implícitas en la psicología introspectiva clásica. Sin embargo, en la comunicación del año veinticuatro, Vygotski empleaba nociones reflexológicas (por muy «liberales» que fueran) para tratar de fundamentar esa ciencia.

Finalmente, Vygotski situaba el problema de la autoobservación en el contexto general de una situación de crisis de la psicología. Insistía en el carácter universal de esa crisis: "No hay tentativa más falsa - decía- que la de pretender que la crisis que ha dividido a la ciencia de nuestro país en dos campos tiene un carácter puramente local, ruso. La crisis reina actualmente en toda la línea en la ciencia psicológica mundial" (1924, pág. 116). En esencia, la crisis entrañaba la ruptura entre una psicología elementarista, sin conciencia, reducida a los reflejos simples e incapaz de dar cuenta de los aspectos propios de las funciones psicológicas complejas, y una psicología subjetiva de la conciencia desencarnada de sus condiciones materiales e incapaz de formular objetivamente las leyes de las funciones superiores. Fundamentalmente, Vygotski proponía un empleo objetivo de la autoobservación y los informes verbales como uno de los puentes para superat esa ruptura profunda.

Vygotski era agudamente consciente, desde sus primeras aportaciones psicológicas, de la situación de crisis que caracterizaba a la psicología de su tiempo. Sin embargo, resulta evidente que aún no había elaborado las categorías que le permitirian posteriormente enfrentarse a esa crisis, y en 1924 se movía en un terreno cercano al de la reflexologia clásica, aunque con planteamientos muy criticos hacia ella. Luego fue haciéndose mayor la distancia que le separaba de los conceptos de los reflexólogos.

La ponencia de Vygotski fue seguida con gran interés por los jóvenes investigadores que se habian hecho cargo del Instituto de 
Psicologia de Moscú. Luria, que era uno de ellos y ocupaba el cargo de subdirector de aquella institución, describe así la impresión que le produjo la aportación de $\mathrm{V}$ ygotski:

"Conoci a Vygotski en 1924, en el Segundo Congreso de Psiconeurologia, que se celebró en Leningrado (...) Cuando Vygotski se levantó para presentar su ponencia, no llevaba ningún texto escrito, ni siquiera notas. Sin embargo, habló con fluidez, sin dar la impresión, en ningún momento, de que tuviera que pararse para buscar en la memoria sus ideas. Aunque el contenido de su ponencia hubiera sido elemental, su presentación habria sido notable por su estilo persuasivo. Pero es que, además, su ponencia no era elemental en absoluto. En vez de elegir un tema menor, como hubiera podido hacer un joven de veintiocho años que hablaba por primera vez a un auditorio en que se encontraban las máximas autoridades de su profesión, Vygotski eligió el dificil tema de la relación entre los reflejos condicionados y la conducta consciente del hombre. El año anterior, Kornilov habia utilizado el mismo auditorio para atacar a las teorias introspectivas en Psicología. Su punto de vista habia prevalecido y su enfoque objetivo, reactológico, era el que predominaba en nuestro instituto. Tanto Bekhterev como Pavlov eran bien conocidos por su oposición a la psicología subjetiva, en la que el concepto de conciencia ocupaba una posición central. Sin embargo, Vygotski defendió la tesis de que el concepto de conciencia debia mantenerse en Psicología, argumentando la necesidad de estudiarlo con procedimientos objetivos. Aunque no consiguiera convencer a nadie de que su enfoque era el correcto, era evidente que aquel hombre, venido de una pequeña ciudad de provincia del oeste de Rusia era una fuerza intelectual con la que había que contar." (1979, pág. 38).

La aportación de Vygotski al Congreso de Leningrado sintonizaba con el interés por construir una psicología objetiva, capaz de dar cuenta de los procesos humanos más complejos, que era el propósito esencial de los nuevos miembros del Instituto de Psicología. Estos tomaron la decisión de pedir a Vygotski que colaborase en las actividades del instituto.

En el otoño de 1924, Vygotski dejó Gomel para instalarse en Moscú. Su primera aportación a los trabajos del instituto dirigido por Kornilov tuvo una extraordinaria importancia. Se trató de una conferencia sobre "La conciencia como problema de la Psicología de la conducta», que dio en el instituto el iq de octubre de 1924.

Es habitual, entre los historiadores de la Psicologia, confundir esta conferencia con la ponencia que Vygotski había presentado en Leningrado nueve meses antes (vid., por ejemplo, la introducción de Cole, en Soviet Psichology, en que dice que el artículo de "La conciencia..." es «la versión escrita de una comunicación de Vygotski al segundo Congreso Pan-ruso de Psiconeurológos, celebrado en Leningrado en 1924") y, desde un punto de vista histórico, es importante deshacer este equivoco. La ponencia de Leningrado y la conferencia de Moscú son distintas y, además, el análisis de sus diferencias es intructivo para ver cómo se iban elaborando y construyendo las ideas de Vygotski entre enero y octubre de 1924: el artículo sobre la conciencia presenta una actitud bastante más crítica e irónica hacia las pretensiones reduccionistas de los reflexólogos y, al mismo tiempo, se acerca más claramente a una idea que terminaría por convertirse en el núcleo principal de la psicología vygotskiana: el principio de la génesis social de la conciencia. 
Lo más característico del artículo de 1924 es que constituye un intento de conjugar la categoría de "reflejo" con la idea del origen social de la conciencia: "Al momento social de la conciencia - decía Vygotski- le corresponde la primacía en el tiempo y en la acción. El elemento individual se constituye, como elemento derivado, sobre la base del componente social y según su modelo exacton (págs. 8 $5-86$ ). Vygotski se servia del mecanismo de los "reflejos reversibles" -aquellos provocados por estímulos que, a su vez, pueden ser respuestas propias - para tender un puente entre la relación social y la conciencia individual, originada a partir de aquélla. "Somos conscientes de nosotros mismos - decía- porque somos conscientes de los otros; y 'de modo análogo, somos conscientes de los otros porque en nuestra relación con nosotros mismos somos iguales que los otros en su relación con nosotros" (pág. 85). La propiedad de ciertos reflejos de ser, al mismo tiempo, respuestas propias y estímulos para uno mismo constituye el fundamento psicológico conjunto de los mecanismos de contacto social y de conciencia: "La conciencia es, como si dijéramos, contacto social con uno mismo", señalaba Vygotski. No un destilado de un desarrollo solipsista "dentro de la piel», sino un resultado de la relación social con los otros.

Algunos psicólogos americanos han tendido a interpretar la obra de Vygotski como una especie de "conductismo mediacional». La conferencia sobre la conciencia admite, evidentemente, esta lectura, desde el momento en que constituye un esfuerzo por ofrecer una interpretación sofisticada de la conciencia, pero sin abandonar el marco E-R proporcionado por la categoría de reflejo. El concepto de ureflejo reversible» es una expresión de la misma idea que lleva a Mowrer, Osgood, Staats y otros a hablar de estímulos y respuestas mediacionales. El propósito fundamental es el mismo: el de no abandonar el marco conceptual de la psicología objetiva del aprendizaje para explicar las funciones superiores y la conciencia. La premisa básica también es la misma: las respuestas propias pueden ser estímulos para uno mismo, del mismo modo que lo son las respuestas de los demás. El supuesto esencial es común: del mismo modo que hay estímulos, respuestas y reflejos externos, podemos hablar de otros que son internos o fraccionales. En suma, podemos situar el artículo sobre la conciencia de 1924 dentro de una orientación mediacional de la psicología objetivista.

Pero de ahí a entender toda la obra de Vygotski como una formulación mediacional va una enorme diferencia. El concepto vygotskiano posterior de «mediación» desbordaba absolutamente cualquier marco de explicación E-R, como el propio Vygotski tuvo buen cuidado en señalar. Precisamente constituía una categoría activa, sustentada en la idea de transformación del medio (y no de respuesta) y de las funciones del propio sujeto (capaz de reobrar, incluso, sobre los reflejos elementales), que Vygotski desarrolló en contraposición explícita a las concepciones mecanicistas y el esquema estímulo-respuesta. Es decir: podemos hablar de una etapa mediacional en la psicologia de Vygotski, pero de ningún modo identificar su sistema maduro con el conductismo mediacional.

El comentario anterior nos ayuda a situar en su justa importancia histórica la conferencia de octubre de r 924 . Esta ha sido considerada, a veces, como "el manifiesto de la escuela histórico-cultural», pero 
tiene, más bien, un papel «transaccional» en el pensamiento de Vygotski: conserva aún muchas adherencias reflexológic.1, i" . ' establece con claridad el principio de la génesis social de la conciencia individual; formula la idea de que "la palabra es el origen de la conducta social y la conciencia" (ibíd), pero sin desarrollar aún las ideas sobre la función de mediación activa de los instrumentos y signos. En resumen, Vygotski aún no habia desarrollado sus propios conceptos lo suficiente como para caer en la cuenta de que el principio de génesis social de la conciencia, y la observación de la estructura semiótica de ésta llevaban a desbordar el marco reflexológico y "reinterpretarlo desde arriba», a partir de un principio de significación capaz de modificar los procesos mismos de señalización (que sí podian ser explicados con el mecanismo de los reflejos condicionados). Por eso, es inexacta la consideración del artículo sobre la conciencia como un manifiesto de la escuela histórico-cultural: no contiene aún las ideas fundamentales (sobre la naturaleza histórica y significativa, más que señalizadora, de las funciones superiores) que caracterizaron a la teoría de Vygotski. Si, representa, sin embargo, un avance importante hacia la solución del "puzzle» conceptual que se expresaba en la crisis de la psicología y la escisión entre objetivismo y subjetivismo.

Desde la llegada de Vygotski a Moscú se formó un pequeño grupo de trabajo formado, al principio, por Luria, que era el secretario científico del Instituto de Psicologia; Leontiev, que tenía un papel de colaborador externo, y el propio Vygotski. Es curioso que éste, que nunca llegó a ocupar en el instituto un puesto directivo, fuera reconocido, desde el comienzo, como «líder intelectual" de aquella «troika» (como ellos mismos llamaban a su pequeño grupo). En un interesante artículo sobre los primeros años de colaboración entre Luria y Vygotski, Radzikhovskii y Jomskaya (198I) han tratado de explicar esta aparente paradoja: Luria era bastante conocido, antes de su encuentro con Vygotski, por sus brillantes trabajos sobre el umétodo motor combinado" que le habia permitido descubrir un procedimiento objetivo de análisis de experiencias emocionantes latentes, en un paradigma de asociación; además tenía una preparación en metodologia experimental superior a la de Vygotski, y siempre ocupó una posición institucional de mayor poder. Como secretario científico del instituto, y, después, como director del laboratorio de psicología de la Academia Krupskaya de educación comunista, siempre estuvo situado en un rango institucional más alto. Entonces, ¿cómo fue posible que se convirtiera en «discípulo» de Vygotski, reconociendo - sin reservassu liderazgo intelectual?

La respuesta es que Vygotsky se presentaba, ante Luria y Leontiev (y, luego, ante sus colaboradores posteriores), como la persona capaz de establecer la dirección metodológica fundamental, "una especie de metasistema" (Radzikhovskii y Khomskaya op. cit.), que permitía desarrollar al máximo las aptitudes y capacidades de sus colaboradores. En el caso de Luria, nos encontramos ante un cientifico brillante, de mente clara, capaz de simplificar los problemas sin perder sus matices fundamentales, con una formación científica clásica. Esas capacidades, sin embargo, necesitaban el complemento de una nueva orientación fundamental, que podía provenir del espíritu humanista, mucho más complejo (y también más ambiguo) de Vygotski. Este era el que poseía una formación filosófica suficiente como para poder analizar en 
profundidad dónde estaba la raíz de la crisis de la psicología, que todos percibian, y señalar las orientaciones fundamentales para construir una sintesis nueva. Precisamente, porque provenia de las humanidades, la fillosofía y la semiótica, Vygotski desplegaba, ante sus colaboradores, un conjunto de categorias nuevas (incluyendo una concepción holista e histórica de las funciones superiores, nociones estructurales y esquemas profundamente dialécticos) que permitian construir, entre todos, la "tercera vía" (un objetivismo no reduccionista) que buscaban. El liderazgo intelectual de Vygotski era, entonces, una exigencia de la situación objetiva, y no sólo un efecto de la atractiva personalidad que todos le reconocían.

Para entender todo esto, debemos situar en su contexto histórico el liderazgo intelectual de Vygotski. El objetivo esencial de construir una psicologia marxista no podía quedar cubierto con una mezcla externa, puramente verbal, de principios marxistas y observaciones psicológicas, ni con una unificación de rasgos (la «sintesis» de que hablaba Kornilov) de escuelas cuyas orientaciones eran, en cierto sentido «inconmensurables». Se trataba de alcanzar un «estadio nuevo" en la historia de la Psicología (Leontiev, op. cit.) y el único investigador del instituto que poseía una formación marxista sólida y realmente asimilada era Vygotski. Los demás consideraron que él era, por tanto, el único capaz de establecer las premisas para alcanzar ese unuevo estadio». Lo primero que habia que hacer era una labor metodológica y de análisis crítico, y Vygotski era, por su preparación humanista, el más capacitado para realizarla.

El programa de trabajo que establecieron, desde un principio, los miembros de la "troika» era, por tanto, ambiciosísimo: se trataba, nada menos, que de analizar, desde un planteamiento histórico y crítico, la situación de la psicología soviética y universal y proponer una alternativa teórica capaz de hacer productiva la "crisis" de la psicología, a la que Vygotski se referia desde sus primeros trabajos. Desde muy pronto, Vygotski se dio cuenta de que la alternativa no estaba en la orientación del «director institucional», Kornilov (ya en 1925 criticaba las insuficiencias del enfoque reactológico). Pensaba que la «reactología) (un enfoque que, de hecho, era muy cercano al conductismo norteamericano), al limitarse al estudio objetivo del comportamiento externo y concebir la conciencia en términos energetistas simples, correspondía más bien a un materialismo mecanicista, incapaz de explicar el paso de la cantidad a lá cualidad, e imposibilitado para incluir en una misma trama explicativa los procesos de energia física y las funciones psicológicas (a no ser mediante la reducción de las segundas a los primeros). En resumen: Vygotski pensaba que Kornilov no se hrabía librado del mecanicismo que él mismo había reprochado a Bekhterev y no había desarrollado una psicología de orientación dialéctica, a pesar de sus numerosos trabajos sobre la relación entre psicología y marxismo. Los miembros de los "troika» buscaban otro camino.

\section{LA CRISIS DE LA PSICOLOGIA Y LA APORTACION METATEORICA DE VYGOTSKI}

En 1925 se le ofreció a Vygotski una oportunidad excelente para continuar aquella búsqueda. Su activa participación en la organización 
de la educación de niños con deficiencias sensoriales y mentales hizo que Lunacharsky, presidente del Comisariado del pueblo para la instrucción, le encargara de presentar una comunicación en el 25 Congreso Internacional de Educación de Sordomudos, que habia de celebrarse en Londres. Alli presentó Vygotski una ponencia sobre "Principios de la educación social de niños sordomudos». Pero, sobre todo, aquel viaje le ofreció la oportunidad de conocer y visitar varias instituciones y laboratorios de psicologia en Inglaterra, Francia, Alemania y Holanda.

Cuando Vygotski volvió de su viaje a Europa occidental se agravó el proceso de tuberculosis que padecía desde 1919. En 1926 tuvo que ser hospitalizado para un largo tiempo de tratamiento $y$ aprovechó la ocasión para profundizar en el análisis de la crisis de la Psicologia, a la que se venía refiriendo desde sus primeros trabajos. En su.período de tratamiento y reposo, escribió un importante ensayo sobre El sentido bistórico de la crisis de la Psicologia. El manuscrito de este libro de Vygotski sufrió, posteriormente, diversos avatares: no fue publicado en vida de Vygotski, se perdió en la segunda guerra mundial, fue encontrado en 1960 y se publicó, finalmente, en 1982 . Sin duda, el libro es uno de los trabajos más importantes y más significativos (desde el punto de vista histórico) de todos los de Vygotski. Ocupa una posición intermedia entre sus primeros trabajos y los escritos en que ya se formulaba, con claridad, una teoria nueva de la génesis y naturaleza de las funciones superiores. En realidad, podemos entender la concepción psicológica de Vygotski como un desarrollo a partir de los análisis realizados en El sentido bistórico de la crisis de la Psicologia, por lo que esta obra debe ocupar un lugar central en la exposición de la teoría misma. La teoría es, en cierto sentido, una respuesta a las cuestiones suscitadas en la Crisis.

En una perspectiva histórica, la psicologia de los años veinte era una espléndida y pluriforme realidad: las investigaciones sobre la actividad nerviosa superior, cuyas premisas habian establecido Pavlov y Bekhterev, comenzaban a dar sus frutos. Los conductistas americanos y los reactólogos soviéticos desarrollaban una psicología objetiva, con procedimientos y resultados semejantes a los de las ciencias naturales. El psicoanálisis se encontraba en un periodo de franca expansión. Los psicólogos de la Gestalt estudiaban las formas complejas de organización psicológica que se dan en la percepción y la solución de problemas. Era aquella una psicología multiparadigmática, de grandes lineas de pensamiento, llena de investigaciones y soluciones geniales. Entonces, ¿dónde estaba la crisis?

En primer lugar, en la propia diversidad, que no era sólo pluralidad y riqueza de ideas, sino también escisión de la Psicología. Vygotski señalaba que no sólo había una incompatibilidad teórica entre las diversas escuelas, sino que los propios becbos, que fundamentaban las construcciones teóricas, eran «incompatibles» cuando se los situaba en un mismo plano de análisis. Con una concepción muy avanzada de la filosofía de la ciencia, Vygotski mantenía que los hechos no son entidades preteóricas en bruto, sino que están cargados de teoria. Por ejemplo, hablando del introspeccionismo, el conductismo y el psicoanálisis, señalaba que «cualquier hecho, expresado en términos de estos tres sistemas, adquirirá tres significados completamente diferentes que 
indican tres aspectos diferentes del hecho o, más precisamente, tres hechos diferentes" (pág. 299). Es decir: lo que son bechos para una teoria (como el reflejo o el complejo de Edipo) no tienen cabida en el universo de discurso de otras. Vygotski empleaba aqui una idea similar a la de los filósofos de la ciencia posteriores (por ejemplo, Feyerabend) cuando hablan de sistemas científicos «inconmensurables». Sencillamente, los diversos sistemas no podrian compararse en un mismo plano. Sus categorías básicas se referirian a distintos niveles de realidad, sus "hechos" y "datos" serían el producto de distintos planos de abstracción e interpretación.

La divergencia de "niveles de realidad» (o de análisis) entre los distintos sistemas sería tan grande que cabria hablar de varias psicologias, de ciencias distintas. Esta fragmentación estaria relacionada con el carácter expansivo de lo que hoy llamariamos "paradigmas» científicos. Al analizar la evolución de la reflexología, el psicoanálisis, la psicologia de la Gestalt y la psicología personalista, Vygotski descubría una misma pauta de desarrollo: a partir de un descubrimiento empírico importante se establece una primera «forma conceptual», y ésta se extiende progresivamente, como una gota de aceite, a la explicación de problemas cada vez más alejados del descubrimiento original. De este modo, la idea se hace progresivamente más abstracta y va diluyendo su significación originaria, a la vez que se justifica en el descubrimiento del que nació. Este proceso alcanza su culminación en la transformación de la idea o "forma conceptual» en un conjunto de principios explicativos muy abstractos y que son aplicables a todos los fenómenos. Finalmente, todo se reduce a reflejos, o a impulsos inconscientes, o a formas pregnantes. Sin embargo, este proceso de expansión de los principios se realiza a costa del poder explicativo de los mismos. Llega un momento en que los principios desbordan los propios límites de la Psicología y se convierten en metodologias generales asimilables a todos los campos de conocimiento. En esa fase, los principios terminan por colapsarse, aplastados por el enorme peso explicativo que se les ha concedido. Se convierten en «filosofias generales», con lo cual terminan por revelar su verdadero origen: en ese estadio "terminal», la idea psicológica - decia Vygotski- revela su verdadero origen social, que antes se ocultaba bajo el disfraz de un hecho de conocimiento (pág. 304).

Ese proceso de expansión progresiva de las ideas psicológicas era, para Vygotski, una expresión sublimada de una profunda necesidad de la psicología: la de encontrar una metodología general. Sin embargo, la forma legitima de construir esa metodología general no sería la expansión espúrea de ideas nacidas de fenómenos específicos, sino la realización de un análisis meta-teórico adecuado. Vygotski no identificaba «análisis metateórico» con "análisis lógico». Se oponia a la reducción lógica de la metodología que proponía Binswanger. Pensaba que, del mismo modo que los hechos están cargados de teoria, las teorias están, por así decirlo, "cargadas de hechos". Incluso las concepciones más abstractas retienen referencias empíricas indirectas. Por eso, el análisis metateórico de la Psicología no deberia asimilarse a una especie de lógica general de la investigación científica, olvidando su carácter psicológico.

Otra alternativa que rechazaba Vygotski era la de intentar formular una psicología general (o una «metodología general») mezclando 
conceptos de diversos planos y orígenes teóricos, para tratar de construir una metodología "sintética». En este sentido, criticaba tanto el «imperialismo reflexológico» de Bekhterev (en que los reflejos terminaban por referirse a planos fenoménicos muy alejados de ellos) como los intentos del "Freudo-Marxismo", en que un conjunto de adjetivos («dialéctico», «inconsciente»... etc.) recubririan una ecléctica amalgama de sistemas despojados de sus características própias. Para Vygotski, la Psicología General (o, si se quiere, "Fundamental») no debía ser un sistema ecléctico sino una ciencia con sus propias categorías, situadas esencialmente en un plano metateórico. $\mathrm{Ni}$ una lógica aséptica, ni una amalgama teórica. Pero, entonces, ¿de dónde deberían provenir las categorías de esa Psicología General?

La respuesta de Vygotski podría parecer sorprendente: de la crisis misma. Desde una concepción dialéctica del desarrollo de la Psicología, la crisis no debería considerarse como un fenómeno negativo o lamentable, sino como una expresión de la oposición creativa de fuerzas capaces de generar, desde la escisión misma, una síntesis sustantiva. Lo primero que habria que hacer, para construir esa síntesis, seria analizar en profundidad la verdadera naturaleza de las fuerzas en colisión. Siguiendo a Münsterberg, Vygotski pensaba que esas fuerzas opuestas podian reducirse esencialmente a dos grandes orientaciones: un enfoque naturalista y una concepción idealista de los fenómenos psicológicos. Esta sería la oposición fundamental subyacente a la fragmentación de la psicología en diversos paradigmas contrapuestos: por una parte, estaría la alternativa de explicar las funciones psicológicas como procesos naturales, incorporando la psicologia a la metodología general de la ciencia de la Naturaleza y a sus supuestos epistemológicos. Por otra parte, la opción de describir o comprender, como fenómenos irreductibles, los contenidos y estructuras psicológicas.

La escisión entre una psicología científica y una psicologia de carácter filosófico o fenomenológico expresaba, para Vygotski, el dilema fundamental de la psicología de su tiempo. En la primera, la "naturalista», veía él una incapacidad para explicar las funciones superiores, especificamente humanas, de conocimiento y acción. En la segunda, un carácter meramente descriptivo y no-explicativo, y una incapacidad para asimilarse al modelo científico de las ciencias en general.

La última parte de El sentido histórico de la crisis de la Psicologia se dedicaba a los intentos de hallar una tercera vía, que no fuera la del objetivismo reduccionista ni la del subjetivismo descriptivo. Vygotski analizaba tres de estos intentos: la Gestalt, la psicología personalista de Stern y los intentos de una psicología marxista.

Vygotski tenia un conocimiento profundo de la tradición gestaltista, y todo indica que era ésta una de las orientaciones de la Psicología de su tiempo que más valoraba y que influyó más decisivamente en su pensamiento. Sin embargo, decía que la Gestalt habia terminado por situarse en unos supuestos naturalistas (aun sin quererlo), sin que ello significara que fuese capaz de enfrentarse a una explicación de las funciones superiores. Aquí el diagnóstico de Vygotski era muy preciso, y se dirigía directamente a la más profunda contradicción de la Gestalt, que consistia en amoldarse externamente a las explicaciones «naturales" (por ejemplo, el supuesto de isomorfismo psico-fisiológico), sin pasar de la descripción a la explicación propia de las ciencias de la Naturaleza. 
Por otra parte, la psicología personalista de Stern, originada en la tradición diferencial, se había convertido progresivamente en una teoria idealista, situándose en la opción opuesta a la de su punto de partida.

Finalmente, Vygotski analizaba los intentos anteriores de construir una psicologia marxista (por ejemplo, el de Kornilov). Se oponía claramente a la "escolástica verbal», consistente en "citar" a los clásicos marxistas sin profundizar realmente en el método dialéctico, y señalaba que el marxismo no contiene soluciones mágicas para la psicología: «La aplicación inmediata de la teoría del materialismo dialéctico a los problemas de la ciencia - decia-, y particularmente a la biologia y la psicología, es imposible, como lo es su aplicación inmediata a la historia y la sociología» (pág. 4I9). Este punto es absolutamente central: ¿Cómo es posible que Vygotski, que trataba de construir una psicología marxista, dijera que el marxismo no era aplicable de forma inmediata a la psicologia?

El problema era éste: los intentos anteriores de desarrollar una psicología marxista habian consistido esencialmente en mezclar los principios marxistas con los hechos y esquemas conceptuales de diversas clases de teorías psicológicas, combinar proposiciones generales (por ejemplo, «lo psíquico es una propiedad de la materia altamente organizada") del marxismo con ideas de la reflexología, el psicoanálisis, el conductismo. Sin embargo, los dos grupos de ideas combinadas (marxistas y psicológicas) mantenían, por así decirlo, una «existencia independiente». Aunque no fueran lógicamente contradictorias, eran sustancialmente ajenas las unas y las otras (Davidov, 1982). El resultado no era una síntesis verdadera, sino aparente: una mezcolanza verbal. ¿Por qué?

La respuesta sería que la relación entre la psicología científica y la filosofía marxista no podía ser una vinculación inmediata, sino mediata. Es decir, era preciso construir un conjunto de categorías intermedias (por llamarlas así), que permitieran establecer una relación verdadera entre los principios más generales del marxismo y las teorías psicológicas más específicas. Del mismo modo que Marx habia utilizado categorías intermedias como las de plusvalía, capital o alienación, para relacionar las ideas del materialismo histórico con la crítica a la economía política, era necesario desarrollar principios y categorias generales, pero de carácter propiamente psicológico, para establecer esa relación mediata, indirecta, entre psicologia y marxismo. A ese conjunto de ideas y principios era, precisamente, a lo que Vygotski llamaba una "psicología general».

Por tanto, el desarrollo de una metodología general (o una psicología general, como decía Vygotski) no sólo era un requisito para superar la crisis de escisión que se daba en la psicología de los veinte, sino también una exigencia previa a la construcción de una psicología marxista. Es evidente que ésta no podía basarse en conceptos como el de plusvalia, capital, o valor de cambio (que eran de carácter económico) ni en principios tan generales como el del carácter de función material de lo psiquico (de naturaleza filosófica), sino que necesitaba sus propios conceptos y sus propios principios, de carácter psicológico. Esos conceptos y principios debían desarrollarse a partir de una crítica de la psicologia, del mismo modo que los de Marx se habian desarrollado a partir de una crítica de la economia política. Una especie de 
"crítica de la razón psicológica» (Yaroshevsky, 1982), que obligó a Vygotski a asumir la posición de metodólogo antes de la de psicólogo. Ese era el único camino para poder formular unos principios metodológicos normativos que permitieran hacer una psicología general. Desde la lógica inherente a la psicología marxista, los pasos a dar eran:

1. Desarrollar una metodologia general de la psicologia.

2. Aislar los principios explicativos generales.

3. Construir, a partir de ellos, categorias y teorias concretas.

La «crítica de la razón psicológica» permitió a Vygotski establecer las exigencias fundamentales que deberían tener los conceptos y principios de esa metodología general. A partir del análisis de la escisión fundamental entre la psicologia objetiva, que reducía las funciones complejas a procesos elementales, y la subjetiva, que preservaba la complejidad de los contenidos de conciencia pero era incapaz de explicar su génesis, resultaba evidente que lo que había que hacer era desarrollar categorías y principios que fueran, al mismo tiempo:

I. No reduccionistas.

2. Explicativos.

3. De carácter genético (dialéctico).

Por tanto, las categorias intermedias no deberían serlo sólo entre los principios generales de la dialéctica y la psicologia concreta, sino, también (y por eso mismo) entre las leyes naturales del organismo (tales como las que se expresaban, por ejemplo, en los mecanismos reflejos) y los productos superiores de la cultura, la historia y el psiquismo humano.

Podriamos decir que la búsqueda de categorías intermedias debia partir del supuesto de que la psicología es, precisamente, una «ciencia intermedia» entre las ciencias de la Naturaleza y las del Espiritu. Pero aquí la palabra «intermedia» no quiere significar "dual». Precisamente, la causa fundamental de la escisión de la psicología era, para Vygotski, la escisión entre las categorías de análisis de procesos psicofisiológicos elementales y las categorias de estudio de los fenómenos de conciencia y cultura. Es decir, el dualismo. Y este dualismo era latente tanto a la psicología introspectiva, como a la ciencia de la conducta o los reflejos, en su intento de reducción de los fenómenos de conciencia a los procesos elementales. Por eso Vygotski hablaba del «idealismo vuelto del revés» de los reflexólogos y les atribuía la más sorprendente de las calificaciones: la de dualistas. La justificación de esta crítica era que, al perder todos los matices de los fenómenos de conciencia - por la reducción refleja de ésta-, hacian evidente la imposibilidad de explicar, por procedimientos científicos, sus productos superiores. Con lo cual, el objetivismo reflexológico tenia que acomodarse a convivir, en las mejores relaciones, con la psicología introspectiva de matiz más idealista (Pavlov, por ejemple, que prohibia hablar de estados subjetivos en su laboratorio, había enviado sus mejores deseos y felicitaciones más entusiastas a Chelpanov, cuando se inauguró el Instituto de Psicología de Moscú).

Se trataba, entonces, de desarrollar categorias y principios que, al tiempo que admitieran un tratamiento explicativo, mantuvieran en su 
propia entraña las caracteristicas esenciales de las funciones psicológicas complejas: de encontrar otra realidad que fuese una mediación entre procesos elementales y funciones superiores. Una realidad no reductible a las expresiones materiales más concretas de lo orgánico ni a un espíritu solitario. $\mathrm{Y}$ aquí acudían, en ayuda de Vygotski, sus viejos conocimientos de Spinoza y el marxismo: Spinoza había insistido en la necesidad de entender el pensamiento no como un "modo» concreto, sino como un atributo esencial de la sustancia, no determinado por la estructura y las partes del cuerpo humano, sino por las condiciones externas de la actividad universal de la Naturaleza (incluyendo a los otros sujetos). En otras palabras, el pensamiento no sería una función formalmente determinada por la estructura de la «extensión» del cuerpo humano, sino por la actividad externa, objetiva, en relación con otros cuerpos (Ilyenkov, 1977). El pensamiento no estaria estructural sino funcionalmente determinado por la forma del mundo externo, y no del propio cuerpo. Por otra parte, las concepciones marxistas llevaban a entender que esa determinación funcional es, esencialmente, de naturaleza social y se relaciona entrañablemente con las formas que toma la actividad productiva, por la cual el hombre transforma la Naturaleza, ya que las formas sociales están determinadas por la propia actividad instrumental implicada en la producción.

En suma, para definir las categorias intermedias, necesarias para desarrollar una psicología general era preciso salir fuera de los límites de lo subjetivo y remitirse a las formas objetivas de la vida social y de la relación activa del hombre con la Naturaleza. A partir de ahí, sería preciso encontrar alguna clase de unidades, que, sin dejar de ser psicológicas, conservaran la marca de esa referencia al contexto social r natural originante de la propia conciencia y de sus productos culturales más elaborados.

El requisito mínimo de tales unidades debía ser el de conservar las caracteristicas esenciales de las funciones superiores de la conciencia. Vygotski compartía con los psicólogos de la Gestalt la idea de que uno de los factores fundamentales en la crisis de la psicología era el modelo elementarista de explicación, según el cual, "explicar» equivale a analizar y descomponer las totalidades en sus elementos constitutivos (prescindiendo de que éstos fueran "reflejos» o "sensaciones»). Para los Gestalt, tal descomposición implicaba, en realidad, una destrucción de los fenómenos estudiados, que perderían sus aspectos peculiares y leyes propias de organización; pues tales leyes caracterizarían a los fenómenos complejos de conciencia precisamente en su calidad de totalidades no divisibles, de formas pregnantes $y$ unitarias.

Vygotski pensaba también que la división de las totalidades complejas en elementos simples, en átomos que ya no conservaban las propiedades de las formas de las que se habían abstraido, hacia imposible el estudio de las funciones superiores de conducta y conciencia. Le gustaba comparar esta estrategia equivocada de investigación con la de un químico que tratara de reconstruir las propiedades del agua a base de sumar las del hidrógeno y el oxígeno. El método de descomponer en elementos las totalidades psicológicas complejas - decía- «puede compararse al análisis químico del agua que la descompone en hidrógeno y oxígeno, ninguno de los cuales tiene las propiedades del total, y cada uno de los cuales posee propiedades que no están 
presentes en la totalidad. Los estudiosos que apliquen este método para buscar alguna propiedad del agua, por qué extingue el fuego, por ejemplo, descubrirán con sorpresa que el hidrógeno lo enciende, y el oxígeno lo mantiene. Estos descubrimientos no ayudarían mucho en la solución del problema» (1934, pág. 23).

Pues bien, éste era un retrato, para Vygotski, de la táctica de investigación predominante entre los psicólogos objetivistas de su tiempo. Entre los conductistas, reflexólogos y reactólogos. En la concepción elementarista de la explicación de estas escuelas, residia la raiz de un inevitable empobrecimineto en su consideración de las funciones superiores. En el artículo sobre «La conciencia como problema de la psicología del comportamiento", por ejemplo, se había referido humorísticamente a la reducción elementarista de todas las funciones superiores a reflejos en la psicología de Bekhterev: «El reflejo, en el sentido en que lo utilizamos, recuerda mucho la historia de Kannitfershtan, cuyo nombre oía en Holanda un pobre extranjero cada vez que preguntaba algo, fuese lo que fuese: ¿a quién están enterrando? ¿De quién es esta casa? ¿Quién acaba de pasar?, etc. En su ingenuidad él pensaba que en aquel país todo lo hacía Kannitfershtan, cuando lo que ocurria en realidad es que esa palabra significaba que los holandeses no entendian sus preguntas... un reflejo es como aquel Kannitfershtan (...) ¿Qué es la percepción?, un reflejo. ¿Qué son el lenguaje, los gestos, las expresiones faciales? También son reflejos. ¿Y los instintos, los impulsos, las emociones? Esos también son reflejos (...) Puede que esto sea cierto, pero la esterilidad científica de tales afirmaciones es absolutamente obvia. Con este enfoque, la ciencia no sólo no aclara ni ilumina los problemas que estudia (...), sino que, por el contrario, lo envuelve todo en una opaca penumbra, donde todo se mezcla y se diluye. Si esto es un reflejo y aquello también, ¿qué es lo que distingue a esto de aquello?» (pág. 10).

Como en el análisis químico del agua, el análisis de las funciones superiores en términos de elementos reflejos dejaba sin explicar las propiedades características de tales funciones, que quedaban tan decoloradas como los propios reflejos, convertidos en una «abstracción» carente de sustancia explicativa. En definitiva, los partidarios de una aprovinacion objtivis a la psicología, que habían logrado éxitos

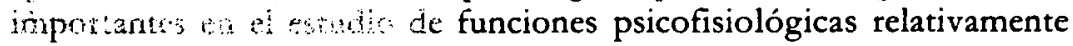
elementales ancilisis de los reflejos condicionados e incondicionados, sensaciones y formas más mecánicas de aprendizaje y memoria) se mostraban incapaces de ofrecer una explicación adecuada de las formas superiores de conducta, al diluir toda su peculiaridad cualitativa en el "Kannitfershtan» del reflejo, eliminar la posibilidad de la intervención causal de la conciencia en el juego de la naturaleza y simplificar a un esquema reactivo las complejas relaciones entre el medio y las funciones de conducta.

Todas éstas eran expresiones de un materialismo mecanicista. En el pensamiento de Vygotski influyó mucho la Dialéctica de la Naturaleza de Engels, que fue publicada en la Unión Soviética en ig25 y -posteriormente- los Cuadernos Filosóficos de Lenin, editados en 1929-1930. A partir de estas obras, la conciencia no podía ser considerada ni como una inmaterial expresión del espíritu ni como un epifenómeno intrascendente, sino como una función compleja de la 
materia, capaz de un reflejo activo de lo real (el concepto de otraženie de Lenin) $y$ originada en una actividad de transformación mediata (es decir, a través de medios) de la materia; pero capaz, al mismo tiempo, de reorganizar a un nivel superior todas las funciones dependientes de ella. Engels había desarrollado la idea de que el empleo de instrumentos y la necesidad de cooperación y trabajo en común habrian jugado un papel decisivo en la transformación evolutiva de la mente animal en la conciencia humana. Esta transformación no podía entenderse como un mero cambio cuantitativo (por ejemplo, por un incremento de las conexiones o de la capacidad asociativa de la mente), sino con arreglo a la ley dialéctica de paso de la cantidad a la cualidad; es decir, en términos del desarrollo de una estructura nueva, que implicaría la transformación de la propia estructura de los procesos dependientes de ella. Vygotski hablaba en sus primeros trabajos de la conciencia como «sistema de transmisión de reflejos». Sin embargo, la definición de la naturaleza de esa transmisión (instrumental, mediadora, significativa, interactiva) le llevó progresivamente a una posición que implicaba negar el sentido de la reducción refleja de la conciencia. $\mathrm{O}$, si se quiere, podriamos decir que, partiendo de una noción de la conciencia más cercana (aunque no sin roces) a los reflejos de Bekhterev, terminó en una concepción más cercana al reflejo tal como lo entendia Lenin.

Ahora bien, esta segunda concepción implicaba, sobre todo, una idea activa del reflejo de lo real que se realiza a través del trabajo de la conciencia. Ahí estaba la esencia de las unidades que Vygotski trataba de encontrar para su psicología general. Al sustituir el análisis por elementos (en los que se pierden las propiedades del todo) por el análisis por unidades (que las preservan), Vygotski se encontró con que la unidad que podia mantener las propiedades de las totalidades más complejas de conciencia era la actividad misma. El fue el primero en situar la categoria de actividad en el lugar central que luego ocuparia en la psicología soviética (Wertsch, I979).

\section{LA ACTIVIDAD INSTRUMENTAL Y LA INTERACCION COMO UNIDADES DE ANALISIS DE LA PSICOLOGIA DE LAS FUNCIONES SUPERIORES}

Para Vygotski, la actividad (deyatel'nost) no era respuesta o reflejo solamente, sino que implicaba un componente de transformación del medio con ayuda de instrumentos. El concepto de actividad estaba muy estrechamente relacionado con el de mediación. El empleo de útiles y de medios representa, al mismo tiempo, el desarrollo de un sistema de regulación de la conducta refleja (pero que no se confunde con ella) y la unidad esencial de construcción de la conciencia. Podríamos decir que las herramientas, los utensilios, son tan necesarios para la construcción de la conciencia como de cualquier artefacto humano. Permiten la regulación y transformación del medio externo, pero también la regulación de la propia conducta y de la conducta de los otros, a través de los signos, que son utensilios que median la relación del hombre con los demás y consigo mismo. Puesto que la conciencia es "contacto social con uno mismon tiene una estructura semiótica. $Y$ el análisis de los signos es «el único método adecuado para investigar la conciencia humana» (Vygotski, 1977, pág. 94). 
Las premisas de esta solución al problema de la unidad de análisis de las funciones superiores se encontraban en realidad en el pensamiento marxista clásico. Son evidentes, por ejemplo, en la idea de Engels de que es el trabajo el que crea al hombre, en enunciados de la Dialéctica de la Naturaleza, como el siguiente: «La especialización de la mano significa la berramienta y ésta presupone la actividad especificamente humana» (Engels, J925. cit., pág. 19). A Vygotski le gustaba también citar el aforismo de Bacon: «Nec manus nuda, nisi intellectus sibi permissus multum valent. Instrumentis et auxilibus res perficitur». ¿En qué residió entonces la originalidad de Vygotski?

Ante todo, en darse cuenta de que en la conducta instrumental estaba la solución al problema de encontrar una unidad que cumpliese, realmente, un papel «unificador» de la psicología naturalista con la descriptiva de las funciones superiores. Después, en convertir las afirmaciones filosóficas de Engels en hipótesis genéticas concretas; que podian ser instrumentos conceptuales básicos para los psicólogos. Finalmente, en ampliar genialmente el concepto de instrumento a las nociones de simbolo y signo. Por decirlo en pocas palabras: Vygotski se percató de que un análisis dialéctico de las premisas de la psicología llevaba a una nueva concepción del origen, desarrollo y naturaleza de las funciones superiores que permitia a la psicologia salir del «solipsismo" en que la habian encerrado tanto los reduccionismos objetivistas como las tesis idealistas. El sujeto no se hace de dentro afuera. No es un reflejo pasivo del medio ni un espiritu previo al contacto con las cosas y las personas. Por el contrario es un resultado de la relación. Y la conciencia no es, por asi decirlo, un manantial originante de los signos, sino que es un resultado de los propios signos. Las funciones superiores no son solamente un requisito de la comunicación, sino que son un resultado de la comunicación misma. Sé que estas afirmaciones pueden parecer paradójicas y siguen siendo difíciles de entender desde las concepciones solipsistas del desarrollo (que aún tienen tanta fuerza en la psicología actual), pero constituyen la esencia de la posición de Vygotski.

La posibilidad de transformar el mundo material mediante el empleo de herramientas establece las condiciones para la modificación de la propia actividad refleja y su transformación cualitativa en conciencia. Pero este proceso está mediado por la construcción de una clase especial de herramientas; a saber, las que permiten realizar transformaciones en los otros, o bien en el mundo material a través de los otros. A estas herramientas las llamamos "signos» y son proporcionadas esencialmente por la cultura, por las personas que rodean y "construyen» al niño en desarrollo; en una palabra, por los otros. A partir de aquí puede entenderse la afirmación de que el vector fundamental del desarrollo es el definido por la interiorización de los instrumentos y de los signos por la conversión de los sistemas de regulación externa (instrumentos, signos) en medios de regulación interna, de autorregulación. Al interiorizarse, a su vez, estos sistemas de autorregulación modifican dialécticamente la estructura de la conducta externa, que ya no podrá entenderse como mera suma c expresión de reflejos.

La concepción instrumental de Vygotski estaba, por tanto, indisolublemente unida a la idea de la génesis histórico-cultural de las 
funciones superiores. Si la conducta simbólico-instrumental termina por constituirse en fundamento de la actividad voluntaria y de los simbolos interiores de la conciencia, ello se debe a que primero se ha transformado en simbólica por mediación de los otros y ha servido para regular su conducta. Las fuentes de la actividad voluntaria no están ni en las cimas del espiritu ni en las profundidades del cerebro (Luria). La escisión entre el idealismo de los fenomenólogos y el positivismo naturalista de los objetivistas era una consecuencia de la pérdida del eslabón fundamental de conexión entre las funciones fisiológicas y las creaciones más complejas y libres de la mente, y ese eslabón no residiria en el propio individuo, sino fuera de él, en las formas colectivas e históricamente determinadas de la vida social. Las funciones superiores no tienen sólo un origen natural, sino que tienen, ante todo, una bistoria social; recordemos la frase de Vygotski en 1924: "La conciencia es, como si dijéramos, contacto social con uno mismo". Pero sucede que "uno mismo", como ser consciente y capaz de actividad voluntaria, es resultado de un desdoblamiento que es permitido por la relación con los otros. Es decir: Vygotski partía de la idea de la "génesis social del individuo". La conciencia y las funciones superiores se enraizan en el espacio exterior, en la relación con los objetos y las personas, en las condiciones objetivas de la vida social. No son un resultado de las asociaciones reflejas de un cerebro sumido en un vacio social, ni una consecuencia del despliegue de las posibilidades prefiguradas de un espíritu solitario, sino construcción resultante de una relación; procesos en que se replica y refleja la acción sobre los objetos $y$, más concretamente, sobre los objetos sociales. A partir de estas premisas puede entenderse la ley fundamental del desarrollo de los procesos superiores. Es la que podemos denominar ley de la doble formación y que Vygotski establecía en 1930 del siguiente modo:

«En el desarrollo cultural del niño, toda función aparece dos veces: primero, a nivel social, y mảs tarde, a nivel individual; primero entre personas (interpsicológica), y después, en el interior del propio niño (intrapsicológica). Esto puede aplicarse igualmente a la atención voluntaria, a la memoria lógica y a la formación de conceptos. Todas las funciones superiores se originan como relaciones entre seres humanos" (cit., pág. 94).

Vygotski llamaba «internalización» a la reconstrucción interna de una actividad externa. Para él, la internalización implicaba una reorganización de las actividades psicológicas sobre la base de las operaciones con signos y suponia la incorporación de la cultura al sujeto al mismo tiempo que la configuración del propio sujeto y la reestructuración de las actividades reflejas del organismo.

¿Y cuál era el papel dé la conducta instrumental en todo este desarrollo? Vygotski establecía una analogía básica entre signos y herramientas, por la función mediadora de ambos. Sin embargo señalaba también que seria peligroso extremar las semejanzas entre los utensilios materiales y los signos, o considerarlos isomórficos en cuanto a sus funciones: "Una diferencia fundamental entre signo y herramienta... es el distinto modo en que orientan la actividad humana. La función de la herramienta no es otra que la de servir de conductor de la influencia humana en el objeto de la actividad; se halla externamente orientada y debe acarrear cambios en los objetos (...) Por otro lado, el signo no cambia absolutamente nada en el objeto de una operación psicológica. 
Así pues, se trata de un medio de actividad interna que aspira a dominarse a sí mismo; el signo, por consiguiente, está internamente orientado" (ibid., pág. 9r). Ahora bien, antes de ser medios de actividad interna, los signos son mediaciones externas, instrumentos brindados por el medio cultural del niño. Y en la obra de Vygotski está prefigurada (aunque no desarrollada) la idea de que como mediaciones externas (antes de interiorizarse) los signos son desarrollos ontogenéticos de la propia conducta instrumental, cuando ésta se realiza en situaciones interpersonales. Si no, no podría entenderse el bello ejemplo que emplea Vygotski para ilustrar las relaciones entre conducta instrumental y signos: el desarrollo de los gestos de señalar. Al principio es sólo un intento de alcanzar, de asir un objeto. Pero, «cuando la madre acude en ayuda del pequeño y se da cuenta de que su movimiento está indicando algo, la situación cambia radicalmente. El hecho de señalar se convierte en gesto para los demás. El fracasado intento del niño engendra una reacción, no del objeto que desea sino de otra persona" (ibid., pág. 93). Cuando el niño pueda establecer la relación entre su intento de asir y la reacción de la madre, desarrolla una función nueva; el movimiento, que antes estaba orientado al objeto, lo está ahora a la persona. "El movimiento de asir-dice Vygotski - se transforma en el acto de señalar" (ibídem). Y esta transformación implica una condensación, una simplificación física del acto, que establece la base de su internalización.

Sin los otros, la conducta instrumental no llegaria a convertirse nunca en mediación significativa, en signo. Sin la conducta instrumental no habría -materiales para realizar esa conversión. Sin los signos externos no sería posible la internalización y la construcción de las funciones superiores. Vygotski establecía así una definición precisa de éstas: "podemos emplear el término de función psicológica superior o conducta superior, al referimos a la combinación de herramienta y signo en la actividad psicológica» (ibid., pág. 92).

Debemos resumir las posiciones anteriores (quizá excesivamente esquemáticas) antes de seguir adelante. Con el fín de ser claro me permitiré enunciar los aspectos fundamentales del enfoque instrumental en una serie de enunciados concisos, aun afrontando el riesgo de simplificar excesivamente las ideas de Vygotski:

I. La unidad de análisis de la psicología de las funciones superiores es la actividad instrumental.

2. Las funciones superiores implican la combinación de herramientas y signos en la actividad psicológica.

3. La transformación de lo instrumental en significativo está mediada y permitida por la relación con los demás.

4. La conversión de la actividad en signo implica su condensación.

5. Los signos son, en su origen, mediaciones para regular la conducta de otros. Con ellos, los demás regulan la conducta del niño y éste la conducta de ellos.

6. El vector fundamental de desarrollo de las funciones superiores implica la internalización de los procesos de relación social.

7. Por tanto, el origen de esas funciones no está en el despliegue 
centrifugo del espiritu o las conexiones cerebrales, sino en la historia social.

8. La cultura proporciona las herramientas simbólicas necesarias para la construcción de la conciencia y las funciones superiores (fundamentalmente los símbolos lingüisticos).

9. El desarrollo no consiste esencialmente en la progresiva socialización de un individuo primordialmente "robinsoniano" y «autista", sino en la individualización de un organismo básicamente social desde el principio.

ı. Podriamos decir que el individuo, como organización consciente de procesos y funciones internas con signos (que posibilitan la actividad voluntaria y el control autorregulatorio) es un destilado de la relación social.

I 1. La escisión y crisis entre una psicología objetiva de funciones elementales y una psicología subjetiva e idealista de las superiores puede resolverse con un paradigma unificador que restablezca el eslabón que falta, saliendo fuera del sujeto, a las formas sociales de relación, pues sólo así será posible recuperar, desde una perspectiva cientifica y explicativa, al propio sujeto.

Es evidente que estos enunciados encierran un ambicioso programa de reconstrucción de la psicologia, que implicaba cambios conceptuales y metodológicos de muy largos alcances, y todo un proyecto de investigación. Vygotski no tuvo tiempo de completar, ni siquiera en sus líneas más esenciales, ese programa. Sin embargo resulta necesario preguntarse cómo pudo desarrollarlo en el brevísimo periodo transcurrido desde el Congreso de Leningrado en 1924 y los últimos años de la década de los veinte, a partir de la redacción de su libro sobre $E l$ sentido bistórico de la crisis de la Psicologia, de 1926.

Un aspecto importante de su genialidad consistió en construir una "sintesis superior» a partir de un conjunto amplio de influencias. En primer lugar, y como ya hemos indicado, Vygotski era un teórico marxista. Habia comprendido en profundidad las sutilezas del método dialéctico y conocía bien los trabajos de Marx, Engels y Lenin, incluyendo la literatura que estaba apareciendo mientras él mismo llevaba a cabo la tarea de construir una psicologia dialéctica. Indudablemente, ideas esenciales, como la dé la génesis social de la conciencia o el papel de las herramientas y la actividad productiva en los procesos de humanización ( $y$ hominización) fueron inspiradas por nociones fundamentales de Engels y Lenin.

Además, Vygotski tenía un amplio conocimiento de la psicología de su tiempo. Retuvo muy fundamentalmente la influencia del trabajo pavloviano sobre la "actividad nerviosa superior" y las unidades estructurales básicas de las funciones adaptativas: los reflejos condicionados. La psicofisiologia pavloviana subyacia al análisis materialista de las funciones mentales. Aunque Vygotski no aceptara las tesis reduccionistas de Bekhterev y los reflexólogos, conocia bien su trabajo (en I928, poco después de la muerte de Bekhterev, Vygotski publicó un articulo en su memoria en la revista Educación pública). El substrato de conocimiento e interés por la psicofisiología influyó siempre en la obra de Vygotski (y más aún en sus desarrollos finales). 
Por otra parte, Vygotski recogió la influencia de la biologia evolucionista y el conjunto de hipótesis, formuladas en su contexto, sobre el origen del hombre y los procesos de hominización. No sólo se vio influido por las interpretaciones que hacía Engels de estos procesos, sino que acudió a los propios biólogos. Luria (1979) cuenta que Vygotski mantuvo una correspondencia habitual con el biólogo evolucionista V. A. Wagner, especialista en el estudio comparativo de la conducta animal, y cuyas ideas sobre la evolución le impresionaron mucho. Aunque este aspecto de la obra de Vygotski ha sido poco estudiado, una de sus características más notables es, precisamente, su coherencia con los conocimientos sobre la filogénesis del hombre. En el papel decisivo asignado a la conducta instrumental y la cooperación social como origen de las funciones superiores se refleja el cuadro filogenético de la transformación de los hominidos al pasar a un medio de sabana, liberar las manos gracias a la bipedestación, desarrollar el empleo de utensilios y organizarse en grupos de cooperación para la defensa, la caza, la recolección y, más a largo plazo, la transformación productiva de la naturaleza. Hay que advertir que Vygotski no estaba dispuesto a aceptar la noción simplificada de la ontogénesis como recapitulación de la filogénesis. Sin embargo, todo su trabajo está fuertemente impregnado de una concepción evolucionista de la propia ontogénesis. Se rastrea esa influencia en su concepción fundamental sobre el desarrollo de las funciones superiores, en su oposición al absurdo biológico que supondría considerar lo psíquico como un derroche epifenoménico de la naturaleza y no como función de adaptación a ella, y en la propia definición y concepción del método caracteristico de la escuela histórico-cultural: el método instrumental o genético-experimental, que prescribía la observación de las funciones psicológicas en el momento mismo de su construcción genética y no después de su cristalización en estructuras terminadas.

Otra influencia fundamental en el pensamiento de Vygotski fue la que provenía de sus abundantes lecturas y conocimientos de la psicologia occidental, especialmente de lengua alemana. Entre los investigadores de su época que más influyeron en los miembros de la Escuela histórico-cultural, Luria (1979) cita a Kurt Lewin, Heinz Werner, Wolfgang Köhler, William Stern, Karl Bühler y Charlotte Bühler. Aunque no aceptaran su tendencia a la descripción fenomenológica (vs. la explicación), ni el "subitalismo emergentista» de algunos de ellos (como Stern), sí compartian su convicción del carácter emergente de las propiedades de las funciones superiores y la imposibilidad de reducirlas a las inferiores.

Estas eran algunas de las influencias fundamentales sobre el pequeño grupo que se iba formando alrededor de Vygostki. Sin embargo, la sintesis, el producto final, llevaba un marchamo de originalidad y claridad de ideas que era muy característico de su genio. También lo era el carácter de bocetos con que presentaba frecuentemente sus ideas, la forma de comunicarlas en pinceladas rápidas, más que en un sistema detallado, articulado y completo. Como dice Bruner, «el genio de Vygotski era de carácter elusivo. A diferencia de Pavlov o Piaget, por ejemplo, no había nada de masivo o glaciar en el corpus de su pensamiento y en el desarrollo de éste. Era, más bien, como el último Wittgenstein: a veces aforístico, frecuentemente impresionista, vivido en sus iluminaciones» (1982, pág. 4). Estas caracteristicas dificultan una 
presentación sistemática y orgánica de su pensamiento. En psicologia, los escritos de Vygotski eran, muchas veces, esquemas, dibujos rápidos de intuiciones, más que cuadros detallistas. Probablemente influyera en ello el hecho de que Vygotski no tuvo tiempo (y quizá lo supiera desde su empeoramiento en 192s) para realizar un desarrollo orgánico, sistemático y articulado hasta el destalle de sus ideas, pero había algo más: una tendencia a ver las cosas de forma abierta, desde perspectivas múltiples y un estilo "cromático» de pensamiento, regulado no sólo por la forma fría de las ideas, sino también por la variedad pluriforme de la realidad del hombre y la cultura. Por todo ello, resulta muy adecuada la comparación que ha hecho Stephen Toulmin (1978) entre el genio de Vygotski y la genialidad versátil y ligera de Mozart. La analogía, en este caso, puede ir más allá de la temprana muerte de ambos.

Este modo "cálido" de pensamiento tenía un gran atractivo para los colaboradores y alumnos de $\mathrm{V}$ ygotski. Al principio, los tres miembros del pequeño grupo originario se reunían en casa de Vygotski, una o dos veces por semana, para discutir los aspectos fundamentales del nuevo edificio teórico que se iba configurando. Tenían numerosas ocasiones para trabajar en común: aparte de las reuniones más privadas, compartían el trabajo en el Instituto dirigido por Kornilov, y en 1927-1928 se incorporaron los tres al laboratorio de la Academia Krupskaya de Educación Comunista. Paulatinamente, el grupo fue abriéndose a jóvenes estudiantes deseosos de participar en el trabajo de construcción que exigia el diseño de Vygotski. Los primeros fueron Bozhovich, Levina, Morozova, Slavina y Alexander Zaporozhets. Después, se incorporaton Elkonin, que llegaba de Leningrado, y Galperin, que provenia de Jarkov. Basta con repasar esta lista para intuir la enorme influencia que -a pesar de los intentos posteriores de sepultarla - habria de tener a largo plazo la obra de Vygotski.

En general, el método de trabajo que seguían consistía en la construcción de modelos experimentales, basados en las ideas discutidas por Vygotski, Leontiev y Luria, y la incorporación posterior de los más recientes colaboradores a los proyectos de trabajo, incluyendo sus propias ideas. Luria era el encargado de organizar el trabajo de los estudiantes, que realizaban estudios-piloto basados en las hipótesis de la Escuela histórico-cultural.

El periodo de i925 a 1930 fue decisivo para la organización de aquel grupo de jóvenes psicólogos llenos de entusiasmo. Los miembros del grupo se sentían partícipes en una labor de creación, en la construcción de una psicología nueva. Hasta 1930 estuvieron rodeados de la indiferencia general o la incomprensión de sus conceptos sobre la psicología, pero ello no impidió que desarrollaran, con rapidez, los aspectos más esenciales de la arquitectura teórica de la psicología instrumental y comenzaran, a finales de la década de los veinte, a realizar observaciones experimentales para ilustrar y contrastar las nuevas ideas.

Luria ha recordado, con viveza, aquellos tiempos de entusiasmo:

«Es extraordinariamente dificil, después de pasado tanto tiempo, recuperar el enorme entusiasmo con el que se llevaba a cabo aquel trabajo. Todo el grupo dedicaba casi todas sus horas de vigilia a nuestro gran plan de reconstrucción de la psicologia. Cuando Vygotski se iba de excursión, los estudiantes escribian poemas en honor de 
su viaje. Cuando daba una conferencia en Moscú, todo el mundo iba a oírle.

Sus conferencias constituian siempre una gran ocasión. No era nada raro que hablase durante tres, cuatro o hasta cinco horas de un tirón. Además lo hacia con un puñado de notas. Buena parte del material que ha quedado para describir el trabajo de Vygotski proviene de las notas taquigrafiadas de aquellas conferencias" (1979, pág. 32).

En los últimos años de la década de los veinte (desde 1928), las líneas fundamentales del nuevo planteamiento teórico estaban diseñadas. Era el momento de comenzar a recoger observaciones que diesen un soporte empírico al enfoque instrumental que se estaba construyendo.

\section{LOS ESTUDIOS EXPERIMENTALES SOBRE LA GENESIS Y VARIABILIDAD CULTURAL DE LAS FUNCIONES SUPERIORES Y EL METODO GENETICO EXPERIMENTAL}

El proyecto teórico de Vygotski implicaba la realización de estudios experimentales centrados, principalmente, en dos grandes áreas: i) la génesis y desarrollo de las funciones superiores en el niño, y 2) la influencia de las variables transculturales en la naturależa de los procesos cognitivos. Es necesario destacar la perspectiva básica con la que se realizaban las investigaciones en uno y otro campo, las hipótesis más generales que subyacian a aquellos primeros trabajos de la Escuela histórico-cultural:

I. La idea directriz de los estudios sobre desarrollo era la de poner de manifiesto los procesos de construcción, uin vivo", de las funciones $y$, muy especialmente, el papel de los instrumentos y signos en dicha construcción, así como la mediación "cultural», representada por el propio experimentador.

2. En cuanto a los estudios transculturales, el principio que los guiaba era éste: $s i$ las funciones superiores tienen un origen cultural, entonces su propia naturaleza será variable y dependerá de las características de la cultura en que se configuran. Vamos a referirnos ahora brevemente a algunos de los trabajos realizados por los colaboradores de Vygotski en estas dos grandes áreas.

1. En la investigación sobre el desarrollo de las funciones superiores pueden destacarse los experimentos de Leontiev sobre memoria, de Sakharov y Sif, sobre formación de conceptos; de Morozova, sobre procesos de elección múltiple, y los trabajos de Zaporozhets, sobre organización de la conducta motora; Levina, sobre lenguaje y planificación de la acción, y Luria, sobre el pensamiento y el lenguaje en el niño.

Los trabajos sobre memoria quedaron, principalmente, a cargo de Alexei Leontiev. En esencia, su trabajo con niños normales y deficientes, consistia en brindarles la posibilidad de emplear estimulos auxiliares para ayudarse en el recuerdo de una serie de estimulos (por ejemplo, un trineo dibujado para recordar la palabra «caballo»). Los niños menores no hacian uso de las ayudas, aun cuando fuesen capaces de recordar, por un proceso "natural», algunas palabras. En una fase posterior, incorporaban las claves a la propia tarea de recuerdo, pero éstas frecuentemente evocaban traducciones diferentes a las establecidas por el experimentador (por ejemplo, «nieve», y no caballo). Posterior- 
mente, las claves externas ya jugaban un papel claro en los procesos de recuerdo, pero los niños no se servian de sus propias claves internas hasta los 9-10 años. Este paso representaría la internalización significativa de herramientas-signo que, en este caso, constituirian medios de regulación de los propios procesos de memoria. Hay que destacar la cercanía de este trabajo con respecto a investigaciones recientes sobre control metacognitivo de la memoria (vid. por ejemplo, Flavell y Wellman, 1977), que muestran la importancia del desarrollo de las estrategias de control de los propios procesos de memoria en la determinación de la competencia de recuerdo. En realidad, esta referencia a los aspectos metacognitivos (es decir, al control y regulación de los procesos cognitivos como tales) es característica de todas las investigaciones evolutivas del grupo de Moscú. La originalidad de la posición de la Escuela histórico-cultural, en este aspecto, residiría en el supuesto implícito de que el desarrollo cognitivo está determinado y regulado por el desarrollo metacognitivo, por la adquisición e internalización de utensilios de autorregulación. Desde la perspectiva vygotskiana, el desarrollo cognitivo (para seguir con la terminologia actual) sería esencialmente desarrollo metacognitivo.

Morozova incorporó el sistema de presentación de claves de Leontiev a sus propios experimentos sobre tareas de elección compleja en niños de tres y cuatro años, demostrando el valor de éstas en la facilitación de una tarea que, de otro modo, planteaba exigencias muy superiores a las posibilidades cognitivas de los niños.

Sin duda, las claves que tienen una importancia más decisiva en la regulación de la acción y de las funciones cognitivas son las de carácter lingüístico. El lenguaje se convierte, a lo largo del desarrollo, en el instrumento fundamental de la regulación de la acción y el pensamiento. La asimilación de los símbolos lingüísticos a la actividad práctica e instrumental del niño significa un primer paso, de enorme importancia, en la transformación cualitativa y dialéctica de la acción humana: «el momento más significativo en el curso del desarrollo intelectual, que da luz a las formas más puramente humanas de la inteligencia práctica y abstracta, es cuando el lenguaje y la actividad práctica, dos líneas de desarrollo antes completamente independientes, convergen" (1930, cit., pág. 48). El lenguaje, nacido como estructura comunicativa, es incorporado a los sistemas de mediación instrumental del niño y se convierte, a lo largo del desarrollo, en el regulador fundamental de esa mediación. «Los niños - decia Vygotski- resuelven tareas prácticas con la ayuda del lenguaje, así como con la de sus ojos y sus manos. Esta unidad de percepción, lenguaje y acción, que en última instancia produce la internalización del campo visual, constituye el tema central para cualquier análisis del origen de las formas de conducta específicamente humanas" (ibid., págs. 49-50).

A este tema central de la función planificadora del habla dedicó sus primeros trabajos R. E. Levina. Su procedimiento consistía en plantear a niños de tres y cuatro años problemas de inteligencia práctica semejantes a los que Wolfgang Köhler habia utilizado en sus estudios sobre solución de problemas en chimpancés. Cuando a los niños se les plantean situaciones-problema que exigen soluciones inteligentes de "rodeo», diferenciación medios-fines y empleo de instrumentos (por ejemplo, tratar de conseguir un caramelo que está fuera de su alcance, 
pero que podría obtenerse empleando un palo y un taburete que el niño tiene cerca), se comportan, en las edades más tempranas, como los chimpancés. Sin embargo, hay un momento en que la actividad del niño presenta un cambio muy significativo: se acompaña de un «lenguaje egocéntrico», que describe y analiza el problema pero sin guiar todavía su solución. Paulatinamente, ese lenguaje adquiere la función de guiar y planificar la propia acción del niño. Ya no es un mero acompañante de la acción, ni está simplemente fundido en la unidad percepción-lenguaje, acción, sino que es el instrumento fundamental de análisis de la percepción y de regulación y planificación de la acción. En suma, adquiere el valor instrumental (como mediador de la propia acción) que tiene en los adultos. En este desarrollo, la acción misma se modifica: se hace más libre, más independiente del campo perceptivo, más flexible y mediata, más reflexiva $e$ indirecta. Pero también se modifica la propia estructura del lenguaje egocéntrico, que se irá condensando, haciéndose predicativo y elíptico, sintético y comprimido, en un proceso de progresiva interiorización. Las investigaciones de Levina proporcionaron un material observacional decisivo para la construcción teórica que posteriormente realizaría Vygotski en Pensamiento y lenguaje.

Una orientación muy cercana fue la que guió a los trabajos de Alexander Zaporozhets sobre la organización de la acción motora a lo largo del desarrollo. El procedimiento consistía en plantear a los niños situaciones en que la realización de una actividad motora debía obedecer a una regla externa. En este caso, también se manifestaba la evolución desde una motricidad impulsiva y no regulada hasta un control motor (interno", a través de una fase intermedia de control externo y mediado por los estimulos externos o las claves verbales de los adultos. También Luria realizó investigaciones sobre el desarrollo del control motor.

Finalmente, debemos citar las investigaciones del propio Luria sobre la capacidad infantil de crear espontáneamente (por medio del dibujo) claves instrumentales capaces de ayudar a las funciones cognitivas, y los importantes trabajos de Sakharov y Sif, sobre clasificación y formación de conceptos, que ilustraban los profundos cambios de significado que sufren las palabras a lo largo del desarrollo, en la medida en que se van modificando las estructuras pre-conceptuales que las sustentan, que pasan de los «cúmulos inorganizados» a los complejos y pseudoconceptos, antes de ser significaciones propiamente conceptuales. Estos estudios también tendrían una gran trascendencia en la posterior construcción de Pensamiento y lenguaje.

El estilo teórico y los primeros resultados de aquellos trabajos pueden analizarse, sobre todo, en un libro que publicaron Vygotski y Luria en 1930 titulado Estudios sobre la bistoria del comportamiento. Se basaba aquella obra en la idea de una «analogía débil» entre el desarrollo cultural de la humanidad y la ontogénesis de las funciones superiores. Entre el desarrollo de los sistemas de mediación instrumental y las estructuras de signos en el hombre primitivo y el niño. Aquella analogia formaba parte de muchas concepciones evolutivas y antropológicas de los años veinte. Era explícita en antropólogos como Thurnwald y Levy-Bruhl, que influyeron en Vygotski, y en psicólogos evolutivos, como Heinz Werner, cuyos trabajos eran bien conocidos 
por los jóvenes investigadores de la Escuela de Moscú. Los capítulos sobre la conducta de los antropoides y las formas culturales del hombre primitivo fueron realizados, para aquella obra, por Vygotski, que mostró siempre un gran interés hacia los temas de antropología y psicologia comparada.

2. Las consideraciones teóricas que fundamentaban los Estudios sobre la bistoria del comportamiento fueron las mismas que motivaron a la realización del segundo tipo de investigaciones a que nos referíamos antes, sobre la influencia de las variables transculturales en los procesos cognitivos. En el análisis de Vygotski, la crisis que habia dado en una escisión entre el estudio natural de las funciones adaptativas elementales y la descripción fenoménica de los contenidos superiores de conciencia, era también la premisa de una quiebra entre la psicología individual y el estudio de las formaciones culturales variadas de las sociedades humanas. Los mismos supuestos elementaristas que daban razón de la incapacidad de Wundt y los reflexólogos para explicar funciones superiores, la daban también de su imposibilidad de situar al sujeto en su entorno cultural de construcción. El propio Wundt se daba cuenta de ello cuando asignaba a la Völkerpsychologie, y no a la psicologia experimental, el estudio de los contenidos superiores del pensamiento. Desde los supuestos de la Escuela socio-cultural, las funciones superiores se concebian como transformaciones interiorizadas de patrones de interacción social, y la construcción de la conciencia como incorporación de la cultura, a través de la relación. Esto queria decir, también, que los psicólogos de la Escuela de Moscú se oponían a las concepciones universalistas sobre la naturaleza de las funciones superiores, dominantes por ejemplo entre los psicólogos de la Gestalt, para los cuales las formaciones superiores de la percepción y el pensamiento eran resultado de la estructuración endógena de formas cerradas, más que de la interacción interpersonal. En suma, las orientaciones de Vygotski llevaban a la idea de la naturaleza cultural de las funciones superiores, cuya ilustración más clara debía ser la demostración de que la propia estructura de esas funciones es diversa entre las diversas culturas.

El momento que vivía la Unión Soviética en los años treinta podia ser especialmente adecuado para analizar la influencia de las variables culturales sobre las funciones superiores de percepción, memoria y pensamiento. El programa de mecanización y colectivización del trabajo y la propiedad, que se había puesto en práctica a partir de finales de los veinte, daba lugar a un fuerte cambio cultural y de organización social de millones de campesinos y pastores, que se incorporaron a formas colectivas de trabajo y convivencia y a una campaña de alfabetización y educación. Con ello se establecía una situación que permitía comparar el funcionamiento cognitivo de grupos que aún mantenian las formas tradicionales de organización y cultura, con el de otros que, aunque tuvieran la misma cultura de origen, estaban sufriendo una situación de cambio cultural acelerado. En 1930 y 1931, Luria dirigió dos expediciones a Uzbekistan y Khigiria, en Asia Central, donde los cambios estaban siendo especialmente marcados e implicaban, en muchos casos, el paso de culturas nómadas de.pastoreo a granjas colectivas. A la segunda de estas expediciones fue el gestaltista alemán Kurt Koftka (que, según cuenta Luria, no se integró en el trabajo de equipo ni pudo comprender, a 
partir de sus premisas universalistas, sus objetivos principales). En los estudios realizados se analizaban los procesos de percepción, generalización y abstracción, razonamiento y solución de problemas en los grupos más tradicionales y los asimilados a la campaña de alfabetización y cambio social. Los resultados de aquellas investigaciones no se publicaron de forma completa hasta cuarenta años después, en la Historia social de los procesos cognitivos de Luria. En ello pudo influir el hecho de que, aunque las diferencias en funciones clásicamente concebidas como universales (p. e. en percepción) fuesen favorables a las tesis de la Escuela de Moscú, los datos no eran fácilmente interpretables (Cole, 1984), pero también la intuición de que aquellos estudios y sus resultados podian prestarse a interpretaciones inadecuadas y manipulaciones políticas, como efectivamente ocurrió posteriormente. A Vygotski se le acusaría de "gran chauvinista ruso», sobre la falsa impresión de que las investigaciones en Asia Central daban una imagen depreciada del funcionamiento psicológico de los sujetos de culturas tradicionales. Esto era una equivocación lamentable: precisamente, la concepción sociocultural ha sido una de las pocas alternativas psicológicas capaces de dar cuenta, desde una perspectiva no-etnocéntrica, de la naturaleza y diversidad cultural de los procesos superiores. La interpretación de tales procesos como actividades instrumentales de adaptación, que reflejan propiedades de los mecanismos de interacción y las formas sociales de organización, excluia la posibilidad de etnocentrismo y universalización inadecuada de las funciones superiores. Es éste un ejemplo más del falseamiento que se produce cuando los resultados descriptivos de la investigación son utilizados desde ópticas políticas y normativas en el peor sentido de la palabra: la historia de la ciencia ofrece abundantes ejemplos de la tendencia de los poderes a ocultar los hechos cuando no corresponden a los intereses y, de pasada... sacrificar al mensajero de los hechos (al cientifico) por haberse atrevido a recogerlos.

Cuando los psicólogos occidentales, educados en el operacionalismo y en la interpretación cerradamente positivista de la experimentación, analizamos aquellas primeras investigaciones de Vygotski y sus colaboradores, tenemos una sensación de provisionalidad, de estudios "poco cocinados» (Cole y Scribner, 1979). La presentación detallada de los resultados es sustituida por descripciones rápidas sin artefactos estadísticos. Los experimentadores asumian una posición activa y versátil en las situaciones experimentales. Estas características no se debian sólo al carácter piloto y provisional que, sin duda, tenían muchos de aquellos trabajos, sino también a la lógica metodológica a que llevaban las concepciones de la escuela sociocultural. Conviene que nos detengamos brevemente en las concepciones acerca de la metodologia en psicologia desarrolladas por Vygotski.

Una de las ideas más enraizadas en Vygotski era la de que la investigación psicológica no debería limitarse a la contrastación de modelos artificiales y ajenos al mundo real. Lo que ahora llamamos "validez ecológica" era una de sus aspiraciones fundamentales. Los ambientes reales de trabajo, educación y clinica eran los contextos adecuados para que la psicologia recogiera sus observaciones y tradujera sus posibilidades de transformación y mejora de las condiciones de los hombres. Por otra parte, la supresión «experimental» de las variables socioculturales, que ha sido un desideratum de gran parte de la 
investigación experimental, sería incompatible con la propia lógica de la escuela sociocultural, que consideraba las funciones superiores como producto de la interacción cultural (entendiendo la palabra "cultura» en su sentido más amplio). Podríamos decir que, según esa lógica, tratar de estudiar procesos complejos eliminando la influencia de las variables culturales, sería como tirar el agua de la bañera con el niño dentro, eliminar la peculiaridad de esas funciones.

Vygotski rechazaba la concepción positivista de los métodos como algo neutro, enteramente divorciado de los enfoques teóricos. Los entendía más bien, a la manera marxista, como realizaciones pragmáticas de los supuestos teóricos. Por ello, estaba convencido de que la crítica a los modelos anteriores de las funciones psicológicas implicaba también una crítica a sus productos metodológicos, y también creía que la formulación de una aproximación enteramente nueva a la génesis y naturaleza de esas funciones, llevaba a la construcción de una nueva metodología. Por muchas diferencias que pudiera haber entre los procedimientos empleados por las distintas escuelas de psicologia (de Watson y Bekhterev a Wundt y los gestaltistas), todas ellas, en opinión de Vygotski, partian de lo que él llamaba un esquema estimulo-respuesta. En realidad, la adopción de este esquema por los psicólogos introspectivos de finales del siglo XIX habria supuesto un paso importante en el encauzamiento de la psicología por el "camino firme» del estilo y el método de las ciencias naturales. Sin embargo, este esquema, originado en la investigación psicofísica de los fenómenos psicológicos más simples y reactivos, seria inadecuado para estudiar las formas superiores y especificamente humanas de conducta. El supuesto de que partiría el esquema E- $R$ seria el de variación cuantitativa de las respuestas en función de variaciones cuantitativas en los estimulos, pero sería incapaz de dar cuenta de las variaciones dialécticas de cualidad entre la conducta animal y las formas superiores de conducta humana. Partiendo de la distinción, establecida por Engels, entre los enfoques naturalistas y dialécticos de la historia, Vygotski consideraba que los métodos E-R en psicologia tenían las mismas limitaciones que los enfoques naturalistas de la historia; la más notable de estas limitaciones sería la imposibilidad de explicar adecuadamente la función transformadora que el hombre mismo ejerce sobre la naturaleza y la historia. En suma: tanto los esquemas E-R como las aproximaciories ankurulistas partían de una reducción injustificable de las re!acics cusules hombre-naturaleza a una sola direcrion, ia de lis influencia de la naiuraleza, estimulos, medio, etcétera, en ci hombre, siendo incapaces de explicar la «vuelta dialéctican de la causalidad a través de la acción del hombre sobre la naturaleza, medio, estímulos, etcétera.

La crítica de los modelos naturalistas de explicación y método (incluyendo entre ellos el esquema E-R) implicaba la formulación de una nueva metodologia, consistente con el enfoque sociocultural para el estudio de los procesos superiores. Vygotski lo definía como «método genético-experimental», tal como se expresaba, por ejemplo, en el empleo de los procedimientos del método funcional de doble estimulación, que se empleaba para el estudio de funciones superiores en niños o en las investigaciones transculturales con adultos. Vygotski caracterizaba al método por tres rasgos fundamentales: i) implicaba el análisis de procesos y no de productos terminados; 2) se dirigia a una explicación "genotipica" de la conducta, en vez de limitarse a una 
descripción "fenotípica» de la misma, y 3) se trataba de estudiar el proceso mismo de cambio, de formación de las conductas, en lugar de conformarse con la investigación de «conductas fosilizadas»

1. El primero de estos rasgos suponía un punto importante y, desgraciadamente, olvidado en los enfoques dominantes en psicología cognitiva (aferrados al modelo solipsista y agenético de la Inteligencia Artificial); a saber, que el enfoque evolutivo es ur componente esencial de la aproximación experimental en psicologia. En muchas investigaciones del grupo de Moscú, la idea básica consistia en la inducción artificial de un proceso de desarrollo, la suscitación experimental de una especie de "microevolución», que permitía reconstruir las fases principales de la construcción de funciones superiores.

2. En la alternativa "explicación versus descripción", Vygotski se situaba, como ya hemos comentado, entre los investigadores convencidos de la necesidad de construir una psicología explicativa, que fuesé capaz de sobrepasar las semejanzas y diferencias "fenotipicas» entre las funciones, para acceder a un nivel más profundo de explicación genotípica. Por eso no aceptaba quedarse en el análisis introspectivo, incapaz por naturaleza de ir más allá de la pura descripción. Aspiraba a descubrir (como hizo, por ejemplo, en el análisis del desarrollo del monólogo al lenguaje interior) las raices genotípicas comunes de expresiones fenotípicas diferentes, y también (como en el estudio del distinto significado conceptual de las palabras infantiles y adultas) las divergencias genotípicas entre estructuras fenotipicamente semejantes. Como Marx, pensaba que la ciencia sería una empresa superflua si todos los objetos fueran genotípica y fenotípicamente equivalentes (pues, en tal caso, la experiencia cotidiana y su descripción fenomenológica razonable bastaría para el desarrollo del conocimiento).

3. La tercera característica del método genético-experimental era su naturaleza dinámica: pensaba que, en psicología, muchos procesos sufren un largo proceso de cambio hasta llegar a «fosilizarse». El análisis fenotípico de los productos del desarrollo sería, por eso, incapaz de establecer su auténtica naturaleza. Se trataba, ètonces, de reconstruir los procesos de génesis, formación y transformación de los procesos en condiciones experimentales. Es decir, la idea no era formular una especie de "anamnesis clínica» de las funciones, sino una «anamnesis experimental». Ello implicaría tratar de reconstruir, a partir de las hipótesis teóricas de la Escuela Sociocultural, los ciclos de formación de la conciencia y las funciones superiores. Esa era la esencia del método funcional de doble-estimulación, que consistía en plantear a los sujetos problemas que solían estar más allá de sus capacidades de solución inmediata a partir de su competencia actual, y al mismo tiempo, medios, que pódian tomar el valor de signos, capaces de regular y favorecer la realización de las tareas propuestas. Esto es lo que hacia Leontiev cuando brindaba a los niños de sus experimentos claves que podian emplear en los procesos de recuerdo, y Morozova en los estudios sobre tareas de elección compleja, o Zaporozhets cuando ayudaba al control motor mediante claves verbales externas. En otras investigaciones, lo que se estudiaba era precisamente la capacidad de los sujetos de construir sus propios instrumentos de regulación cognitiva, como en los estudios de Luria sobre el uso de dibujos como claves para el recuerdo. Se trataba, en definitiva, de estudiar los procesos de 
realización de funciones cognitivas mediante claves auxiliares especificas. Por eso hablaba Vygotski de "doble estimulación»: por una parte se presentaban los estímulos "target», que los sujetos tenían que recordar, seleccionar, clasificar, etcétera; por otra, un conjunto de estimulos instrumentales, que permitian objetivar y exteriorizar los procesos de formación de las funciones, que consistiria esencialmente en el desarrollo de mediaciones (instrumentales o simbólicas) necesarias para su realización.

Naturalmente, este método implicaba una actitud activa del experimentador. A diferencia de la concepción del esquema $E-R$, en que éste se concebía esencialmente como un factor a neutralizar, en bien de la aséptica neutralidad de los datos sobre la conducta reactiva (a los estímulos y sólo a ellos), el experimentador se consideraba en las investigaciones de la Escuela de Moscú como un sujeto en interacción que, por serlo, objetivaba los procesos de adquisición y desarrollo de las funciones superiores, reconstruyendo su génesis. La idea de la génesis interactiva y social de las funciones superiores llevaba directamente a esta metodología. Podriamos decir que el experimentador se entendia como un representante de la cultura y de los grupos sociales que configuran, a través de la relación, las conductas superiores, al proporcionar al niño instrumentos y signos con los que regularlos y construirlos.

Sin embargo, podríamos preguntarnos hasta qué punto se objetivaban, mediante estos procedimientos, los procesos de desarrollo de las funciones. ¿No se estaría dando, más bien, un proceso de aprendizaje, in situ, de cómo solucionar las tareas? ¿No seria artificial el aparente desarrollo producido en estas condiciones? ¿Hasta qué punto podría considerarse como un artefacto de la influencia del examinador la microgénesis de las funciones? La respuesta a estas cuestiones exige una comprensión adecuada de la concepción vygotskiana sobre las relaciones entre el aprendizaje y el desarrollo, así como el recurso a la noción de «zona de desarrollo potencial» en que se sintetiza su análisis de dichas relaciones.

\section{LAS RELACIONES ENTRE APRENDIZAJE Y DESARROLLO Y LA «ZONA DE DESARROLLO POTENCIAL»}

La tesis de la génesis social e instrumental de las funciones superiores implicaba un replanteamiento completo del viejo problema psicológico de las relaciones entre aprendizaje y desarrollo. Para el análisis de las ideas tradicionales sobre dichas relaciones me permitiré emplear algunos de los conceptos que utilizó Vygotski al referirse a la "crisis" de la psicologia, aunque no tengo conocimiento de que él mismo se sirviera de ellos en este tema específico. Es decir, trataré de realizar un "análisis vygotskiano" del problema, pero no recogido de afirmaciones explícitas del propio Vygotski.

Hemos visto que Vygotski analizaba la crisis de la psicologia de su tiempo, en términos de una alternativa entre un objetivismo reduccionista y una psicologia descriptiva con matices idealistas. Podemos decir que cada una de estas orientaciones implicaria una concepción diferente de las relaciones entre aprendizaje y desarrollo. La primera, al reducir 
las funciones superiores al esquema reactivo de los reflejos, llevaba implícita la idea de que el desarrollo consiste esencialmente en ${ }^{\circ}$ la formación de conexiones reflejas o asociativas. Por otra parte, al ser los reflejos o asociaciones entendidos como los modelos paradigmáticos de aprendizaje, el desarrollo - desde esta concepción- debería consistir precisamente en aprendizaje, comprendiendo por tal la multiplicación de vínculos reactivos de tipo E-R. La tendencia objetivista a la reducción del desarrollo a aprendizaje sería coherente con la propensión a concebir la conducta en términos esencialmente reactivos y a desvalorizar el papel activo y transformador del sujeto en el aprendizaje. También con la idea de una diferencia meramente cuantitativa entre las funciones más elementales, compartidas por el hombre con los animales y las funciones superiores. El desarrollo quedaria limitado, en esta perspectiva, a la acumulación de respuestas posibles y la construcción de hábitos o de asociaciones. Vygotski atribuía a James (que no era un objetivista) y a Thorndike esta orientación, pero es la que puede rastrearse sobre todo en Watson y algunos conductistas. En resumen, la premisa esencial de este enfoque podría ser ésta: «El desarrollo es (con las cualificaciones que sean) aprendizaje, hay una identidad fundamental entre ellos».

La segunda orientación implicaría una "distancia insalvable» entre las funciones superiores del espíritu y los procesos reactivos del organismo. Desde esta perspectiva resultaría difícil entender que el desarrollo pudiera consistir en la incorporación del medio o la complicación de los mecanismos reactivos, con la evidente consecuencia de que ello abocaría a una concepción "endogenista" y "solipsista» del desarrollo, entendido como despliegue de capacidades prefiguradas en el organismo o el espiritu. Si las funciones superiores son - según esta lógica - irreductibles a los procesos elementales de reacción al medio, entonces su formación no depende de la complicación de tales procesos, ni está esencialmente condicionada por la adquisición de hábitos, asociaciones, respuestas, etcétera. En suma, el desarrollo es un proceso «interno", mientras que el aprendizaje es algo externo, que no está complicado activamente en el desarrollo. El resumen de esta orientación podría ser éste: "El desarrollo no es (con las cualificaciones pertinentes) aprendizaje, sino despliegue de posibilidades endógenas del sujeto; el desarrollo es condición del aprendizaje, que constituye un proceso externo de incorporación del medio; pero el aprendizaje no es condición fundamental del desarrollo».

Desde luego, estas son caricaturas. Podriamos analizar, por ejemplo, la posición de Piaget (considerada por Vygotski como más cercana a esta segunda perspectiva), que es muy compleja y llena de matices. Sin embargo, estos bocetos caricaturescos sirven para destacar dos orientaciones principales, que se han dado en el análisis de las relaciones entre aprendizaje y desarrollo por lo menos desde la vieja polémica entre los racionalistas y los empiristas. Además, pueden servir para poner de manifiesto dos puntos importantes: (1) A pesar de las evidentes diferencias entre uno y otro enfoque, los dos tienen una cosa en común: la concepción del desarrollo como elaboración y sustitución de respuestas (o ideas) innatas (tanto da que se llamen reflejos incondicionados como nociones de la mente). Pero hay un segundo punto que está muy relacionado con esa idea: (2) Una y otra orientación 
parten de una concepción esencialmente solipsista del sujeto. Aunque pudiera parecer que este enunciado sólo es aplicable, en rigor, a las orientaciones más idealistas del segundo tipo, también lo es a las primeras, pues la reducción del sujeto a un complejo de mecanismos reactivos significa su disolución como polo activo de relación.

Pero, como señala Vygotski, hay una diferencia importante entre estas dos concepciones de la relación aprendizaje-desarrollo, que se refiere a los supuestos sobre la relación temporal entre ellos. Los teóricos del primer tipo creen que aprendizaje y desarrollo son simultáneos (o que son «lo mismo»), los del segundo entienden que los ciclos evolutivos de desarrollo preceden a los de aprendizaje.

Naturalmente, hay variadísimas posiciones intermedias de todos los matices. Vygotski cita, como ejemplo, la orientación de Koffka: el desarrollo se basaría en dos procesos distintos y relacionados, la maduración y el aprendizaje. La primera prepara y condiciona al -segundo, pero éste estimula y potencia la propia maduración. Esta última condición depende, por su parte, de que el aprendizaje consista en la adquisición de estructuras transferibles y no de respuestas específicas. Sin embargo, los teóricos de orientación más asociacionista tenderían a concebir el aprendizaje (y el desarrollo) en términos de adquisición de respuestas o habilidades específicas.

Una idea implícita en la mayor parte de las concepciones tradicionales sobre el aprendizaje y el desarrollo es que, tanto uno como otro, implican esencialmente la acumulación de cambios cuantitativos. Esta consideración es muy clara en el caso de los planteamientos objetivistas que, como hemos visto, solían llevar a la identificación del desarrollo con el aprendizaje y la reducción de éste a formación progresiva de más y más asociaciones. Por otra parte, en el enfoque de las funciones superiores como despliegue endógeno de competencias prefiguradas en el organismo, el desarrollo no tiene por qué entenderse en términos de cambios cualitativos, pues precisamente la dificultad de esta orientación para «soldar" la evolución de los procesos reflejos elementales con las formas complejas de conducta estaria directamente relacionada con su dificultad para entender, en términos dialécticos, la transformación de las modificaciones cuantitativas en cambios de cualidad.

La perspectiva de la Escuela de Moscú era, en este aspecto, muy diferente: «Nuestro concepto del desarrollo - decía Vygotski- implica un rechazo de la opinión generalmente sostenida de que el desarrollo cognoscitivo resulta de la acumulación gradual de cambios independientes. Por el contrario, nosotros creemos que el desarrollo del niño es un proceso dialéctico complejo, caracterizado por la periodicidad, la irregularidad en el desarrollo de las distintas funciones, la metamorfosis o transformación cualitativa de una forma a otra, la interrelación de factores externos e internos y los procesos adaptativos que superan y vencen los obstáculos con los que se cruza el pequeño. Muchos estudiosos de la psicología infantil, enfrascados en la noción del cambio evolutivo, ignoran estos puntos decisivos, esas transformaciones revolucionarias y espasmódicas tan frecuentes en la historia del desarrollo del niño" (1930, cit., pág. 116). Ahora bien: la concepción del desarrollo en términos de cambios cuantitativos $y$ cualitativos que hacía compatibles las agregaciones evolutivas con las «transformaciones revolucionarias", tenia, a nuestro entender, unas consecuencias directas en el 
análisis de las complejas relaciones entre aprendizaje y desarrollo. Implicaba admitir la posibilidad de que, si bien aprendizaje y desarrollo no son idénticos, el aprendizaje pueda convertirse en desarrollo. Es más: desde la perspectiva de $V$ ygotski, el aprendizaje seria una condición necesaria para el desarrollo cualitativo desde las funciones reflejas más elementales a los procesos superiores. En el caso de las funciones superiores, el aprendizaje no sería algo externo y posterior al desarrollo (como para los teóricos más idealistas), ni idéntico a él (como para los más conduccionistas), sino condición previa al proceso de desarrollo.

La razón es evidente: el desarrollo de las funciones superiores exigiría, como ya hemos comentado, la apropiación e internalización de instrumentos y signos en un contexto de interacción. Y esto es aprendizaje. Sólo que, como decia también Vygotski, «el aprendizaje humano presupone una naturaleza social especifica y un proceso mediante el cual los niños acceden a la vida intelectual de aquellos que les rodean» (ibid., pág. 136). La maduración, por sí sola, no sería capaz de producir las funciones psicológicas que implican el empleo de signos y símbolos, que son originariamente instrumentos de interacción, cuya apropiación exige, inevitablemente, el concurso y la presencia de los otros. En definitiva, el proceso de "desarrollo" de las conductas superiores consiste precisamente en la incorporación e internalización de pautas y herramientas de relación con los demás. Sólo es posible porque el niño vive en grupos y estructuras sociales, $y$ porque puede aprender de los otros, a través de su relación con ellos.

Sin embargo, reducir la relación entre aprendizaje y desarrollo a una dirección única del primero al segundo sería una simplificación. Es evidente que las posibilidades de que el niño incorpore las herramientas y signos, que se construyen o presentan en sus relaciones con los demás, depende a su vez del grado de desarrollo anterior. Sería inútil, por ejemplo, que el profesor de primero de EGB tratase de lograr la apropiación e interiorización activa, por parte de sus alumnos, de los instrumentos de cálculo infinitesimal. En esto no hace falta insistir: el aprendizaje sólo se produce cuando los utensilios, signos, símbolos y pautas del compañero de interacción son incorporables por el niño en función de su grado de desarrollo previo. Pero no sólo eso: el aprendizaje depende también del desarrollo potencial del sujeto. Este es un concepto que sintetiza varios aspectos de la concepción vygotskiana sobre la relación entre aprendizaje y desarrollo, por lo que debemos aclararlo en sus aspectos esenciales.

Para definir la relación entre la evolución del niño y su aprendizaje, no basta con establecer el nivel evolutivo en términos de las tareas o actividades que el niño es capaz de realizar por si solo, sino que es preciso determinar qué es capaz de hacer con la ayuda de otros. La humanización se realiza en contextos interactivos en los cuales las personas que rodean al niño no son objetos pasivos o simples jueces de su desarrollo, sino compañeros activos que guian, planifican, regulan, comienzan, terminan, etc., las conductas del niño. Son agentes del desarrollo. Al conjunto de actividades que el niño es capaz de realizar con la ayuda, colaboración o guía de otra(s) persona(s) le llama Vygotski univel de desarrollo potencial", diferenciändolo del «nivel de desarrollo actual", que es aquel que corresponde a ciclos evolutivos $\int 2$ llevados a cabo y que se define operacionalmente por el conjunto de 
actividades que el niño es capaz de realizar por sí mismo, sin la guía y ayuda de otras personas.

A partir de estas definiciones es fácil entender el concepto vygotskiano de zona de desarrollo potencial (Zona blizbaishego razvitiya): "No es otra cosa - dice- que la distancia entre el nivel actual de desarrollo, Jeterminado por la capacidad de resolver independientemente un problema, y el nivel de desarrollo potencial, determinado a través de la resolución de un problema bajo la guia de un adulto o en colaboración con otro compañero más capaz» (ibid., pág. I 33 ).

Vygotski criticaba la tendencia psicométrica a definir simplemente el nivel de desarrollo actual, y la propensión pedagógica a situar los objetivos didácticos en dicho nivel de desarrollo. Al medir el nivel de desarrollo en cuanto a las fases evolutivas previamente realizadas, los tests limitarian su validez y posibilidades de predicción en los contextos educativos. Por otra parte, la limitación de objetivos educativos al ámbito del desarrollo actual, daria lugar a una educación conservadora y poco capaz de favorecer el desarrollo: «El aprendizaje orientado hacia los niveles evolutivos que ya se han alcanzado resulta ineficaz desde el punto de vista del desarrollo total del pequeño - decía-. Este tipo de enseñanza no aspira a un nuevo estadio en el proceso evolutivo, sino que más bien va a remolque de dicho proceso. Así pues, la noción de una zona de desarrollo potencial nos ayuda a presentar una nueva fórmula, a saber, que el "buen aprendizaje» es sólo aquel que precede al desarrollo" (ibid., pág. 138 ).

El concepto de «zona de desarrollo potencial» sintetiza la concepción del desarrollo como apropiación e internalización de instrumentos proporcionados por agentes culturales de interacción. Define las funciones que aún no han madurado, pero están en proceso de hacerlo. A diferencia del nivel de desarrollo actual, que permite una caracterización retrospectiva del desarrollo, posibilita una definición prospectiva del mismo, por lo que su importancia práctica es mucho mayor. Además, la noción de desarrollo potencial es decisiva para analizar el papel de la imitación y el juego en el desarrollo del niño. Podemos decir que aquélla permite la transformación del desarrollo potencial en actual, mientras que el juego «crea una zona de desarrollo próximo en el niño» (1934, cit., pág. 1 56), que se sitúa normalmente por encima de su edad y posibilidades de acción actual, e incorpora como potenciales los instrumentos, signos y pautas de conducta de su cultura.

La posibilidad de hablar de una «zona de desarrollo potencial» (y no sólo del desarrollo actual) depende de una característica esencial del aprendizaje humano, que es su capacidad de suscitar procesos evolutivos que sólo son activos en las situaciones de relación entre personas. Estas consideraciones nos permiten dar ahora algunas respuestas a los interrogantes que planteábamos antes, al hablar del método genético experimental de los investigadores de la Escuela de Moscú. Nos preguntábamos entonces si tal método permitía la objetivación del desarrollo real o más bien ponía en juego procesos de aprendizaje, por influencia del experimentador, favoreciendo la imagen de un desarrollo artificial. Podriamos dar una respuesta muy rápida a esta cuestión: en cierto modo, el desarrollo de las funciones superiores humanas es, necesariamente, artificial. Es un artificio de la cultura y de la relación con los demás. El método genético-experimental de Vygotski situaba 
el análisis de los procesos de desarrollo en la zona de desarrollo potencial, a través (naturalmente) de la influencia activa del experimentador y del aprendizaje activo del sujeto. Sucede que el aprendizaje, a través de la influencia, era para Vygotski el factor fundamental del desarrollo.

\section{LAS CONCEPCIONES EDUCATIVAS DE VYGOTSKI Y SUS APORTACIONES A LA PAIDOLOGIA Y DEFECTOLOGIA}

El interés por los problemas de aprendizaje y desarrollo no se limitó en Vygotski a la especulación teórica o la perspectiva psicológica, sino que se tradujo en un esfuerzo sostenido por acercarse a los procesos educativos reales, tanto en los niños normales como en los niños con necesidades especiales. Es más: la inmensa mayoria de sus trabajos se dedicaron a temas de paidología y defectología, más que a cuestiones psicológicas en sentido estricto. Probablemente la expresión más clara del genio y la capacidad de Vygotski es ésta: el delicado y gigantesco edificio teórico que hemos descrito en páginas anteriores, lo estaba construyendo al mismo tiempo que se dedicaba fundamentalmente a otras cosas, relacionadas pero distintas. En 1930 había publicado un libro de psicología general (los Estudios de Psicologia del Comportamiento, de 1930) y siete dedicados a problemas más relaciona dos con la educación normal o especial. También había publicado numerosos artículos sobre la educación de niños ciegos, deficientes, sordomudos, etc., fundamentalmente en las revistas Paidologia y Problemas de Defectologia, de cuyo consejo de redacción era miembro muy activo. Por otra parte, los libros y artículos de paidologia y defectología tienen un carácter más "acabado" y estructurado que los de psicología (Mecacci, 1983). En suma: si analizamos la producción de Vygotski entre 1924 y el año de su muerte, encontramos que dirigió la mayor parte de sus esfuerzos a problemas cercanos a la educación real, escribió la mayor parte de sus artículos y libros sobre ellos, presentó una gran cantidad de comunicaciones y ponencias sobre temas de paidología y defectología, etc. Además, desde el punto de vista de su dedicación profesional, Vygotski ocupó puestos más relevantes en estos campos que en la psicologia: recordemos que nunca ocupó un cargo directivo en el Instituto de Psicología de Moscú, que en la universidad era profesor de Paidologia (no de Psicologia) y que, en 1925 , fundó un laboratorio de psicología de niños con deficiencias del cual provino después el Instituto Experimental de Defectologia, en el que ocupó un cargo de director cientifico entre 1931 y 1934. Este Instituto ha coordinado, desde entonces, la investigación, enseñanza y programación educativa de los niños con necesidades especiales en la Unión Soviética, así como su incorporación a "centros especiales» o "aulas especiales». Vygotski realizó, además, una actividad clinica (y no sólo teórica o institucional) en este campo. En sus observaciones y protocolos sobre niños con distintas clases de minusvalías' y deficiencias, se basaba en un enfoque cualitativo, que trataba de capturar la organización peculiar de sus funciones y conducta, más que en la descripción a base de rasgos unidimensionales de carácter cuantitativo. Desgraciadamente, los protocolos de las consultas de Vygotski se perdieron en la segunda guerra mundial o desaparecieron al morir su colaboradora L. Gishelina, que los conservaba. Sin embargo, su estilo de trabajo se 
mantuvo en la forma de actuación clínica de los colaboradores que luego se dedicaron a los problemas de los niños con distintas deficiencias, como Morozova y Levina (Luria, 1979).

No podemos extendernos aqui en las concepciones de Vygotski sobre las alteraciones y deficiencias del desarrollo y las alternativas educativas para los niños que las presentan (el tema es suficientemente complejo como para requerir, por lo menos, de otro artículo como este), por lo que nos limitaremos a bosquejar las líneas más generales de su pensamiento en este tema. De forma coherente con su propia teoría, Vygotski no concebía las deficiencias en términos de disminución cuantitativa de determinadas funciones, sino de una organización cualitativamente diferente de ellas. Un niño deficiente no es como un niño normal más pequeño o, simplemente, menos capaz de ejercer ciertas habilidades, sino que posee una estructura funcional peculiar, que debe ser analizada y objetivada por el psicólogo. Aun cuando la génesis de la deficiencia pueda referirse a una disminución de los recursos asociativos que constituyen la base «material» de las funciones superiores, ello se traduciría en formaciones psicológicas que implicarian una determinada organización, con rasgos cualitativos propios, de tales funciones y de las subordinadas a ellas. Esto significaria también que los niños con alteraciones y deficiencias del desarrollo pueden requerir una educación especial, debido a que su funcionamiento psicológico es también «especial» y no simplemente "menor». Vygotski no pensaba que la alternativa educativa fundamental de los niños con deficiencias fuera su incorporación, sin más, al sistema educativo ordinario, sino una educación basada en la organización especial de sus funciones y en sus características más positivas, en vez de sus aspectos más deficitarios. Una educación con objetivos fundamentalmente compensatorios. Las nociones fundamentales sobre el desarrollo, que tenía Vygotski, le permitian ver, con perspectivas de futuro, las posibilidades de compensación con niños con distintas alteraciones, pues -como ya hemos comentado- el desarrollo no se concebía como una vía única y unidireccional o como una simple evolución cuantitativa, sino como un camino dialéctico, complejo e irregular, con variaciones cuantitativas y metamorfosis cualitativas, que implicaria la sustitución sistemática de unas funciones por otras y la incorporación de mediaciones externas, para convertirlas en internas.

A partir de esta visión del desarrollo, la educación especial podía entenderse como una sistemática destinada a proporcionar al niño mediaciones (signos, símbolos, instrumentos) capaces de favorecer el desarrollo en función de su estructura psicológica peculiar. Sin embargo, Vygotski reconocía que habria casos en que las funciones de mediación y la capacidad de emplear instrumentos auxiliares estarian muy deterioradas. Y se refería especificamente a trabajos de Eliasberg, sobre diagnóstico diferencial en función de la capacidad de usar instrumentos y del empleo de signos: «evidentemente - decia- la capacidad de emplear signos en calidad de instrumentos auxiliares del comportamiento se deteriora solamente con el desarrollo de la demencia) (1931, cit., pág. 134). Está claro que aquí se referia, sobre todo, a los que hoy se llamarian casos de autismo, psicosis infantiles y deficiencia con aislamiento severo, en los cuales se da efectivamente una correlación de la incompetencia social y el aislamiento, los rituales y deficiencias en la conducta exploratoria e instrumental y las alteracio- 
nes $y$ deterioros en las competencias de simbolización y lenguaje (Wing, 1981). Esta correlación es un dato importante a favor de la concepción general del desarrollo que tenia Vygotski (Rivière, 1983). También parece obvio que, según esta idea evolutiva, las posibilidades de compensación y construcción de funciones superiores, en sujetos con deficiencias severas de la conducta social y/o instrumental, se verían muy disminuidas o impedidas.

Pero en los niños en que no se da esta clase de perturbaciones (es decir, en aquellos cuyo déficit es más explicable en términos de una deficiencia asociativa o más exclusivamente intelectual, y no como «imposibilidad de adquirir mediaciones»), la educación especial podria jugar el papel decisivo de proporcionar (si se me permite esta expresión) "prótesis instrumentales», mediaciones capaces de provocar una "organización sustitutiva» de las funciones superiores. De estas mediaciones, tendrían una importancia fundamental aquellas que permiten una regulación de la propia conducta o de las propias funciones mentales. Dicho en términos actuales: Vygotski proponia, como objetivo básico para la educación especial, el de proporcionar al niño recursos metacognitivos. Algunas de sus observaciones en este sentido resultan sorprendentemente modernas: «deberiamos estudiar -decia, por ejemplo- no tanto la memoria de que dispone el niño con retraso mental, como el grado en que puede servirse de ella. La insuficiencia del desarrollo del niño con retraso mental consiste, sobre todo, en el desarrollo insuficiente de las formas superiores de comportamiento en la incapacidad de controlar los propios procesos de comportamiento, en la incapacidad de servirse de ellos» (ibidem). Podriamos recordar, por ejemplo, que Belmont y Butterfield (1969, 1971) y Ellis (1970) han demostrado, muy posteriormente, las deficiencias que tienen los niños con retraso mental en lo referente al control metacognitivo y empleo espontáneo de estrategias de repetición y reciclaje («rehearsal») en la MCP. También los datos de Brown, Campione, Bray y Wilcox (1973) demostrando que los deficientes podian unormalizar» la realización de determinadas tareas cognitivas al proporcionárseles dichas estrategias. Estas observaciones, como los procedimientos de «enriquecimiento instrumental» de Fevertin, están en la linea de las propuestas de investigación y educación especial que hacia Vygotski por los años treinta.

Aquellas propuestas se hacian en el contexto de una "ciencia general de la deficiencia", o defectologia, que tenía el carácter de un sistema que globalizaba, en una unidad, los aspectos neuro-biológicos, psicológicos, sociales y educativos del análisis de las diferentes deficiencias. Esta concepción globalizadora y unitaria era muy afin a las líneas principales del pensamiento de Vygorski, puesto que él entendía el desarrollo como transformación cualitativa, por la cultura, de los mecanismos neurobiológicos de adaptación, y se acercaba a la deficiencia desde una perspectiva de definición cualitativa de la organización peculiar de las funciones psicológicas. Es decir, la idea de una defectología como sintesis de conocimientos sobre las deficiencias era fácilmente incorporable al propio sistema (también sintético y globalizador) de Vygotski. Pero, adernás, correspondia a la propuesta de construir una ciencia general del niño y su evolución, que era lo que se conocía como "Paidología». 
La historia de la Paidología soviética y del papel de Vygotski en ella es, todavia hoy, dificil de reconstruir con objetividad. En su origen, la Paidología era una expresión del gran interés por los problemas del niño y la educación en los años posteriores a la revolución. Al mismo tiempo, incorporó de facto muchas influencias occidentales y, especialmente, de la práctica psicométrica. Para uno de sus grandes creadores, el psicólogo Pavel P. Blonskii (que había sido el primer discipulo de Chelpanov que se opuso al idealismo de éste en su Ensayo de Psicologia cientifica, de 1920), la Paidología no debia consistir en una mera aplicación al niño de leyes psicológicas abstractas, o en una pedagogía experimental artificial, sino en una ciencia unitaria del desarrollo del niño, que podria colaborar con las disciplinas especificas (psicología, sociologia, biologia, etc.), pero sin reducirse a ellas ni ser un saber "eclécticon, sino, por el contrario, sintético; es decir, capaz de establecer leyes propias del desarrollo y una estructura teórica propia, irreductible a la de otros saberes más particulares. Vygotski estaba, y no sólo en este aspecto de sus concepciones, cerca de Blonskii. Estaba convencido, como éste, de que ala conducta únicamente puede comprenderse como la historia de la conductan, de la necesidad de entender el desarrollo en términos dialécticos y del papel de la actividad productiva en la génesis dialéctica de las formas superiores de conducta. Compartía la idea de que la Paidología no debia ser una ciencia ecléctica, que mezclase observaciones anatomo-fisiológicas, genéticas, psicológicas, etc., sino una ciencia con sustancia propia y carácter unitario que tratase el problema general del desarrollo. Los conceptos fundamentales de tal ciencia deberían tener un carácter sintético, referible a diferentes planos particulares. Por ejemplo, la noción de "zona de desarrollo potencial», podia remitirse a la neurofisiologia (en que alumbraria la gran plasticidad de las funciones neurofisiológicas superiores), a la pedagogía (en que prescribía una elaboración prospectiva de los programas), a la psicología, como ya hemos visto, etc. También los conceptos relacionados con las fases del desarrollo y su periodización podrian ocupar ese papel transicional y de sintesis a partir de las disciplinas particulares.

La práctica real de los paidólogos no se correspondió, sin embargo, con las propuestas teóricas de Vygotski y Blonskii. Desgraciadamente, parece ser cierto que los paidólogos se convirtieron en "testólogos", muy alejados de las condiciones educativas concretas y que, sin conocer a fondo la situación individual de los sujetos a que sometian a sus pruebas ni tener un contacto continuado y cercano con el sistema escolar, mandaban a grandes cantidades de niños a centros especiales. Paulatinamente, la paidología se convirtió en una especie de usuperestructura" dañina para la escuela. Personas con dos años de preparación posterior a la enseñanza secundaria (que era todo lo exigido para el título de paidologia) y que no estaban en las escuelas, sino fuera de ellas, pasaban tests y cuestionarios a los niños y sólo en función de sus resultados (sin más conocimientos de los niños y sus condiciones) podian remitirles a centros especiales o decidir su destino escolar posterior. Controlaban la admisión y agrupamiento de los alumnos en las aulas sobre la base de los resultados de sus tests $y$, muy frecuentemente, sin ninguna consideración hacia las opiniones de los educadores y personas que convivian constantemente con los niños. Los paidólogos (que dependian del Comisariado de Educación) decidian la profe- 
sión futura y estudios profesionales de los alumnos de los centros escolares. En el año I93 I se publicó un primer decreto sobre las escuelas primarias y secundarias, que criticaba la práctica de los paidólogos y trataba de limitar los evidentes abusos que se estaban produciendo. Una lectura superficial de lo que viraba ocurriendo permitiria afirmar que aquel decreto era perfectamence fwificable. Los propios psicólogos y la opinión pública en general eran comrarios a la práctica real que estaban realizando los paidólogos. Vygotski también criticaba el empleo indiscriminado de tests y la tendencia a reducir a los individuos a parámetros fijos, «cristalizados», a homogeneizarlos. Insistia en la necesidad de poner de manifiesto no sólo el desarrollo "terminado" de los sujetos, sino, más bien, sus posibilidades de desarrollo (la "zona de desarrollo potencial») y de construir instrumentos adecuados para ello. Además afirmaba la exigencia de una definición cualitativa de la organización funcional de los sujetos. Sus obras de Paidologia (Paidologia de la edad escolar, de 1928, Paidologia de la Adolescencia, de 1929, y la póstuma sobre Fundamentos de Paidologia, publicada en 1935) presentaban una imagen de un saber sistemático y sintético del desarrollo, muy lejano de los aspectos más lamentables de la práctica paidológica.

Sin embargo, el decreto de 1931 y las primeras criticas que se formularon a Vygotski y los miembros de la Escuela de Moscú ya en aquel año, admiten una lectura más profunda. En los últimos años de su vida, Vygotski estuvo sometido a un escrutinio crítico que, aunque se revistiera de formulaciones especificas sobre aspectos de su psicología o de malintencionada vinculación de su figura con las prácticas criticables de los paidólogos (que él era el primero en repudiar), escondía una crítica de su concepción global del hombre y de la educación. Las formas de ideología y de organización social que empezaban a perfilarse en la Unión Soviética, a partir de 1929, eran difícilmente compatibles con las posiciones que representaba Vygotski. En pocos años (los cinco transcurridos entre 193 I y 1936) lo que comenzó como una justificable crítica a las prácticas frecuentes entre los paidólogos, terminó por convertirse en una intervención decisiva sobre la propia psicología y sus diversas orientaciones, en una expresión de dirigismo que daría al traste con algunas de las promesas más interesantes de la psicologia soviética. En aquella situación de dirigismo, Vygotski no era un hombre cómodo. Era un marxista convencido y profundo, pero ése podía ser, desde ciertos puntos de vista, uno de sus aspectos más "peligrosos». El rechazó siempre el «método de las citas", con el que muchos psicólogos soviéticos comenzaban justificando su ortodoxia: después de dos o tres citas de Marx, Engels, Lenin o Stalin, pasaban a desarrollar su tema, que generalmente no tenía nada que ver con las propias citas. En realidad, esa era una manifestación de la incipiente tendencia a convertir la ciencia en escolástica, el pensamiento vivo en expresión temerosa y sometida, la dialéctica en estructura pétrea. En sus últimos años (especialmente los dos anteriores a su muerte), la situación de Vygotski -y también la de otros psicólogos dialécticos- era delicada. Murió antes de ver el avance incontenible de los nuevos poderes y también la destrucción de muchas de sus ilusiones: pero pudo ver, al final de su corta vida, cómo se anunciaban tiempos dificiles para la psicología. Para entender esta situación es necesario que describamos someramente las condiciones 
sociopolíticas que se dieron en la Linión Soviética en los ultimos ainos de la vida de Vygotski y que coincidieron con las primeras criricas (que fucron cada rex más seteras, hasta alcanzar su culminación cuando el ya habia muerto "oportunamente») a su sistema.

\section{LA UNION SOVIETICA EN LOS PRIMEROS AÑOS TREINTA Y ALGUNAS CRITICAS A VYGOTSKI}

Si el periodo inmediatamente posterior a la revolución soviética (1917-1929) habia significado, fundamentalmente, la apertura de un debate abierto ! rico en las diversas ciencias ( $y$, desde luego, en psicologia) y la construcción de sistemas variados, en un clima de pasión intelectual y de creación (entre ellos, el sistema de Vygotski), el periodo posterior a 1929 supuso una acentuación y endurecimiento de los debates, pero también el comienzo del sometimiento de las fuerzas intelectuales a los intereses del poder politico y los primeros sintomas de un dirigismo en la ciencia, que terminaria por acartonar y cercenar muchas de las posibilidades generadas por la propia revolución. Podemos considerar entonces, que el periodo de 1929 a 1936 tienc, en la vida intelectual de la Linión Soviética, un carácter de transición entre los creativos y pluriformes años veinte postevolucionarios y los planteamientos uniformes y cstáticos posteriores a 1936.

los comienzos de los años treinta significaron desde el punto de vista sociopolitico, un cambio decisivo en la historia soviética. Ios enfrentamientos anteriores entre el aparato estalinista y los grupos de oposición a él, tanto por la derecha como por la izquierda, se habian resuelto de forma concluyente a favor de Stalin. Jos elementos y factores capitalistas, que habian sido estimulados por la nueva política económica de los últimos años de Lenin, fucron eliminados. Ia oposicion trotskista habia sido vencida, y el propio Trotsky, expulsado de la Linión Soviética. I.a facción de Bukharin, en el ala derecha, habia perdido toda influencia. Las propuestas politicas para el «socialismo en un solo pais» de Stalin suponian un fuerte cambio de dirccción (que implicaba "innovaciones" ideológicas sustanciales) en el sentido general de la politica soviética y debieron ser asumidas por los grupos sociales e intelectuales. Todo ello implicaba la colectivización de sistemas de producción, distribución e intercambio y también (y ello es muy significativo para entender algunas de las criticas a Vygotski) la extension de una ideologia nacionalista y con claros componentes de xenofobia y suspicacia hacia las influencias externas, incluidas las intelectuales. Todaria en el periodo 1929-1931, definido por el enfrentamiento intelectual con las posiciones idealistas y de mecanicismo materialista, y por la influencia de la publicación de los Cuadernos filosóficor de lenin (todo lo cual tuvo, como sabemos, un peso decisivo en la propia obra de Vygotski), encontramos mucho de la fresca creatividad de los años anteriores, y de libre circular de ideas (aun cuando fueran frecuentes los enfrentamientos), pero en años posteriores la "crítica" tenía un significado más negativo y empezaba a tener, también, unas implicaciones más peligrosas y menos puramente «intelectualess.

Muchas de las facetas de aquella sociedad pueden explicarse por el terrible esfuerzo encaminado a industrializar el campo, colectivizar la 
producción y lograr mantener, desde el punto de vista económico, la difícil situación de la Unión Soviética posrevolucionaria. El primer plan quinquenal exigia el concurso material de las fuerzas sociales. También implicaba aquel esfuerzo una cierta claridad intelectual y de propósitos, una unidad en torno a proyectos sociales claros. La dirección sociopolítica de la Unión Soviética, en los tiempos del primer plan quinquenal, exigía (en la visión del aparato ideológico y administrativo) la entrega y el sacrificio de extensos sectores sociales, entre los cuales estarian los propios intelectuales, obligados a someterse a la demanda de claridad y de unidad ideológica y llevados, más o menos directamente, a la necesidad de desconfiar de influencias intelectuales externas y a acomodar sus ideas a un proyecto social común establecido sobre la base de la interpretación del marxismo por el aparato estalinista. Todo esto fue un proceso lento y que manifestó sus facetas más negativas (para la libertad intelectual) después de la muerte de Vygotski y de 1936. Pero en los años 32, 33, 34, ya comenzaban a ser frecuentes las "críticas" y "autocríticas", y las acusaciones basadas más en una simplificación escolástica del marxismo y menos en concepciones dialécticas profundas.

Por otra parte, la apertura del debate social sobre la Paidología tuvo como consecuencia un interés por analizar y determinar, desde el poder ideológico, el desarrollo de la propia psicología. En el año I931, la célula del Instituto de Psicología de Moscú aprobó una resolución en la que se criticaba la concepción reactológica de su director, Kornilov, y se proponia una reorganización del Instituto. El cese de Kornilov abrió un breve periodo en que los miembros de la Escuela históricocultural parecian ser los herederos de la supremacia institucional que antes tenía la reactología. Pero aquello fue un espejismo: el nuevo director del Instituto fue Kolbanovsky. La resolución (publicada en la revista Psicologia, en 1931) y en el proyecto de reorganización, publicado en 1932, no sólo se criticaba la reactologia, sino, también, la teoría de la Escuela histórico-cultural, a la que se acusaba de tener un carácter «abstracto» e «idealista» (!). Era evidente que el hombre que más había contribuido a la construcción de una psicologia materialista y dialéctica no resultaba cómodo para el poder de aquellos tiempos. Lo que era conocimiento profundo de la psicología de su tiempo fue interpretado, por algunos sectores, como «eclecticismo» e «influencia occidental». De todas formas, aquellas primeras críticas no eran más que una expresión de lo que estaba empezando a ser moneda corriente en la psicología soviética, y no tenían mayor importancia que la de expresar el enfrentamiento entre distintas tendencias en psicología. Pocos años después, el dirigismo tendría unos efectos mucho más devastadores.

Una respuesta de los miembros de la Escuela histórico-cultural al incremento de presiones ideológicas, fue el intento de fundar un departamento de Psicologia, que recogiese las líneas esenciales del trabajo que estaban realizando. Como no pudieron encontrar una institución en Moscú que aceptase su propuesta como grupo, se pusieron en contacto con el Instituto Psiconeurológico de la Universidad de Jarkov, para formar un departamento de Psicología. Alli se desplazaron Vygotski, Luria, Leontiev, Zaporozhets y Bozhovich. Sin embargo, sólo estos tres últimos permanecierơn en Jarkov, donde mantendrian posteriormente un departamento de Psicología que suponia una continuación (sobre todo, a partir de la interpretación e 
innovaciones de Leontiev) del pensamiento de Vygotski. Luria volvió pronto a Moscú y Vygotski compaginó las actividades en Jarkov, Moscú y el Instituto Pedagógico Hertzen de Leningrado, hasta su muerte, en 1934.

Aún tuvo tiempo para realizar algunos cursos en la Facultad de Medicina. En los últimos años de su vida, Vygotski se interesó cada vez más por problemas de neurologia y neuropatologia, scbre todo en relación con el viejo tema de la localización de las funciones en el sistema nervioso. Intuia justificadamente que su teoria de la naturaleza y génesis de las funciones superiores tenía implicaciones útiles para analizar, de nuevo; el problema de la organización.de las funciones en el sistema nervioso. Esta fue una de la razones que le llevaron a comenzar (junto con Luria) estudios de medicina y neurología en los últimos años de su vida. Para explicar las concepciones de la organización funcional del sistema nervioso, que comenzaba a perfilar Vygotski en sus últimos años, debemos referirnos primero a su idea general del desarrollo, a la que también dedicó una atención especial en la última parte de su vida.

\section{EL DESARROLLO COMO PROCESO HISTORICO: LAS APORTACIONES DE VYGOTSKI A UNA TEORIA GENERAL DEL DESARROLLO}

En La Historia del Desarrollo de las Funciones Psicológicas Superiores, un texto escrito en 1930 y 1931 e inédito hasta 1960 , se presenta la explicación más completa y detallada de la concepción bistórica del desarrollo que tenia Vygotski. El pensaba que los enfoques clásicos del desarrollo estaban lastrados por una perspectiva esencialmente ahistórica: por la tendencia a reducir los problemas del desarrollo de las funciones psicológicas bien a las «leyes eternas de la Naturaleza» o bien a las "leyes eternas del Espíritu», a considerar el desarrollo como "Fisiologia o Matemática del Espíritu, y no como historia del comportamiento humano comprendido como un aspecto de la historia general de toda la humanidad» (1960, Cit., pág. 93). Este carácter ahistórico se expresaria también en muchas concepciones estructurales del desarrollo: "Aqui, nuevamente, a la luz -o semipenumbra- de las estructuras "todos los gatos son pardos»: con la simple diferencia de que a una eterna ley de la naturaleza, la ley de asociación, la sustituye otra ley, también eterna, de la naturaleza: la de estructura" (ibid., pág. 94). En este caso, se da una propensión a desligar el desarrollo cultural del desarrollo histórico, a considerar que el desarrollo cultural del niño (que para Vygotski era equivalente al de las funciones superiores) está regulado por una especie de "fuerza interior" o «lógica inmanente». Vygotski se referia, evidentemente, a las investigaciones de Piaget cuando criticaba la consideración de fenómenos como el animismo, el egocentrismo infantil, el artificialismo como «formas psicológicas congénitas" (ibid.), abstraidas de los contextos sociales y culturales que conforman las funciones superiores.

Para Vygotski, el desarrollo humano sólo podía entenderse como síntesis producida por la confluencia de dos órdenes genéticos diferentes: la maduración orgánica y la historia cultural. Estaria, por una parte, la evolución biológica de la especie (que se expresa y refleja en el proceso 
ontogenético de maduración) hasta dar en el "homo sapiens». Por otra parte, el proceso de desarrollo histórico, de evolución cultural desde el hombre primitivo, que incidirá también directamente, a través de la relación con las personas que le rodean, en el desarrollo psicológico de cada niño. "Toda la particularidad -decia Vygotski- y la dificultad del problema del desarrollo de las funciones psicológicas superiores consiste en el hecho de que estos dos aspectos de la ontogénesis se funden en uno solo, constituyendo realmente un proceso unitario, aunque complejo" (ibid., pág. 98).

Ahora bien, a diferencia de lo que sucede en la ontogénesis, en que se realiza una síntesis peculiar de la maduración y el desarrollo histórico-cultural del sujeto, en la filogénesis no se da la confusión entre una y otra linea de desarrollo. Por eso, Vygotski pensaba que el análisis de la filogénesis seria una ayuda importante para «desatar el intrincado nudo que se establece entre maduración y desarrollo cultural- en la psicologia infantil» (ibidem). El análisis filogenético no debería hacer olvidar, sin embargo, que la ontogénesis no es reflejo de la filogénesis, ya que en aquélla se da, precisamente, el entrelazamiento y la sintesis de líneas evolutivas que no se mezclan filogenéticamente. De modo que la investigación de la filogénesis era considerada por Vygotski como una herramienta útil para el estudio del desarrollo del niño, pcro no como un espejo de éste.

Al deslindar los dos procesos de desarrollo que se dan en la génesis del hombre como colectivo (es decir, como especie animal o miembro de un grupo social y una cultura), nos encontramos con una diferencia fundamental entre ellos; a saber, mientras que el desarrollo cultural no implica transformaciones en la estructura biológica de la especie, las mutaciones biológicas son el fundamento del desarrollo evolutivo. Lo que define el desarrollo de las formas superiores de cultura y comportamiento es el hecho de que se crean y perfeccionan "órganos artificiales», instrumentos, que potencian y amplifican las posibilidades de conocimiento y control de la Naturaleza, dadas por la dotación biológica de nuestra especie.

Sin embargo, el enunciado de que las transformaciones históricas de la cultura humana no implican cambios de estructura biológica, plantea algunos problemas difíciles a la psicologia: ¿En qué sentido sería posible el desarrollo ontogenético de las funciones superiores sin un cambio o desarrollo equivalente del sistema nervioso o el cerebro? ¿Qué factor juega un papel equivalente al del «desarrollo orgánico» en la génesis de esas funciones?

Para responder a estas cuestiones hay que aclarar primero cuál es la función esencial de los hemisferios cerebrales y las formaciones más complejas y "nuevas» del sistema nervioso. Vygotski estaba de acuerdo con Paulov en que esa función sería la de señalización. El sistema nervioso del hombre y de los animales más cercanos a él es, en un sentido muy fundamental, un sistema de formación de señales. Las señales múltiples, variables, versátiles, que se construyen mediante los mecanismos de formación de los reflejos condicionados, al permitir que estimulos originalmente «neutros" tomen el valor de "señales» de ciertos estímulos relevantes para la adaptación del organismo, amplían enormemente esas posibilidades de adaptación. Como Paulov, Vygotski hablaba de la «actividad señalizadora de los grandes hemisferios». 
Ciertamente, esa función señalizadora de los hemisferios es una condición necesaria para el desarrollo de las formas más complejas y especificamente humanas de comportamiento, pero no es suficiente. Aunque la formación de reflejos condicionados amplíe las posibilidades adaptativas, la adaptación que permite es esencialmente acomodatoria (por emplear un término de Piaget); es decir, se basa en un "reflejo» de los nexos naturales entre los estimulos del medio. Podemos decir que el mecanismo de los reflejos condicionados le permite al sistema nervioso "aprovecharse" de las asociaciones y nexos entre sucesos que se dan en la Naturaleza, prescindiendo de su intervención. La formación de reflejos condicionados no implica la transformación de la Naturaleza, sino una acomodación más precisa (y anticipatoria) a sus modificaciones. Sin embargo, la conducta del hombre se caracteriza por la modificación activa de la naturaleza y su transformación. La respuesta adaptativa a las "señales" (estimulos condicionados) que construyen los hemisferios cerebrales implica, más bien, una adaptación pasiva al medio.

Por eso, Vygotski insistía en que, en el caso del hombre, se construye una función nueva, que va más allá de la función señalizadora de los hemisferios y que no puede reducirse a ella: es la función de significación. Esta nueva función ya no depende de los nexos previos que se dan en la Naturaleza, sino que implica la instauración activa de nuevos nexos, de "estímulos artificiales». «El hombre - dice Vygots$\mathrm{ki}$ - introduce estímulos artificiales, "significa" el comportamiento e instaura, mediante los signos (...) nuevos nexos en el cerebro» (ibid., pág. 122). La introducción de los signos implica una modificación esencial en el mundo humano, pero tambièn en la uestructura interna" del sujeto humano. Vygotski hablaba de un Principio de Significación como esencial para explicar la naturaleza de las formas superiores de comportamiento en el hombre. Este principio consistiría en que el hombre instituye, desde el exterior, nexos cerebrales y a través de ellos dirige al propio cerebro y, como consecuencia, al propio cuerpo.

El principio anterior permite plantear nuestra cuestión en un plano nuevo: ¿Cómo es posible establecer, desde fuera, nexos cerebrales y regular el cuerpo y la conducta a través de la regulación del propio cerebro?

Vygotski pensaba que esa posibilidad depende de la confluencia de dos factores:

I. La posibilidad de construcción de nexos nuevos, no prefijados, entre los estímulos del medio, por el mecanismo de formación de los reflejos condicionados.

2. La influencia del carácter social de nuestra especie y de las formas de interacción.

En realidad, los signos son nexos nuevos que se construyen y crean en el curso de la interacción. «En el proceso de la vida social - decía Vygotski- el hombre ha construido y desarrollado sistemas muy complejos de nexos psicológicos, sin los cuales no hubiera sido posible la actividad productiva y la vida social en todas sus formas) (1960, cit., pág. 123). La idea implícita aquí es que los signos son resultado de una convención social. Podriamos decir (yendo un poco más allá de las afirmaciones explícitas de Vygotski) que esa convención, el proceso en 
el cual se negocian los significados entre los miembros de nuestra especie, no sólo se ha dado a lo largo de la historia del desarrollo colectivo de la humanidad, sino que se produce cotidianamente en el desarrollo de cada niño bumano.

Una consecuencia de las consideraciones anteriores es que la regulación individual del comportamiento está originada en la reguĺación social. Ja vida social del hombre como especie hace necesaria (en expresión de Vygotski) una cierta subordinación de la conducta del individuo a las exigencias generales del grupo. Como consecuencia, es necesaria también la formación de sistemas complejos de señales, de origen comunicativo, que a su vez regulan y dirigen la formación de nexos condicionados en el cerebro del sujeto individual. Es decir, las formas complejas de adaptación, aquellas que provienen de las exigencias de agrupamiento y cooperación y de transformación productiva de la Naturaleza en los miembros de nuestra especie, re-obran una transformación de los mecanismos regulatorios del comportamiento situados en un nivel inferior $y$ más individual. Si se permite esta metáfora, podemos decir que mientras que los animales son desarrollados evolutivamente por la naturaleza, los hombres son también y además fabricados por otros hombres socialmente organizados. Pero, por eso mismo, pueden llegar a alcanzar una capacidad de regulación de su propia conducta (y de control metacognitivo de sus procesos mentales) muy superior a la de cualquier animal: " $\mathrm{Si}$, como hace Paulov, comparamos la corteza de los grandes hemisferios con un enorme cuadro de señales, podriamos decir que el hombre ha creado, por si mismo, las llaves de ese cuadro" (ibid., pág. I 2 ). Especialmente gracias a la construcción social del lenguaje, y que permite regular desde fuera la actividad de la corteza de los grandes hemisferios cerebrales.

Siguiendo con la comparación anterior, Vygotski señala que en la ontogénesis y la filogénesis el desarrollo psicológico del hombre no sólo se define por el perfeccionamiento evolutivo de ese «cuadro de señales" (los grandes hemisferios, especialmente la corteza cerebral), sino también, y sobre todo, por la fabricación de esa llave esencial para su regulación que es el lenguaje. Eso significa también la posibilidad de construcción de "circuitos artificiales" en el cerebro humano. Y la llave para la formación de estos circuitos la tienen, en principio, los adultos que rodean al niño; como dice Vygotski: uel aparato y la llave están en distintas manos. El hombre influye mediante el lenguaje sobre los otros hombres" (ibidem). Así podemos afirmar que las crías de nuestra especie se convierten y transforman cualitativamente en niños de nuestra cultura porque no nacen en un mundo de silencio, sino enlazados a los otros, que son los que tienen las llaves con las que es posible abrir su cuadro interno de señales.

Es evidente que este modelo del desarrollo implicaba la necesidad de volver sobre el problema de la organización funcional del sistema nervioso. Se planteaba la cuestión del significado preciso (a nivel funcional) de esa posibilidad de crear unexos desde fuera» en la corteza de los grandes hemisferios. Se requería de un modelo de sistema nervioso suficientemente plástico, versátil, flexible, con la suficiente moldeabilidad como para admitir la posibilidad de modificación funcional por la cultura. Vygotski intuía que su teoria del desarrollo debía traducirse en una nueva teoria de la organización de los sistemas 
funcionales del sistema nervioso central. Esa fue una de las razones que le llevaron a realizar cursos de medicina en sus últimos años y a interesarse por los procesos de alteración de los sistemas neurofuncionales, especialmente en la afasia. Es obvio que Vygotski no tuvo tiempo material más que para esbozar las líneas generales de solución al problema de la organización de las funciones neurofisiológicas. Fue su amigo y colaborador, Alexander Romanovich Luria, el que continuó esta línea abierta por Vygotski, y que sólo había quedado esbozada en los últimos años de la década furiosa en que cruzó, y cambió, la psicologia cientifica de nuestro siglo.

\section{EL BOCETO DE UNA TEORIA DE LA ORGANIZACION NEUROFISIOLOGICA DE LAS FUNCIONES SUPERIORES Y LOS INTERESES NEUROPSICOLOGICOS DE VIGOTSKI}

Ya hemos indicado que la adquisición de funciones de significación (y especialmente del lenguaje) no supondria, en la opinión de Vygotski, el desarrollo de un sistema más, sobreimpuesto a los sistemas funcionales «inferiores», que permiten la formación de reflejos condicionados, sino que implicaría una transformación completa de la organización de las funciones en el sistema nervioso. Desde sus primeros trabajos (por ejemplo, en un artículo publicado en 1926 sobre "El problema de las reacciones dominantes"), Vygotski había insistido en la importancia del hecho de que el mecanismo de formación de estímulos condicionados en el hombre no es equiparable, sin más, a los mecanismos de condicionamiento animal. El hombre, al ser capaz de registrar y "reflejar" la realidad mediante los significados colectivos, generalizadus, analíticos, convencionales y abstractos del lenguaje, no requiere (d.) proceso lento, gradual de formación de conexiones temporales a través del condicionamiento y el refuerzo. Naturalmente, Vygotski admitía que en el hombre se dan los procesos de condicionamiento. Pero se dan de otro modo. Son transformados y regulados (o, al menos, regulables) por los significados. Ciertamente, los estudios sobre psicología y fisiología de la actividad nerviosa superior han demostrado que el lenguaje permite la formación de vinculaciones nerviosas estables, cuyas leyes de funcionamiento no corresponden a las leyes clásicas del condicionamiento. Como comenta Luria (1968), "estos resultados dan lugar a la consideración de que se puede llamar con razón al sistema nervioso central (SNC) del hombre sistema nervioso conceptual, y que las leyes de funcionamiento del sistema nervioso central del hombre poseen una muy clara especificidad" (pág. 134).

Es importante aclarar cuäl era el problema al que se enfrentaba Vygotski en este campo: se trataba de construir un modelo del sistema nervioso que pudiera, en efecto, ser "conceptual», culturalmente moldeable "desde fuera". Es evidente que la tesis de la génesis social de las funciones superiores planteaba la difícil cuestión de cómo "diseñar" un SNC que fuera capaz de transformaciones relacionadas con el empleo de herramientas y la construcción de nexos significativos en función de convenciones culturales. ¿De qué clase podrían ser esas transformaciones producidas por el proceso de humanización?

Vygotski rechazaba la hipótesis de que pudieran ser transformaciones estructurales. Para él, la estructura del sistema nervioso o de la corteza 
de los grandes hemisferios no se modifica por el hecho de que se adquieran habilidades de empleo de herramientas, signos o símbolos lingüísticos. Era preciso, entonces, admitir que esos procesos lo que producirian sería modificaciones funcionales, cambios en la organización funcional de la actividad de los hemisferios cerebrales. Pero para admitir la posibilidad de modificaciones funcionales en el SNC era necesario contar primero con un modelo adecuado de la organización funcional del sistema nervioso.

Es obvio que ese modelo no podia ser el que proponía una «localización» precisa de las funciones superiores, basado en los descubrimientos de Broca y Wernicke sobre los «centros» reguladores del lenguaje. Aquellos descubrimientos habian provocado la proliferación de "mapas" de centros cerebrales, que incluían en ocasiones localizaciones específicas para la regulación de actividades tan claramente determinadas por la historia y la cultura como la formación de conceptos («localizada" por algunos en la región parietal inferior izquierda) o la escritura. La idea de un mapa estático de centros capaces de regular funciones superiores no era compatible con la afirmación de que esas funciones están determinadas por la historia y la cultura. Significaría convertir de nuevo (esta vez por el camino de las localizaciones) en Naturaleza estática lo que es un resultado dinámico de la historia.

En oposición a las tesis «localizacionistas», algunos neurólogos y psicólogos como Monakow, Goldstein y Lashley proponian un modelo "holista», basado en la idea de que el cerebro funcione "como un todo" en la regulación de las funciones superiores. El concepto de «equipotencialidad" de Lashley sería una expresión de esta orientación, que extremaba la posición antilocalizacionista de Hughlings Jackson. Sin embargo, las posiciones holistas más extremadas se encontrarian con dificultades para establecer una relación clara entre el funcionamiento psicológico y la estructura cerebral. La situación, en este terreno, sería paralela a la crisis de la psicología que Vygotski había señalado unos años antes. Del mismo modo que en Psicología se daba la oposición entre un elementarismo reduccionista y un holismo fenomenológico, igualmente incapaces de explicar adecuadamente la génesis y raturaleza

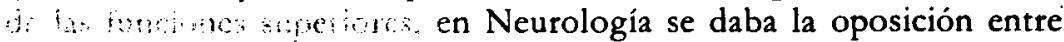

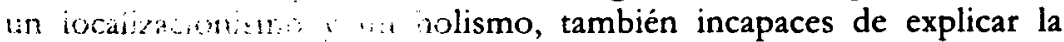
organizacion funcionial de los procesos superiores del sistema nervioso. Algunos neurólogos de la tendencia más «holista» han recurrido, como premisa o punto de llegada, a formulaciones claramente dualistas y espiritualistas, como si lo psíquico «entrara» en el cerebro, para servirse de él (Eccles, por ejemplo, ha sido un claro exponente de este enfoque). Vygotski preveía la dificultad de asimilar la posición holista más extrema a una concepción materialista de las funciones superiores.

Podemos establecer un esquema simplificado, pero muy claro, de la situación: las orientaciones más localizacionistas eran incompatibles con la naturaleza histórica de las funciones superiores; las más holistas, difíciles de compaginar con su carácter de funciones de la materia. Era necesario, también en este campo, encontrar una tercera alternativa.

Si partimos de la base de que las funciones superiores se constituyen en la historia, se modifican dialécticamente en el desarrollo, y son el resultado de la influencia de la cultura a través de la interacción, es 
necesario suponer que su substrato funcional, en el sistema nervioso, consiste en sistemas flexibles que interrelacionan (de diversas formas) el funcionamiento de centros específicos. Esta era, en esencia, la solución que proponía $\dot{V}$ ygotski. La concepción sistémica de las funciones superiores implicaba el supuesto de que tales funciones corresponden a interrelaciones entre zonas corticales, que cumplen aisladamente funciones específicas (asegurando asi la significación funcional de la estructura material del sistema nervioso), pero configuran relaciones cambiantes a lo largo del proceso de desarrollo (con lo que podrian dar cuenta de la naturaleza histórica de las funciones). En el curso de la historia, se establecen conexiones, se crean órganos funcionales, que no requieren organizaciones morfológicas nuevas, sino que implican reorganizaciones dinámicas de las texturas de relaciones funcionales establecidas en el sistema nervioso. Los órganos funcionales son, por tanto, un resultado del desarrollo. En cierto modo, se podría decir que el cerebro humano es, desde un punto de vista funcional, un resultado de la historia. En un artículo que Vygotski escribió poco antes de su muerte, y que era la base de una comunicación que pensaba presentar en el Primer Congreso Ucraniano de Psiconeurología (realizado en el año 34, cuando Vygotski ya habia muerto) se desarrollabà esta idea: "Estamos convencidos de que un sistema de análisis psicológico adecuado, desde el punto de vista de la teoría de la localización, debe basarse en la teoría histórica de las funciones psicológicas superiores, en cuya base está la teoría de la estructura sistémica y semiótica de la conciencia del hombre, que parte del reconocimiento de la importancia primordial: nales.

a) De la polivalencia de las relaciones y conexiones interfuncio-

b) De la formación de sistemas dinámicos complejos, que integran una serie de funciones elementales.

c) Del reflejo generalizado de la realidad en la conciencia) (1934, cit. pág. 303). Estas ideas .implicaban la necesidad de sustituir los análisis estructurales y funcionales, incapaces de explicar la actividad (como unidad esencial del análisis de los procesos superiores y la conciencia), por un análisis interfuncional o sistémico, que sería el único capacitado para explicar el substrato nervioso de las funciones complejas. También suponia una actitud crítica hacia los intentos de extrapolar los resultados del estudio de la localización funcional en animales al caso del hombre, ya que en éste se daría un principio nuevo de organización de ia actividad nerviosa en sistemas funcionales construidos por la historia y variables en el desarrollo (Vygotski, op. cit.).

Esta concepción llevaba a establecer un principio de gran importancia; a saber: que el papel jugado por las distintas regiones cerebrales en la organización de las funciones psicológicas superiores cambia a lo largo del desarrollo. Por eso las lesiones focales de áreas corticales pueden tener efectos diferentes en la infancia y la edad adulta (Luria, 1979). Puede ocurrir, por ejemplo, que en el niño la lesión impida o limite el desarrollo de funciones superiores determinadas, mientras que en el adulto perturba funciones más elementales, reguladas por aquéllas, y en menor grado las superiores. «El poder de sistematización de un centro -dice Luria - se propaga desde abajo hacia arriba en la 
primera infancia, y desde arriba hacia abajo en la edad adulta" (op. cit., pág. 135).

Estos principios permitian establecer las bases de una nueva ciencia, que fue desarrollada principalmente por Luria: la neuropsicologia. En este campo, Vygotski no tuvo tiempo más que de establecer algunos fundamentos que luego jugaron un papel decisivo en la construcción de esta ciencia, pero es evidente que tenía una «actitud neuropsicológica» en su aproximación a las perturbaciones neurológicas en los últimos años de su vida. La participación en la organización del departamento de Psicología en la Academia Psiconeurológica de Jarkov, asi como su colaboración con los miembros de la clínica neurológica de Moscú, le dieron oportunidades de poner a prueba, en la clínica neurológica, sus hipótesis teóricas. Al final de su vida, estaba a punto de obtener la dirección del laboratorio de Psicología del Instituto de Medicina Experimental, donde habia comenzado a estudiar, de forma sistemática, casos psiquiátricos y con lesiones celebrales. El enfoque neuropsicológico de estos casos es claro cuando se examina el tipo de pruebas que inventaba Vygotski para contrastar sus hipótesis clínicas. Un bello ejemplo es el que relata Luria, sobre un paciente con la enfermedad de Parkinson:

"Observamos el hecho paradójico de que pacientes que no podían dar dos pasos sucesivos en un suelo plano, eran capaces de subir escaleras sin dificultad. Formulamos la hipótesis de que, al subir escaleras, cada paso representaba una señal a la que respondían los impulsos motores del paciente. Cuando se suben escaleras, el flujo sucesivo y automático del movimiento que se da cuando se camina sobre una superficie plana, es reemplazado por cadenas de reacciones motoras discretas. En otras palabras: se reorganiza la estructura de la actividad motora, y el sistema involuntario, organizado a nivel subcortical, que rige ordinariamente la ambulación, se ve remplazado por una respuesta consciente a cada eslabón de la cadena. Vygotski empleó un procedimiento muy simple para construir un modelo de laboratorio de este tipo de reorganización del movimiento. Puso en el suelo una serie de papelitos, y pidió a un paciente que caminara de uno a otro. Sucedió algo maravilloso: un paciente, que no era capaz de dar más de dos o tres pasos por si mismo cuando caminaba por la habitación, andaba fácilmente de papelito en papelito, como si estuviera subiendo una escalera. Le habiamos ayudado a superar los síntomas de su enfernedad, al permitirle reorganizar los procesos mentales empleados en la ambulación. Había compensado su defecto, transfiriendo la actividad del nivel subcortical, que estaba dañado, al nivel cortical, que no estaba afectado por la enfermedad) (1979, pág. 128).

En este caso, los estudios realizados se dirigieron principalmente a analizar el efecto de mecanismos de regulación y autorregulación consciente (por ejemplo, por medio del lenguaje) en la conducta motora de los sujetos. Los resultados permitian desarrollar "prótesis significativas" para compensar los efectos de la enfermedad de Parkinson. El problema que más interesó a Vygotski fue, sin embargo, el de la afasia. Pensaba que la perturbación del sistema esencial de regulación y autorregulación, que es el lenguaje, daria lugar a una conducta inmediata, regulada esencialmente por procesos reactivos no mediados. En este campo, los hechos demostraron, posteriormente, que las hipótesis de Vygotski partian de una simplificación excesiva del concepto (complejísimo) de afasia, y de las funciones psicológicas (muy variables) de los pacientes afásicos. Después de la muerte de Vygotski, 
Luria haría contribuciones de enorme importancia para el desarrollo de la afasiologia.

\section{PENSAMIENTO Y HABLA: LA CONCEPCION SEMIOTICA DE LA CONCIENCIA Y LA GENESIS, ESTRUCTURA $Y$ FUNCION DEL LENGUAJE INTERNO}

Vygotski murió a los 37 años, el i de junio de 1934, en el sanatorio Serebryany Bor. En sus últimos años, su obra científica se había realizado en una lucha constante contra la enfermedad. Dos meses después de su muerte, apareció la obra por la que habría de ser más conocido en el campo de la psicologia y en los de la lingüistica y las humanidades: Myslenie $i$ rec, "Pensamiento y habla". Constituye una especie de compendio de las ideas fundamentales desarrolladas en usus años de psicólogon, y aplicadas al problema del lenguaje humano, que habia sido preocupación esencial de Vygotski desde su periodo de formación. Los capítulos centrales del libro (del segundo al sexto) habian sido escritos entre 1929 y 1934, como artículos breves o prólogos. El primero y el último fueron elaborados por Vygotski, poco antes de su muerte, para dar una unidad al libro. El último («Pensamiento y palabra») puede considerarse su núcleo esencial y, en opinión de algunos investigadores (por ejemplo, Meccaci, 1983; Wrertsch, 1979), apuntaba a una nueva concepción de los procesos mentales, que Vygotski no pudo elaborar ni ha sido desarrollada aún de forma completa.

Como el resumen (o, más bien, la versión modificada que circula por Occidente) de Pensamiento y Lenguaje ${ }^{1}$ es suficientemente conocido por los lectores de habla castellana, me limitaré a delinear los que me parecen aspectos más esenciales de la obra y a desarrollar brevemente algunas de sus implicaciones. Para ello vamos a comenzar por establecer el sentido de P. L. en el marco general de las concepciones psicológicas de Vygotski.

Ya hemos comentado que la búsqueda de una unidad, que conservara las características fundamentales de las funciones psicológicas más complejas del hombre, habia llevado a Vygotski a la categoria de actividad, de transformación mediata e instrumental del medio a través de la conducta. Cuando esa actividad mediata se refiere a las personas, más que a los objetos físicos, se transforma en significativa, por influencia de los otros; es decir: de los grupos sociales que transmiten la cultura al niño humano y, al hacerlo, le «humanizan" en sentido estricto. Es, por tanto, en las interacciones, donde tienen su origen los signos, que son primordialmente instrumentos (mediaciones) de relación entre personas. Su función primordial es la de comunicación, de tal modo que un sujeto no construiria o adquiriría signos si no fuera porque está entre otros sujetos (la asimbolia que presentan los niños

\footnotetext{
1 Este es el título dado inadecuadamente a Myslemie $i$ rec en varias traducciones occidentales (por ejemplo, inglés, italiano, castellano). Como ha señalado Wertsch (1979), en ruso hay una clara distinción entre rec (habla) y yazyk (lenguaje). El concepto de rec es amplio y, en Vygotski se refiere, sobre todo, al lenguaje como actividad funcional, incluyendo, por tanto, un sentido muy pragmático, que se puede contraponer al de lenguaje como estructura abstracta o código analizable con independencia de su empleo interactivo. No se trata, por tanto, del habla como realización motora, sino como actividad (deyatel'nost') instrumental, situable en el plano de las unidades de análisis de la Psicologia, de que hablaba Vygotski.
} 
que no han tenido contactos con personas es un dato coherente con la concepción vygotskiana). Estos instrumentos de interacción (los signos) no se incorporan a una conciencia previa, o una especie de espiritu innato, que tuviera el sujeto, sino que podemos decir que la propia conciencia, el mismo sujeto y, si se quiere, el «espíritu" son resultados y "construcciones" de los signos: el sujeto lo es no como unidad biológica o miembro de nuestra especie animal, sino como individualidad propiamente humana y transmisor de cultura; el espiritu porque no es una sustancia independiente e inmaterial, sino una formación de cultura; y la conciencia lo es no como trama solitaria, sino porque consiste, precisamente, en una forma de contacto social con uno mismo. Ese «contacto social con uno mismo» se posibilita por el hecho de que la organización psicológica, a través de la relación con los demás, se "desdobla» (por decirlo con un término no muy exacto) y replica con respecto así misma, las pautas de inter-acción. Tal proceso está permitido por el hecho de que los signos, que tenian primariamente un carácter externo, de instrumentos objetivos de la mediación entre personas, se internalizan hasta convertirse en instrumentos internos y subjetivos de la relación de un sujeto consigo mismo. Podemos hablar de un plano de conciencia a partir de ese "desdoblamiento", permitido por la internalización de los instrumentos de relación entre personas. Por eso, hablar de la génesis y naturaleza social de la conciencia equivale a referirse a su estructura semiótica.

Por otra parte, es evidente que las herramientas semióticas más poderosas en el contacto social y la regulación interhumana de la conducta son las palabras. Son, en un sentido muy esencial, convenciones humanas construidas por la cultura para la comunicación e inter-regulación de la conducta. Por ello, un problema esencial cuando nos enfrentamos al tema de la génesis y naturaleza de la conciencia, es de analizar los procesos de internalización del lenguaje y la organización o estructura semántica a que éstos dan lugar. En cierto modo, podemos referirnos también (como hace Vygotski) a la «estructura semántica» de la conciencia. Esto quiere decir, en primer lugar, que la conciencia - y las funciones superiores - son mecanismos de significación, y plantea la cuestión siguiente: ¿de qué modo significan?

Para dar una primera respuesta a esta cuestión, tenemos que referirnos a otra definición de la conciencia que propone Vygotski, y que se relacionaba con el concepto de otrazenie de Lenin: la conciencia como reflejo activo y generalizado de lo real. Esto quiere decir que la conciencia no refleja lo real por una especie de imposición empírica directa de las cosas, sino sirviéndose de categorias y conceptos, estableciendo "formas de unidad" en su reflejo indirecto de los objetos y las relaciones. Estas formas de unidad son, además, la condición que permite hablar de un plano semántico en el lenguaje y (consiguientemente) en la propia estructura de la conciencia. Si la conciencia constituyera un reflejo directo de lo real, no tendria pertinencia hablar de significado. Por otra parte, las formas de unidad que permiten un reflejo mediato de lo real no son «a priori» kantianos, con un carácter innato, sino construcciones genéticas, cuya forma y estructura se modifica y varía a lo largo del desarrollo.

En el desarrollo no sólo varía el significado de los signos y la 
refleja lo real, sino que el desarrollo mismo consiste, en cierto modo, en una variación más fundamental aún: «la verdadera esencia del desarrollo - dice Vygotski- se halla en el cambio de la estructura interfuncional de la conciencia» (1934, cit., pág. 22). Es decir: aparte de las variaciones internas de las funciones psicológicas que constituyen la trama de la estructura misma de la conciencia, se da una modificación mucho más fundamental en la organización de las relaciones entre esas funciones. En ese sentido, podemos hablar del carácter dialéctico del desarrollo y de cambios cualitativos en él. De revoluciones genéticas y no sólo de evolución cuantitativa en el desarrollo humano.

De estas transformaciones cualitativas, la que tiene una importancia mayor es la que permite un cambio esencial de la regulación de la conducta, pasando de una regulación externa (por los estímulos del medio, como en los procesos de condicionamiento), a una regulación inter-personal (por ejemplo, por el lenguaje de los otros) y, finalmente, a una regulación interna (a través de los signos y significados que constituyen el tejido de la conciencia propia). El cambio de la estructura interfuncional de la conciencia se relaciona así, de forma muy estrecha, con el cambio de los sistemas de regulación de la conducta, y de la estructura de los procesos dependientes de las mediaciones significativas, internas o externas.

Las consideraciones anteriores nos permiten establecer con más claridad el horizonte problemático a que atendía Vygotski en Pensamiento y Lenguaje. Las concepciones clásicas de la relación entre el pensamiento y el lenguaje, por debajo de sus diferencias, pártían del supuesto implícito común de que su forma de relación permaneceria invariable a lo largo del desarrollo. Frente a ellas, el postulado esencial de Vygotski era que la conexión entre pensamiento y palabra no es una vinculación primaria e invariante, sino que se origina en el desarrollo, y se modifica y hace más estrecha a lo largo de él. La dificultad tradicional para entender estas transformaciones interfuncionales se relacionaria con el modo elementarista de explicación, y con la tendencia a reducir el desarrollo de la conciencia al desarrollo autónomo de cada una de sus funciones. Por ejemplo, en las explicaciones reduccionistas del objetivismo clásico se tendería a postular una identificación o fusión de pensamiento y lenguaje (al reducirse ambos a reflejos, hábitos, etc.), lo que haría desaparecer, como por ensalmo, el problema de sus relaciones. En el polo opuesto estarían las posturas que postulan una segregación o disyunción total entre pensamiento y lenguaje: por ejemplo, los investigadores de la Escuela de Würzburgo, que liberan al pensamiento de todos sus componentes sensoriales, considerando al lenguaje como simple «ropaje externo" de aquél. Del mismo modo que las dificultades del primer planteamiento provendrian de emplear elementos de análisis inadecuados para investigar las relaciones entre pensamiento y lenguaje (por ejemplo, los reflejos), las del segundo se deberían a la tendencia a separar en elementos de pensamiento, por una parte, y palabra, por otra, las unidades de pensamiento verbal. El problema era, por tanto, el de definir una unidad ( $y$ no elemento) de análisis, adecuada para estudiar las variantes relaciones entre pensamiento y lenguaje.

En el caso del pensamiento verbal, que constituye la trama esencial de la estructura semiótica de la conciencia, la unidad interna de análisis 
(es decir: aquello que conserva todas las propiedades del total y no puede dividirse más sin perderlas) es el significado, cuya esencia consiste, como ya hemos dicho, en ser un reflejo generalizado de la realidad, que supone un paso cualitativo (un salto dialéctico) con respecto a la sensación, al referirse no a objetos aislados sino a grupos o clases de objetos y relaciones: “claramente, entonces, el método que debemos seguir en la exploración de la naturaleza del pensamiento verbal es el del análisis semántico - decía Vygotski-, el estudio del desarrollo, el funcionamiento y la estructura de esa unidad (significado) que contiene al pensamiento y el lenguaje interrelacionados" (ibid., pág. 26).

Cuando se toma como unidad el significado, se deshace la disociación (producida por el análisis elementarista) entre las funciones comunicativa y representacional del lenguaje. La comunicación requiere significado y no puede prescindir ni del signo ni del reflejo de generalización, ya que la experiencia individual, en sentido estricto, no es comunicable a menos que se codifique en categorias más o menos convencionales. Pero, como las formas de unidad de reflejo generalizado de la realidad varian a lo largo del desarrollo, la estructura misma de la comunicación lo hace también (por ejemplo, ciertos pensamientos son incomunicables a los niños). La variación genética del significado puede analizarse en dos planos: en un plano, por asi decirlo, externo se da una lenta toma de conciencia, por parte del niño, del valor simbólico y convencional de las palabras ( $y$ aqui Vygotski critica la idea de Stern de una "raiz intencional" del lenguaje, por descubrimiento súbito de que las cosas tienen nombre, y se remite a la concepción piagetiana de las palabras vividas por el niño como atributos reales de los objetos) y del valor del lenguaje como reflejo generalizado y convencional de lo real. En un plano interno, se plantea el problema de la construcción genética de los conceptos, y aquí se referia Vygotski a los experimentos de su propio equipo sobre formación de conceptos en niños, que permitían establecer una linea genética desde los cúmulos inorganizados de la infancia (agrupaciones de objetos diversos sin ningún fundamento) a los complejos (en que los elementos ya no se agrupan por impresiones subjetivas, sino por relaciones variantes reales y objetivas construidas por la experiencia directa y no por abstracción lógica), los pseudoconceptos (producto de la interacción entre el modo infantil del pensamiento en complejos y el lenguaje adulto, y que son formas fenotípicamente similares a los conceptos, pero genotipicamente diferentes) y, finalmente, los conceptos potenciales (productos ya de una abstracción, pero aún muy elemental y "aisladora») y los conceptos propiamente dichos, que serian como un producto genético o una sintesis de los pseudoconceptos y los conceptos potenciales. Es decir: de funciones de análisis y síntesis, de generalización y de abstracción.

Para Vygotski el lenguaje no jugaría un simple papel de comparsa con respecto a este desarrollo de las formas de unidad con que la conciencia refleja, de modo generalizador, lo real. No es un vestido externo del pensamiento, sino que establece para él - por así decirlouna "dirección categorial», de manera que «el pensamiento no se expresa simplemente en palabras, sino que existe a través de ellas» (ibid., pág. 166). Es ésta una idea similar a la de Wittgenstein (1957), cuando señala que uen el lenguaje es donde se conectan una expectación y su realización” (pág. 131), o a la de Merleau-Ponty (1969), cuando dice 
que en el lenguaje "se cumple» el pensamiento. Es también, la misma concepción de Bolton ( 1972 ), según la cual «a misteriosa propiedad del lenguaje es que en él se efectúa la transición de lo tácito a lo expliciton (pág. 207). Pero Vygotski va más allá: a través del lenguaje -decía también, en cierto modo, se construye lo tácito. Se modifica: "La estructura del lenguaje - decía Vygotski- no refleja simplemente la del pensamiento; esa es la razón de que las palabras no puedan ser utilizadas por la inteligencia como si fueran ropas a medida. El pensamiento sufre muchos cambios al convertirse en lenguaje» (pág. 167). Estos cambios, podemos decir, se refieren tanto al aspecto macrogenético como al nivel microgenético. En el primero, como hemos señalado, el lenguaje establece la dirección categorial que permitirá la construcción de los conceptos (la idea de Vygotski implica que sin lenguaje no sería posible desarrollar conceptos en sentido estricto). En el plano microgenético (es decir: el que lleva desde la construcción de un pensamiento a su formulación lingüística), la instantaneidad del pensamiento se transforma en el espacioso análisis temporal de la expresión verbal: "El pensamiento no está formado por unidades separadas como el lenguaje. Cuando deseo comunicar el pensamiento de que hoy vi a un niño descalzo, con una blusa azul, corriendo por la calle, no veo cada aspecto en forma separada: el niño, la camisa, el color azul, la carrera y la carencia de zapatos. Concibo todo esto en un solo pensamiento, pero lo expreso en palabras separadas. El que habla generalmente tarda varios minutos para expresar un pensamiento. En su mente, el pensamiento completo está presente simultáneamente, pero en el lenguaje debe desarrollarse de forma sucesiva. El pensamiento puede compararse a una nube que arroja una lluvia de palabras" (Vygotski, 1934. Cit., pág. 193). En la medida en que el lenguaje se convierte en herramienta fundamental del pensamiento éste sufre transformaciones tanto micro-genéticas como macrogenéticas.

Cuando decimos que el lenguaje «se convierte» en instrumento de pensamiento (y de regulación de la acción) es porque, en principio, no lo es. Un supuesto esencial de Pensamiento y Lenguaje es que éste y aquél tienen raices genéticas distintas, y que luego se sintetizan dialécticamente en el desarrollo. El estudio de esta síntesis (del proceso por el cual se convierte el lenguaje en pensamiento, y el pensamiento en lenguaje), exigía la investigación del origen, el desarrollo y la estructura del lenguaje interior, que es una de las aportaciones fundamentales de P. L.

La materialización de la idea vygotskiana de que el pensamiento «se realiza en la palabra" implicaba remitirse al habla interna como instrumento esencial de mediación del pensamiento. $Y$ aquí se planteaban tres tipos de problemas: (I) los relacionados con la génesis y el desarrollo del pensamiento verbal, (2) los referidos a sus funciones, y (3) los vinculados con su estructura y organización.

I. La hipótesis genética sobre el lenguaje interior fue una de las aportaciones más geniales de Vygorski. Como es sabido, se opuso a la concepción piagetiana del monólogo infantil como simple expresión de un "pensamiento egocéntrico", que era claramente opuesta a sus propias ideas sobre los vectores esenciales del desarrollo. Piaget, en sus primeras obras, había entendido el desarrollo en términos de socialización progresiva del pensamiento del niño (desde una fase «autista», no adaptado a lo real que tenderia a satisfacer deseos más que a establecer 
verdades, a un "pensamiento socializado", consciente, dirigido por propósitos presentes al sujeto y susceptible de contrastación con lo real). La "fase egocéntrica» sería intermedia entre las dos anteriores, estaria a medio camino entre ellas y caracterizaria un pensamiento definido por la dificultad, o incapacidad, de coordinar el punto de vista propio con el ajeno, de cambiar de marco de referencia, de justificar los propios razonamientos, de transformarse en función de las contradicciones, etcétera. El lenguaje "egocéntrico» seria un reflejo de esta forma de pensamiento.

Es claro que esta secuencia genética era la contraria a la que permitian establecer los supuestos esenciales de la teoría de Vygotski: para él, el desarrollo no se definiría por una "progresiva socialización" de una organización primordialmente autista y solitaria, sino más bien por la progresiva individuación de una organización esencialmente social desde su origen. Esto obligaba a replantear el problema de la significación genética del monólogo infantil y a reinterpretar las propias observaciones de Piaget, según las cuales este disminuye por el momento en que el niño entra en la edad escolar. Para Piaget esta disminución (y su eventual desaparición), era expresión de los cambios en el pensamiento, y la socialización progresiva de éste.

La solución de Vygotski era muy diferente: el monólogo no desaparece, realmente, sino que "se sumerge», hasta convertirse en instrumento interno del pensamiento. Es la premisa genética del lenguaje interior. La mejor manera de demostrar indirectamente esta secuencia de desarrollo, que lleva del monólogo infantil al lenguaje interior, era demostrar que aquél no se limita a reflejar la estructura cognitiva preestablecida, sino que cumple funciones esenciales que no pueden «desaparecer" sin más en la ontogénesis. Y esto nos lleva al segundo punto: el de las funciones del lenguaje interior y de su precursor genético, el «lenguaje egocéntrico» del niño.

2. En el estudio funcional del lenguaje egocéntrico, podemos diferenciar dos clases de investigaciones: unas referidas a su función objetiva (la que realmente tiene), y otras relativas a su función subjetiva (la que el niño cree que tiene). Una de las observaciones fundamentales de Vygotski fue la de que existe una curiosa discordancia entre estos dos planos funcionales, de manera que el $\mathrm{L}$. E. posee, de hecho, una función que no es la que "cree» el niño que tiene. La metodología empleada para el análisis de la función objetiva era muy simple. Consistía esencialmente en dificultar la actividad espontánea del niño y medir los cambios en L. E. en estas circunstancias. El resultado era claro: los niños aumentaban la cantidad de L. E. cuando su actividad se veia dificultada u obstruida (por ejemplo, cuando el niño se disponía a dibujar y se encontraba, sin esperarlo, sin papel o lapiz). Por otra parte, la observación de la relación temporal entre L. E. y actividad mostraba una secuencia de desarrollo definida por una progresiva anticipación de aquél con respecto a ésta. Al principio, el lenguaje egocéntrico señala el final de un punto cambiante de actividad, luego se "traslada" a los puntos centrales de ésta; finalmente, se situa al comienzo, asumiendo una función directiva y elevando la actividad del niño al nivel de conducta intencional en sentido propio. Esta secuencia constituye una pista clara para desvelar la función objetiva que adquiere progresivamente el $L$. E.: la de regular y planificar la actividad, y servir de instrumento esencial 
para la resolución de problemas cognitivos (vid. Beaudichon, 1975). Esta regulación, en la medida en que el lenguaje mismo se independiza de los factores contextuales y pragmáticos más directos, pasando de un plano sin-práxico a un plano sin-semántico (por emplear la terminologia de Luria, 1979), se hace también más independiente del campo inmediato de'la percepción y la actividad concurrente (Wertsch, 1979), permitiendo convertir en acción (es decir, en conducta guiada por metas subjetivas), el comportamiento del sujeto (este análisis, que va más allá de los enunciados explícitos de Vygotski, se basa en el concepto de "acción» de Leontiev). En este sentido, podemos decir que el $\mathrm{L}$. E. no sólo es un requisito ontogenético del lenguaje interior, sino también de la «intención», en su sentido más pleno.

Aunque objetivamente la función autorregulatoria y planificadora del lenguaje del niño se diferencia progresivamente de su función primaria de comunicación - a través del desarrollo del L. E.-, subjetivamente el niño sigue tratando al L. E. como si fuera un lenguaje social. En experimentos realizados por Vygotski, Luria, Leontiev y Levitina se demostraba que, cuando se dificulta objetivamente la comunicación del niño (por ejemplo, situándole ante extraños, aislándole, haciendo sonar un ruido fuerte, etcétera), éste disminuye la cantidad de lenguaje egocéntrico, lo que demostraría que, lejos de representar una «actitud egocéntrica", éste sería sentido por el niño como un lenguaje social (aun cuando ya no lo sea en sentido estricto). Este tratamiento subjetivo del «lenguaje privado" como si fuera lenguaje social revela dónde están sus origenes: en la función social y comunicativa del lenguaje. El lenguaje nace, en la ontogénesis, como un instrumento social de comunicación. Del magma primitivo de esa función social, se diferencia progresivamente una forma "privada», que permite organizar la acción y "programarla», disponer mejor los recursos y estrategias de solución de problemas, y establecer explícitamente metas de acción independientes de las circunstancias inmediatas. Supone, por tanto, un paso decisivo en el desarrollo que lleva del control estimular o inter-personal de la actividad al control intra-personal. El monólogo infantil expresa este desarrollo de las que podríamos llamar «funciones intrapersonales» del lenguaje. Sin embargo (y esto se entenderá por todo lo que hemos dicho de la concepción teórica de Vygotski), la construcción de estas funciones intrapersonales no implica que las formas de lenguaje privado - el monólogo infantil y el habla interior"pierdan" su carácter social. Por el contrario: profundizan en él. ¿Cómo es esto posible?

Lo es porque la construcción del sujeto y de su conciencia es, en sí misma, una construcción social (volvemos de nuevo a la idea de la conciencia como "contacto social con uno mismo»), y porque la privacidad (o, si se quiere, la subjetividad) tiene como condición paradójica el previo desdoblamiento. Por eso podemos decir que cuando el niño se habla a si mismo (reproduciendo, en principio, las pautas de relación significativa con los demás), está construyendo su conciencia y elaborándose como sujeto en un plano más alto que el permitido por los que llamariamos procesos de primer orden (los procesos inferiores). Son los procesos de segundo orden, permitidos por la replicación intrapersonal de las pautas interpersonales (y que toman como argumentos a los procesos de primer orden) los que permiten la construcción más delicada de la sociedad, que es la conciencia humana. En todo 
este proceso, el desarrollo de la función autorregulatoria de los signos (especialmente, el lenguaje), juega un papel capital, porque da lugar a la gestación de formas que, al internalizarse, se transforman, en un sentido propio, en conciencia. Por eso, Vygotski terminaba Pensamiento $y$ Lenguaje con este enunciado: «Las palabras tienen un papel destacado tanto en el desarrollo del pensamiento como en el desarrollo histórico de la conciencia en su totalidad. Una palabra es un microcosmos de conciencia humana» (pág. 197).

El desarrollo funcional por el cual se elaboran las «funciones privadas» del lenguaje implica, como hemos señalado, la elaboración de formas lingüísticas con características estructurales propias. Y esto nos lleva al tercer aspecto esencial del análisis vygotskiano de la génesis y naturaleza de las formas privadas del lenguaje, que es el relativo a su estructura y la significación de ésta.

3. Del mismo modo que el análisis de las funciones del L. E. del niño constituye un importante dato favorable a la hipótesis genética de relación entre el monólogo infantil y el lenguaje interior, el análisis de la estructura del monólogo, a lo largo del desarrollo, ofrece ciertos datos que serian difícilmente explicables si no se situasen en esa secuencia genética. La "inescrutabilidad" y el carácter idiosincrático del lenguaje egocéntrico se hace cada vez mayor entre los tres y los siete años (fenómeno que, evidentemente, es contrario a la evidencia de una mayor socialización en el niño de siete años), y las diferencias estructurales entre él lenguaje interpersonal y el intrapersonal son cada vez más marcadas. Las peculiaridades estructurales que desarrolla el lenguaje privado deben relacionarse con el proceso de internalización: "Con el aislamiento progresivo del lenguaje para uno mismo - decía Vygots$\mathrm{ki}-$, su vocalización se torna innecesaria y carente de significación, e incluso imposible a causa de sus crecientes peculiaridades estructurales. El lenguaje para uno mismo no puede encontrar expresión en el lenguaje externo. Cuanto más independiente y autónomo se torna el lenguaje egocéntrico, más pobre aparece en sus manifestaciones externas. Finalmente, se separa enteramente del lenguaje para los otros, cesa de vocalizarse y, por tanto, parece desaparecer gradualmente» (pág. 176). La hipótesis de Vygotski era, por tanto, que el monólogo tiene una estructura cada vez más semejante a la que luego poseerá el lenguaje interior. La internalización no consistiría simplemente en un "abandono del sonido", preservando las formas estructurales del habla interpersonal, sino que sería solidaria con un desarrollo estructural guiado, a su vez, por la exigencia de una mayor eficacia y economia en el cumplimiento de las funciones de autorregulación y programación propias del lenguaje privado. Por eso, el lenguaje egocéntrico ofrecería, sobre todo en sus últimas etapas, un excelente material observacional para analizar la estructura del pensamiento verbal, al ser como una objetivación externa de éste. Al referimos a dicha estructura, emplearemos el término «lenguaje privado» para referirnos al conjunto «L. E.-L. interno".

Podemos situar en varios planos el análisis de la estructura del lenguaje privado (tal como se objetiva, sobre todo, en las últimas manifestaciones del monólogo del niño).

1. En un plano lógico (que Vygotski definía como "sintáctico", pero no parece serlo en sentido estricto. Vid. Werstsch, 1979) aparece, 
en él, una tendencia a una forma especial de abreviación, que consiste en la supresión del sujeto lógico, y de los términos relacionados con él, conservándose el predicado. Tenemos, por tanto, como primera y muy esencial caracteristica la de tener un contenido predicativo.

2. En un plano fonológico, el lenguaje privado se caracteriza por la tendencia a la abreviación y elisión de fonemas. Podría relacionarse esta tendencia con el proceso mismo de internalización. «El lenguaje interiorizado - decia Vygotski- se maneja con la semántica y no con la fonética» (pág. 188). Podemos establecer, entonces, como rasgo esencial, la tendencia a la reducción fonética.

3. Esta tendencia a la reducción se manifiesta también en el aspecto morfologico y léxico —elisión de palabras y partes de ellas, etcétera.

4. En el aspecto sintáctico, el lenguaje privado presenta una tendencia a la desorganización, a ser gramaticalmente amorfo.

5. Finalmente, en el plano semántico, el lenguaje privado se define por los siguientes rasgos:

a) El predominio del "sentido" (entendido como "suma de procesos que la palabra provoca en nuestra conciencia», incluyendo la connotación) sobre el significado más convencional (o «de diccionario").

b) La tendencia a combinar los sentidos de varias palabras en una sola, dándose un fenómeno que podría describirse como «sobrecarga de sentidon.

c) La tendencia a la aglutinación de varios vocablos en uno.

Estas peculiaridades hacen que la transición del lenguaje interior al externo no sea una mera vocalización de lo silencioso, sino cun proceso dinámico y complejo, que implica la transformación de la estructura predicativa e idiosincrática del lenguaje interiorizado en un lenguaje articulado e inteligible para los demás" (P. L., pág. 191). Ocurre, en definitiva, que el lenguaje interiorizado constituye una "función en si mismo". Encarna - como el externo- el pensamiento en palabras, pero en él las palabras mueren tan pronto como transmiten el pensamiento. Por eso dice Vygotski que «el lenguaje interiorizado es, en gran parte, un pensamiento de significados puros, es dinámico e inestable, fluctúa entre la palabra y el pensamiento" (ibid., pág. 192).

¿Por qué es tan predicativo y elíptico el L. P., y carga tanto el sentido sobre un conjunto limitado de elementos? A esto hay una respuesta evidente, y casi trivial, pero que ro agota el tema: uno a sí mismo no se lo tiene que "decir todo». Basta con indicar, bosquejar las relaciones para que transcurra el curso del pensamiento. Por ejemplo, la referencia al sujeto lógico de las oraciones generalmente no es necesaria, porque "cuando uno piensa y sabe a lo que se refiere», ni es necesario decirse las palabras y oraciones completas, porque ya sabe uno lo que dice con un breve apunte. Por eso el lenguaje privado tiene, en gran parte, un carácter de boceto rápido. El pensamiento no requiere de la calmosa elaboración analítica de la comunicación interpersonal.

En un penetrante artículo, James V. Wertsch (1979) ha analizado la caracteristica esencial del lenguaje privado, el predominio de la predicación, en términos de la distinción entre sujeto y predicado psicológico y de la teoria de la actividad de Leontiev. Para ello, se ha 
servido de un concepto que tiene gran importancia en la psicolingüística contemporánea: la idea de que las formas lingüísticas son el resultado de un contrato entre lo dado y lo nuevo". Cuando hablamos a otra persona, tratamos de proporcionar información nueva y sólo recurrimos a lo que suponemos "dado» (es decir, a lo que ella sabe, o mejor tiene presente de forma actual en la conciencia) para anclar la nueva información en la estructura de la previamente poseida.

La idea de Wertsch es que la distinción vygotskiana entre sujeto y predicado gramatical debe reinterpretarse como distinción entre lo dado y lo nuevo, en lo que se refiere a la estructura del lenguaje privado. En esta perspectiva, lo característico del lenguaje privado seria la tendencia a formular sólo "lo nuevo" y eliminar "lo dado" por el contexto. Pero aquí se plantea una peculiar dificultad: jacaso no es todo "dado" para el sujeto que se habla a sí mismo?, ¿qué sentido puede tener la diferenciación dado-nuevo cuando nos enfrentamos no a lo que "una conciencia añade en otra», sino a una organización intra-personal?, ¿no está previamente en $\mathrm{mi}$ conciencia el contenido de todo lo que me digo?

En un intento de respuesta, Wertsch recurre a la noción de actividad de Leontiev. En esencia, piensa que - en el caso del lenguaje privado- la organización de lo dado y lo nuevo se refiere a la estructura de la actividad concurrente, o (lo que es equivalente), a la estructura concurrente de la conciencia: "En el caso del habla privada - dice Wertsch - la información dada es el conocimiento que está en la conciencia del "hablante» en el momento de la emisión. La llamada información "nueva» es la que se está introduciendo en la conciencia» (1979, pág. 9 1). En el caso del lenguaje privado adulto esto puede ser dificil de demostrar, pero en el monólogo objetivo del niño, es posible contrastar la hipótesis de Wertsch sustituyendo la categoría de conciencia por su matriz genética: la actividad. En este caso diriamos que «lo dado" es el contexto al que se refiere la actividad y "lo nuevo" se repara a determinados aspectos de la acción que se está llevando a cabo. Las observaciones preliminares de Wertsch, sobre el «lenguaje privado" de niños de dos años parecen favorables a su hipótesis.

\section{ALGUNAS HIPOTESIS VYGOTSKIANAS MAS ALLA DE VYGOTSKI}

Voy a permitirme situar las hipótesis de Vygotski y de Wertsch en un contexto pragmático más amplio, llevando un poco más lejos su análisis de la estructura del lenguaje privado, y relacionándola con la idea de distintos niveles de la estructura en las formas del lenguaje externo del sujeto como hemos dichc. Los actos lingüísticos interpersonales presuponen un "cálculo", por parte del hablante del conjunto de conocimientos sobre el tema de conversación que posee o no el oyente. El objetivo de este cálculo (no necesariamente consciente) es el de construir emisiones relevantes. Es decir, limitar en lo posible la información a los aspectos nuevos, recurriendo a lo dado sólo en lo necesario para anclar y la nueva información en la estructura cognitiva previa del oyente. Clark y Clark (1977) han establecido asi esta especie de "contrato implícito" por el que se guían las situaciones reales de comunicación: 
"Contrato dado-nuevo: el hablante acuerda: (a) emplear la información dada para referirse a la información que piensa que el oyente puede identificar sin ambigüedad a partir de la información que posee de antemano, y (b) emplear la nueva información para referirse a la información que cree que es verdadera pero no era previamente conocida por el oyenten (pág. 92).

Esto significa, en primer lugar, que la organización de las emisiones del hablante depende de los supuestos de éste acerca de los estados de conocimiento del oyente. Podríamos decir que la estructura misma del lenguaje (como actividad psicológica) se organiza alrededor de un núcleo pragmático, cosa que no debería extrañarnos si nos situamos en una perspectiva vygotskiana en que el lenguaje se origina, tanto en el aspecto macro como microgenético, a partir de las funciones comunicativas y de inter-acción.

Ahora podemos ir un poco más allá: en la medida en que un hablante calcula que comparte una mayor cantidad de información con el oyente, y está más seguro de cuál es la información que comparte, podrá deslindar más netamente lo dado de lo nuevo. Por el contrario, cuando el hablante tiene pocos datos acerca del estado de conocimiento del oyente, tiene que elaborar en mayor grado la información, al no poder diferenciar con claridad qué es lo dado y qué lo nuevo. En pocas palabras: la organización del lenguaje interpersonal dependerá del conjunto de supuestos y presuposiciones comunes (o que se creen comunes) entre los interlocutores. Estos supuestos, y la seguridad en ellos, pueden basarse en varias clases de claves, entre las cuales están las siguientes:

I. Claves temáticas, que constituyen el conocimiento del hablante acerca del conocimiento del oyente sobre el tema específico de inter-locución.

2. Claves interpersonales, que se refieren al conocimiento que posee el hablante acerca del oyente mismo, y están condicionadas por las situaciones previas de comunicación, la "confianza" y las presuposiciones comunes entre hablante y oyente.

3. Claves contextuales, que dependen del hecho de compartir o no una situación común en el momento de la comunicación y de que el espacio y el tiempo de comunicación sean compartidos (por ejemplo no lo es el espacio en el caso de las conversaciones telefónicas, y no lo son ni el espacio ni el tiempo en la comunicación postal).

4. Claves para-lingüisticas concurrentes, son las ciatias por los gestos y expresiones del oyente, que permiten al hablante calcular hasta qué punto se está comunicando tealmenté y está siendo entendido.

5. Claves lingüisticas previas, basadas en lo que el hablante ya ha dicho explicitamente, o puede establecer como conocido por el oyente a partir de lo dicho o comunicado por éste.

6. Claves prácticas, relacionadas con lo que el oyente hace o ha hecho con respecto a algo y que permite inferir los conocimientos que posee acerca del «tema de acción».

Fundamentándose en estas claves (y en función de su propio desarrollo, condiciones personales y situación actual), los interlocutores actúan como si respondieran sistemáticamente a dos preguntas: ¿qué creo que sabe el otro acerca de lo que estamos hablando? y ¿con qué grado de seguridad puedo establecer esa creencia? Vamos a permitirnos añadir una cláusula al contrato dado-nuevo, que, a mi entender, es fundamental para salvaguardar las posibilidades de comunicación. Sería la siguiente: 
promete a no eludir una información cuando no esté suficientemente seguro de si el oyente la conoce previamentem.

Aquí el término "suficientemente seguro" es, intencionadamente, ambiguo. Se refiere a un estado subjetivo del hablante. Una hipótesis sugerente es que el hablante emplea, de cuando en cuando, la estrategia de sondear los estados de conocimiento del oyente, avanzando información nueva, sin estar completamente seguro de la dada en el oyente (como si estuviera actuando con una confianza mayor que la que permiten objetivamente las circunstancias), con el fin de economizar pasos en la comunicación. Naturalmente, esta estrategia dependerá de los objetivos de comunicación del hablante con respecto al oyente (de su deseo de relacionarse más o menos profundamente con él), y supone una especie de "transgresión estratégica" de la cláusula adicional del contrato dado-nuevo. La frecuencia y "gravedad" de estas transgresiones dependerian muy decisivamente, según mi punto de vista, de la «imagen subjetiva" (una especie de "fantasma»), que el hablante se construye con respecto al oyente, que puede ser muy lejana a la que podría corresponder a las "condiciones objetivas» de éste. En la medida en que esta lejanía sea mayor, y las transgresiones estratégicas de la "cláusula adicional» sean más osadas, se incrementará la probabilidad de ocurrencia de fallos comunicativos ${ }^{2}$.

Por otra parte, todo el proceso de cálculo de los estados de conocimiento y creencia del interlocutor sobre la base de las claves interpersonales, temáticas, contextuales, etc., depende de un factor genético fundamental; a saber: la capacidad de des-centración del bablante, que le permite situarse, en mayor o menor grado, en la perspectiva ajena. Este enunciado permite explicar algunas observaciones muy comunes en relación con fallos objetivos ( $y$ no subjetivamente sentidos) de la comunicación en niños preoperatorios. Un ejemplo puede ser esta conversación telefónica entre un adulto y un niño de tres años:

$$
\begin{aligned}
& \text { Adulto.- ¿Está algún hermano en casa?» } \\
& \text { Niño.- "Si, éste». } \\
& \text { Adulto.- «QQuién?». } \\
& \text { Niño.- "Pues... éstel». }
\end{aligned}
$$

Naturalmente, aquí se está produciendo un fallo objetivo de la comunicación, ya que el adulto no puede saber quién es «éste» al no compartir las claves especiales del niño (y por eso tiene que hablar por teléfono) que le permitirian desambiguar el demostrativo "éste». Sin embargo, el niño no percibe la causa de este fallo, ni puede comprender por qué el oyente, a su vez, no le comprende a él.

El comentario anterior plantea un dificil problema, y que no es éste el momento de tratar, que es el de cómo hacer coexistir la categoría piagetiana de "descentración» con la concepción vygotskiana del desarrollo como individuación progresiva a partir de una matriz social. En la respuesta que dio Piaget a Pensamiento y Lenguaje, veinticinco años después de la publicación del libro, se encuentra una parte sustancial de la respuesta a este problema. En ella, Piaget reconocía haber sobrevalorado inicialmente las semejanzas entre egocentrismo y "actitud autistan (en un sentido amplio y no técnico de la palabra) y daba

2 Sin embargo, cuando los sondeos más expuestos tienen éxito, profundizan enormemente la comunicación interpersonal y aumentan la "simpatia" entre los interlocutores. 
al concepto de egocentrismo un sentido más propiamente intelectual y menos social. Sin embargo, no estaba de acrierdo en la afirmación de que el L. E. tiene un carácter tan social como el comunicativo, ya que aquél cumple una función individual e indica la existencia del egocentrismo de que hablábamos antes: "Cuando Vygotski afirma que la primera función del lenguaje debe ser la de comunicación global y que el habla posterior se diferencia en egocentrica y comunicativa propiamente dicha, creo que estoy de acuerdo con él. Pero cuando sostiene que esas dos formas lingüísticas son igualmente socializadas y difieren sólo en función, no puedo seguirle, porque la palabra "socialización" se torna demasiado amplia en este contexto: si un individuo $A$ cree equivocadamente que un individuo $\mathrm{B}$ piensa del modo que lo hace $\mathrm{A}$ y no trata de entender la diferencia entre los dos puntos de vista, esto es, sin duda, comportamiento social en el sentido de que existe un contacto entre los dos, pero considero que tal conducta es inadaptada desde el punto de vista de la cooperación intelectual" (vid. respuesta de Piaget en Pensamiento y Lenguaje, cit. pág. 207).

Pero la âfirmación de Vygotski de que el L. E. tiene una naturaleza social tenía, como ya hemos dicho, un doble sentido: en un sentido más superficial, hacía referencia al hecho de que el niño lo siente subjetivamente como social. En un plano más profundo, significaba que, a través del L. E. el individuo se desdobla, al reflejar en sí mismo las pautas de interacción y, de este modo, elabora el tejido de la conciencia, que es una construcción social aunque intra-personal. En este último punto es donde me da la impresión de que "no le seguia» Piaget. Sin embargo el punto es perfectamente compatible con la noción de "centración» intelectual. Es más: en una perspectiva vygotskiana es perfectamente lógico suponer que la descentración es, precisamente, una premisa esencial para la individuación del sujeto a partir de su matriz social, porque constituye una condición del desdoblamiento, que es la premisa de la conciencia entendida como relación social intra-personal. Por tanto, la noción de "centración" (e, incluso, de egocentrismo) intelectual no sólo es compatible con la tesis del origen social de la conciencia y las funciones superiores, sino favorable a ella. Por otra parte, la vivencia subjetiva del carácter social e interpersonal de su L. E. por parte del niño es, como dice Piaget, un índice de dificultad de descentración, tan claro como el empleo de un pronombre demos. trativo por teléfono sin justificación contextual en el lenguaje anterior.

Pero todo esto nos ha llevado muy lejos de nuestros propósitos y conviene que volvamos a ellos. Lo que tenemos, por ahora, es lo siguiente: que la comunicación lingüística se basa en un cálculo recíproco sobre los estados de conocimiento y conciencia de los interlocutores, basado en la imagen mutua, las claves temáticas, interpersonales, contextuales, prácticas, lingüísticas y para-lingüisticas y la capacidad, por parte de cada uno de los interlocutores, de descentrar y tener en cuenta la perspectiva del otro. A partir de aqui, podemos formular la hipótesis fundamental a la que queríamos llegar:

«La estructura del lenguaje inter-personal será tanto más semejante a la del lenguaje privado cuanto más alto sea el número de supuestos (intra-personales, contextuales, etc.) y de presuposiciones comunes que los interlocutores creen que comparten (o calculan que comparten)m. 
La justificación es clara: las peculiaridades estructurales del lenguaje interior se relacionan claramente con el hecho de que el sujeto que se habla comparte consigo mismo todos los supuestos y presuposiciones posibles. Irónicamente, podríamos decir que, cuando uno se habla a si mismo, se están hablando dos personas muy unidas. Esta broma, sin embargo, puede ayudarnos a entender una cosa muy simple: que, cuanto más «unidas» están las personas, más cercana será la organización de su lenguaje a la del lenguaje privado.

Es posible operacionalizar empíricamente el grado de unión por el conjunto de claves a que antes nos hemos referido. Por ejemplo, el lenguaje escrito se emplea, normalmente, cuando las claves contextuales comunes son escasas o nulas. Cuando le escribimos una carta a alguien, no conocemos exactamente el contexto espacial en que estará cuando la lea, el momento en que la recibirá, ni tampoco los gestos que hará al leerla, etc. En esta situación, dada la inseguridad (recordemos la cláusula adicional del contrato dado-nuevo) que tenemos sobre sus estados de conocimiento, nos veremos obligados a elaborar máximamente el lenguaje, alejándonos de las supuestas caracteristicas del lenguaje privado. Esto sucede más aún, cuando escribimos algo (como este artículo) cuyo receptor no puede ser, en nuestra conciencia, una persona concreta, de carne y hueso, cuyo nombre y características personales conocemos, sino una especie de "sujeto universal». Mientras yo escribía estas cosas, por ejemplo, desconocía las condiciones espaciales y temporales, los conocimientos previos, las condiciones personales que tiene quien las está lèyendo en este momento. Ciertamente, tuve que "particularizar" algo ese sujeto universal. Supuse, por ejemplo, que sabría algo de psicología y que le interesarian estos temas. Di por descontados unos conocimientos anteriores (no muy grandes) de filosofia, historia de la psicologia, lingüística (por ejemplo, he supuesto que sabria, de antemano, el lector lo que es el «componente fonológico» del lenguaje). Pero mi interlocutor, mientras escribía, era algo borroso: alguien inconcreto - pensaba yo-, suficientemente interesado en estos asuntos como para leer un artículo (ya demasiado largo) en Infancia y Aprendizaje, alguien por quien sentía una simpatía más bien difusa basada en el supuesto, muy inseguro, de que compartimos ciertas aficiones. Supongo que si el lector ha llegado hasta aqui es porque no me equivoqué mucho en esas previsiones. Probablemente, los que no correspondían a los supuestos anteriores (como tener interés por estos asuntos o una serie de conocimientos previos) ya han abandonado, por las primeras páginas, la lectura del artículo.

En todo caso, mi sujeto de comunicación era tan impreciso, que me vi obligado a elaborar las ideas más de lo que lo haria si estuviera hablando con una persona concreta. La organización del lenguaje escrito es, en este caso, muy diferente de la que tiene el lenguaje interior: lo que en este es elipsis, supresión de partes, predominio de los sentidos y de la predicación en los contenidos, "desorganización» gramatical, se convierte, en el artículo, en predominio de significados convencionales, organización formal, formulación detenida, elaboración espaciosa, puntualización de los temas y del sujeto lógico, erc. Todo ello se debe a que, como dice Vygotski «la comunicación por escrito reposa en el significado formal de las palabras y requiere un número mucho mayor de vocablos que el lenguaje oral para expresar la misma idea. Se dirige a una persona ausente que rara vez tiene en mente el 
mismo tema que el escritor. Por tanto debe explicarse en forma total y se usan expresiones que serian menos naturales en la conversación" (P.L., pág. I 84). Sucede, en definitiva, que el lenguaje escrito tiene que construirse, frecuentemente, sin el substrato de claves temáticas, interpersonales, paralingüisticas, lingüisticas, contextuales y prácticas que sustentan a las situaciones de diálogo y, en el más alto grado, a las de "diálogo con uno mismo", si se permite esta anómala (pero no injustificada) expresión.

Tenemos, así, un continuo que sitúa, en uno de sus extremos, a las formas más idiosincráticas del lenguaje interior, y en el otro, a las más elaboradas y universales del lenguaje escrito. En medio, está el lenguaje oral interpersonal, que constituye la premisa genética de uno y otro, y cuyas formas serán muy variables dependiendo del conjunto de factores (claves de todo orden, estrategias de comunicación, requisitos de descentración, seguridad en los supuestos sobre el otro, etc.) a que nos hemos referido. Si esto es así, se ofrece una oportunidad importante, que es la de objetivar, en el estudio del diálogo (y no ya sólo del monólogo) las caracteristicas del lenguaje intrapersonal. La premisa teórica en que se basa esta posibilidad es la de que, en realidad, todo lenguaje (incluso el más encerrado en los "espacios" privados de la conciencia) es una forma de diálogo, ya que la conciencia misma tiene una estructura dialogal. Esta hipótesis vygotskiana (pero no formulada explícitamente por Vygotski) exige una contrastación a través del análisis de las modificaciones en variables dependientes de tipo estructural (tales como las establecidas por Vygotski en su análisis del lenguaje interior) en función de cambios controlados en las claves objetivas que dan lugar a supuestos, más o menos comunes y seguros, en las situaciones de diálogo.

\section{LAS CRITICAS A VYGOTSKI Y EL PERIODO DEL LARGO SILENCIO EN LA PSICOLOGIA SOVIETICA}

El destino de Pensamiento y Lenguaje, después de la muerte de Vygotski, ilustra perfectamente las enormes dificultades por las que pasó la psicología soviética a partir de 1936. En aquel año, el libro desapareció de la circulación, aunque no fuera prohibido oficialmente. Reapareció, en una nueva edición, en 1956. Esta edición, en que se sustituía el prólogo de Kolbanovsky (el director del Instituto de Psicología que sustituyó a Kornilov) por otro de Luria y Leontiev, presentaba algunos cambios con respecto a la original de 1934. La traducción inglesa de 1962 - por la cual la obra fue conocida en Occidente - tenía aún más modificaciones: de las 350 páginas de la edición original habian desaparecido iso. Luria, que había participado en la elaboración de este "resumen para Occidente», justificaba estos cambios por la necesidad de organizar y elaborar lo que habia sido una prematura expresión del pensamiento de Vygotski, en desarrollo aún cuando murió, y especialmente por la exigencia de reestablecer el diálogo perdido de los miembros de la Escuela de Moscú con los psicólogos occidentales, para lo cual se habian eliminado todos los aspectos que podrian obstruir ese diálogo (por ejemplo, muchos de los más relacionados con el pensamiento marxista). No sé si Luria tenía razón; lo que sí es claro es que estos acontecimientos son un claro exponente de lo que sucedió con la obra de Vygotski después de su 
muerte: primero, un largo silencio. Luego, un conocimiento muy indirecto (sobre todo en Occidente) de componentes parciales y modificados de la obra de Vygotski, cuyas fuentes han permanecido inaccesibles hasta 1982 , en que comenzaron a publicarse las obras completas en ruso. Da la impresión de que la imagen de Vygotski se transformó, en ese proceso, y pasó a ser la de un psicólogo teórico del desarrollo, con olvido de su preocupación esencial por los procesos educativos concretos, la pedagogía y la psicología (Mecacci, 1983).

En realidad, la «desaparición» de Pensamiento y Lenguaje en 1936, se relacionaba con un cambio esencial en la situación de la psicología soviética que tuvo lugar en aquel año. Podromos relacionar este cambio con dos sucesos fundamentales y muy reiacionados: la resolución del Comité Central del Partido Comunista Soviético en contra de la paidologia, y sobre todo la formulación del Proyecto de Constitución de la URSS, que supuso un paso histórico esencial en la cristalización del proyecto estalinista. Naturalmente, Vygotski fue uno de los teóricos implicados en la resolución contra la paidología. Como lo fueron Blonskii, Zalkind y Basov. Curiosamente, algunos de los psicólogos de concepciones más claramente dialécticas. El nombre de Vygotski pasó a ser tabú, y los miembros de la Escuela histórico-cultural pasaron, posteriormente, algunas dificultades. Lo que ocurtía era que, por debajo de la resolución «contra las desviaciones de la paidología en los Comisariados de Educación» (que era como se llamaba la resolución del 4 de julio de 1936), se expresaba una tendencia histórica mucho menos puntual y de mayor trascendencia histórica que la que podia tener la eliminación de la paidología: la tendencia a un centralismo, una homogeneización y un control que ya se anunciaba en los últimos años de la vida de Vygotski. Cuando éste murió, en 1934, ya habian desaparecido todas las revistas dedicadas a la psicología como ciencia independiente: Psicologia en 1932, Paidología en ese mismo año, y después Psicotécnica y Problemas de Investigación y Educación de la Personalidad. La psicología fue una de las ciencias más afectadas por el control rígido de la "pureza ideológica». Un grupo de jóvenes miembros del Instituto de Psicologia (Talankin, Shemiakin, Kogan y Vvedenov) se encargaron del control: prácticamente todas las escuelas de psicologia sufrieron la acusación de antimarxismo. Naturalmente, éste fue también el destino de la Escuela histórico-cultural. Ananiev, que habia repudiado su formación reflexológica previa, señalaba que la teoria de Vygotski conducía objetivamente «a una revisión del materialismo histórico" de carácter idealista. En la revista Psicología (cuando aún existia en 1931), Gmurman ya había apuntado a esta crítica, al señalar que Vygotski «inventaba una naturaleza psicológica abstracta». Pero, a partir de 1936 , las críticas fueron más violentas: en un libro de Rudevna sobre Las distorsiones paidológicas de Vygotski, que se publicó en 1937 , se acusaba a Pensamiento $y$ Lenguaje de "antimarxista». Lo que estaba ocurriendo, en realidad, era que el propio pensamiento marxista libre estaba sucumbiendo bajo el peso del dirigismo y el control, y evidentemente, Vygotski no era un «marxista domesticable». La razón fundamental de las críticas era, en realidad, que en vez de citar directamente a Marx y Engels, o atenerse a lo que ellos habian dicho, había pensado por si mismo desde un planteamiento dialéctico.

También hubo críticas más serias. Merece citarse la de Rubinstein 
si las funciones superiores provienen de la interiorización de la interacción y de la acción misma, ¿cómo podemos explicar la microgénesis interna de una actividad que, en su origen, no está internalizada? "Toda actividad material externa del hombre - decia Rubinsteincontiene ya en su interior componentes psíquicos (fenómenos, procesos) por medio de las cuales aquélla se regula» (pág. 354). Esto nos llevaria a hablar de diversos planos o niveles de interioridad. Pero, cuando Rubinstein planteaba este problema Vygotski ya no estaba. Su postergación como factor de influencia fue lamentable para la psicologia soviética, que ahora le redescubre y comienza a medir el potencial futuro de su pensamiento.

Es cierto que, en muchos aspectos, Vygotski parece haberse adelantado a nuestro propio tiempo.

\section{Referencias}

Balier, R. A.: The new mon in Snviet Psychology. Cambridge: Harvard University Press, 1999.

Bechterev, V. M.: Psichologiia, Refleksologiia i Marksizsm (Psicologia, reflexologia y marxismo). Leningrado, 1929 .

BEI.MONT, J. M., y ButTerfiei.D, E. C.: "The relation of short-term memory to development and intelligence». En LipsitT, L. P., y REESE, H. W. (Eds.): Advances in Child Development and Behavior. Vol. 4. Nueva York: Academic Press, 1969.

BEI.MONT, J. M., y BUTTERFIEI.D, E. L.: "Learning strategies as determinants of memory deficiencies". Cognitive Psychology, 1971, 2, $411-420$.

BoI.TON, N.: The Psychology of Thinking. Londres: Methuen, 1972 (traducción castellana de LuIS CuriL.AR: Introducción a la psicologia del pensamiento. Barcelona: Herder, 1982).

Brown, A.: "Learning and Development: the problems of compatibility, access and induction". Human development, 1982, 2f, 89-119.

BROW'N, A. L.; CAMPIONE, J. C.; BRAY, N. W., y WII.COX, B. L.: «Keeping track of changing variables»: Effects of rehearsal training and rehearsal prevention in normal and retarded adolescents. Journal of Experimental Psychology, 1973, 101, 123-131.

BRL'NER, J. S.: “Vygorski: una perspectiva histórica y conceptualm. Infancia y Aprendizaje, 1981, 14, 3-18.

CI.ARK, H. H., y Cl.ARK, E. V.: Psychology and Language. Nueva York: Harcourt Brace Jovanovich, 1977.

COL.E, M.: (Ed.) Soviet developmental psychology. Nueva York: Sharpe, 1977.

COI.E, M.: "La zona de desarrollo próximo: donde cultura y conocimiento se generan mutuamente". Infancia $y$ Aprendizaje, 1984, 25, 3-17.

Col.E Y SCRIBNER: Introducción a Vygotski, L. S.: El desarrollo de los procesos psicologicos superiores. Barcelona. Critica, 1979.

Davydov, V. V.: Comentarios en "The Mozart of Psychology" de Levitin, K. (Ed.) One is not born a personality. Moscú: Progress Publishers, 1982.

DAvYdov, V. V., y Zinchenkov, P.: "The principle of development in Psychology". Soviet Psychology,

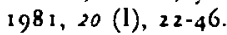

DAVYDov, V. V., y RaDzichovsky, L. A.: "Teorija L. S. V. i dejatel'nostij podchod v psichologii» (“La teoria de L. S. V. y el enfoque de la actividad en psicologia). Voprosy Psichologii, 1980, 6, 48-59.

Dobkin, S.: "Ages and Days. Semyon Dobkin's Reminiscences». Recogido por Levitin, K. (Ed) One is not born a personality. Moscú: Progress Publishers, 1982.

EI.I.IS, N. R.: "Memory processes in retardates and normals». En El.1.15, N. R. (Ed.) International Revien of Research in Mental Retardation. Vol. 4. Nueva York: Academic Press, 1970

Enget.S, F.: Dialectics of Nature. Nueva York: International Publishers, 1940.

FERNANDEZ-TRESPAI.ACIOS, J. L.: "La psicología soviética en contradistinción a la psicología norteamericana». Boletin informativo de la fundación Juán March. Madrid, diciembre de 1978, págs. 3-16.

Fi.nvel.l, J. V., y Well.man, H. M.: «Metamemory». En Kall., R. V., y Hagen, J. W. (Eds.): Perspectives on the development of Memory and Cognition. Hillsdale, N. J.: Lawrence Erlbaum, 1977.

II.Yenkov, E. V.: Dialectical logic. Essays on its History and Theory. Moscú: Progress Publishers, 1977.

KorNItov, K. N. (Ed.): Psichologiia i marksiszm (Psicologia y marxismo). Moscü-Leningrado: Gosizdat, 1925.

Kozul.IN, A.: Reseña de "El significado histórico de la crisis en psicologia» en Siudies in Soviet Thought, $1983,26,249-256$.

KozUt.in, A.: Psychology in Utopia. Toward a Social History of Soviet Psychology. Cambridge, Mass.: The MIT Press, 1984.

L. C. H. C. (Laboratory of Comparative Human Cognition): "What's cultural about cross-cultural cognitive psychologym. Annual Review of Psychology, 1979, 30, 145-172.

LENIN, V. I.: Materialismo y empiriocriticismo. Madrid: Fundamentos, 1974.

Leontiev, A. N.: “Prólogo a Vygotski, L. S.». Psicologia del arte. Barcelona: Barral, 1970.

LEONTIEV, A. N.: "One is not born a Personality!" An interview with Alexei Leontiev. En LEvitin, K.; One is not born a personality. Moscú: Progress Publishers, 1982 (págs. 110-126). 
I.l:(NTIEN, A. N.: El desarrollo del psiquismo. Madrid: Akal, 1983.

l.EVITIX, K.: "Lev Vygotski. A Biographical Profile». Fn LevitiN, K. (Ed.): One is not born a personality. Moscú: Progress Publishers, 1982.

l.ok, A. (Ed.): Action, Gesture and Symbol: The emergence of Language. Nueva York: Academic Press, 1978.

LiRIA, A. R.: "Vygotski y las funciones psiquicas superiores". En LLRLA, A. R.; MisSLCCO et al.: Problemática cientifica de la psicologia actual. Buenos Aires: Orbelus, 1968.

Ll'RIA, A. R.: Cognitive Development. Cambridge: Harvard University Press, 1976.

LL:R1A, A. R.: The making of a Mind. A personal account of Soviet Psychology. Cambridge, Mass.: Harvard University Press, 1979 .

L.R1A, A. R.: Conciencia y Lenguaje, Madrid: Pablo del Rio, 1979 (Visor-Aprendizaje, 1984).

Manacorda, M. A.: "La pedagogia di Vygotskij". Riforma della Scuola, 1979, 26, 31+39.

Missucco Costa, A.: Psychologie Soviétique. Paris: Payot, 1977.

MECACCI, L.: "Vygotskij: per una psicologia dell'uomo». Riforma della Scuola, 1979, 26, 24.30.

MeCacCi, L. (Ed.): Vygotskij. Antologia di scritti. Bolonia: Il Mulino, 1983

Meriani-Pontr, M.: Filosofia y lenguaje. Buenos Aires: Proteo, 1969.

OChs, E., y Schieffel.IN, B. B. (Eds.): Developmental Pragmatics. Nueva York: Academic Press, 1979.

PIAGET, J.: “Comentarios sobre las observaciones criticas de Vygotski». En Vygotski, L. S.: Pensamiento y lenguaje. Buenos Aires: La Pléyade, 1977.

RADzikhosvili, L. A., y JomskaYA, E. D.: «A. R. Luria and L. S. Vygotski: Early years of their collaborationm. Soviet Psychology, 198 I, 20 (I), 3-19.

Rahmani, L.: Soviet Psychology. Philosophical, theoretical and experimental issues. Nueva York: International Universities Press, 1973.

RIVIĖRE, A.: «Interacción y simbolo en autistas». Infancia y Aprendizaje, 1983, 22, 3-29.

Rlibinstein, S.: El desarrollo de la psicologia. Principios y mélodos. Buenos Aires: Grijalbo, 1974.

SCHEdRovitsky, G.: Comentarios en "The Mozart of Psychology". En Levitin, $K$. (Ed.) One is not born a personality. Moscú: Progress Publishers, 1982.

SPINOZA, B.: Etica demostrada según el orden geométrico. Madrid: Editora Nacional, 1980.

STEINER, V., y SoUberman, E.: "Epílogo de Vygotski, L. S." El desarrollo de los procesos psicológicos superiores. Barcelona: Crítica, 1979.

Toulmin, S.: «The Mozart of Psychology». The New York Review of Books. Septiembre de 1978.

VyGotski, L. S.: Psicologia del Arte. Barcelona: Barral, 1970.

VyGorski, L. S.: "El método de investigación reflexnlógica y psicológica». Informe del II Congreso pan-ruso de Psiconeurologia. En Problemas de la Psicologia contemporanea. Leningrado, 1926.

VYGOTSKI, L. S.: "Consciousness as a problem in the psychology of behavior". Soviet Psychology, 1979.

VyGOTSKI, L. S.: Istoriokij smysl psicbologiceskogo krizisa (El significado bistorico de la crisis en psicologia). F.n VyGotski, L. E.: Sobranie Socinenij (Obras escogidas). Moscú: Pedagogika, 1982, págs. 291-436.

VYGOTSKI, L. S.: Sobranie Socinenij (Obras escogidas). Vols. I y 11. Moscú: Pedagogika, 1982.

VyGoTSKi, L. S.: Storia dello Sviluppo delle funqioni psicbiche superiori e altri scritti. Florencia: Giunti-Barbera, 1974 (recoge el trabajo del mismo titulo y otros artículos).

Vycotski, L. S.: Pensamiento y lenguaje. Buenos Aires: La Pléyade, 1977.

VYGOTSKI, L. S.: «From the notebooks of L. S. Vygotski». Moscow University Pecord-Psychology. Series XV. Abril-junio 1977, 89-95.

VyGoTSki, L. S.: "Problemas de método». En El desarrollo de los procesos psicologicos superiores. (Cap. V) Barcelona: Critica, 1979.

VyGoTSkI, L. S.: “Instrumento y símbolo en el desarrollo del niño". En VYGoTSki, L. S.: El desarrollo de los proctsos psicológicos superiores. Barcelona: Crítica, 1979.

VyGoiskl, L. S.: "Internalización de las funciones superiores». En VyGotski, L. S.: El desarrollo de los procesos psicológicos superiores. Barcelona: Critica, 1979.

VYGOTSKI, L. S.: "Interacción entre aprendizaje y desarrollo». En VrGotSki, L. S.: El desarrollo de los procesos psicológicos superiores. Barcelona: Critica, 1979.

VYGOTSKI, L. S.: "La psicologia e la teoria della localizzaziones delle funzioni psichiche" (1934). En VyGOTSKi, L. S.: Antalogia di scritti a caro di Luciano Mecacci. Bolonia: Il Mulino, 1983.

VYGOTSKI, L. S.: La imaginación y el arte en la infancia. Madrid: Akal, 1983.

Vygotski, L. S., y LURia, A. R.: Etudi po istorii povedenija. Obezjano. Primitiv. Rebenok. (Estudios sobre la bistoria del comportamiento. El mono. El bombre primitivo. El niño). Moscú-Leningrado, GI7, 1930.

WERTSCH, J. V.: "The regulation of human action and the given-new structure of private speech". En ZiviN, G. (Ed.): The development of self-regulation through private speech. Nueva York: Wiley, 1973.

WERTSCH, J. V. (Ed.): The concept of activity in Soviet Psychology. White Plains: Sharpe, 1981.

WING, L.: "Language, social and cognitive impairments in autism and severe mental retardation". Journal of Autism and Developmental Disorders, $1981,11,31-44$.

Wittgenstein, L.: Tractatus Logico-Pbilosophicus. Madrid: Revista de Occidente, 1957.

WITTGENSTEIN, L.: Los cuadernos aqul y marrón. Madrid: Tecnos, 1976.

YARoshevsky, M.: Comentarios en "The Mozart of Psychology". Levitin, K. (Ed.): One is not born a personality. Moscú: Progress Publishers, 1982. 